University of Louisville

ThinkIR: The University of Louisville's Institutional Repository

Electronic Theses and Dissertations

$5-2013$

\title{
The Nashville John School : risk deterrence and the reintegrative shaming approach.
}

Robin Malony Valenzuela

University of Louisville

Follow this and additional works at: https://ir.library.louisville.edu/etd

\section{Recommended Citation}

Valenzuela, Robin Malony, "The Nashville John School : risk deterrence and the reintegrative shaming approach." (2013). Electronic Theses and Dissertations. Paper 1480.

https://doi.org/10.18297/etd/1480

This Master's Thesis is brought to you for free and open access by ThinkIR: The University of Louisville's Institutional Repository. It has been accepted for inclusion in Electronic Theses and Dissertations by an authorized administrator of ThinkIR: The University of Louisville's Institutional Repository. This title appears here courtesy of the author, who has retained all other copyrights. For more information, please contact thinkir@louisville.edu. 
THE NASHVILLE JOHN SCHOOL: RISK DETERRENCE AND THE REINTEGRATIVE SHAMING APPROACH

\author{
By \\ Robin Malony Valenzuela \\ M.A., University of Louisville, 2012
}

\begin{abstract}
A Thesis
Submitted to the Faculty of the

College of Arts and Sciences of the University of Louisville

In Partial Fulfillment of the Requirements

For the Degree of
\end{abstract}

\author{
Master of Arts \\ Department of Anthropology \\ University of Louisville \\ Louisville, Kentucky
}

May 2013 

THE NASHVILLE JOHN SCHOOL: RISK DETERRENCE AND THE REINTEGRATIVE SHAMING APPROACH

\author{
By \\ Robin Malony Valenzuela \\ M.A., University of Louisville, 2012
}

A Thesis Approved On

April 19, 2013

By the following Thesis Committee:

Thesis Director, Dr. Julie Peteet

Committee Member, Dr. Jennie Burnet

Committee Member, Dr. Richard Tewksbury 


\section{ACKNOWLEDGEMENTS}

I would like to thank my advisor, Dr. Julie Peteet, for her guidance and support through this process, and throughout my entire experience as a graduate student in the anthropology department. I would also like to thank the other committee members, Dr. Richard Tewksbury, and Dr. Jennie Burnet, for their feedback and encouragement. Additionally, I would like to extend my appreciation to Kenneth Baker, the Program Director of the Nashville John School, and Cary Rayson, Executive Director at the Magdalene Program, for granting me access to the Nashville John School, taking time to meet with me, and contributing their input to this study. I greatly appreciate the time that each of the NJS presenters voluntarily invests in the program each month, as well as their willingness to participate in this ethnography. Lastly, I would like to thank my husband, Francisco, for his unconditional support and encouragement throughout my career as "the eternal graduate student." 


\section{ABSTRACT \\ THE NASHVILLE JOHN SCHOOL: RISK DETERRENCE AND THE REINTEGRATIVE SHAMING APPROACH

\author{
Robin Malony Valenzuela
}

April 19, 2013

Contemporary anti-prostitution campaigns focus on curtailing "the demand" by punishing sexual service consumers. One component of this approach is a diversion program, or "john school," offered to those who are caught buying prostitution. This ethnography focuses upon the Nashville John School (NJS), which consists of informational presentations that educate johns about the risks associated with prostitution. By employing a restorative justice approach, the NJS exemplifies elements of John Braithwaite's "reintegrative shaming” theory (1989), which seeks to hold offenders accountable for their wrongdoing while avoiding stigmatization.

This ethnographic study utilizes participant observation in the NJS, as well as individual interviews with program presenters and participants, to explore how the NJS employs reintegrative shaming, and how participants respond emotionally. For participants that already hold anti-prostitution sentiments prior to entering the NJS, the program can reduce hostility towards authorities, increase empathy towards potential victims, and justify the enforcement and sanctioning of prostitution laws. 


\section{TABLE OF CONTENTS}

ACKNOWLEDGEMENTS ....................................................ii

ABSTRACT ..................................................................

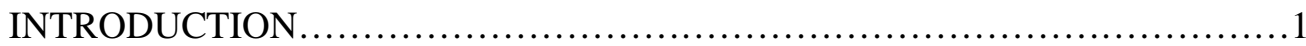

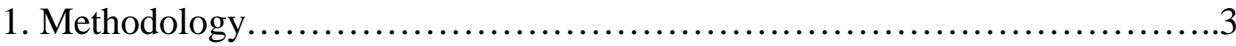

2. Origins of the John School Diversion Program............................11

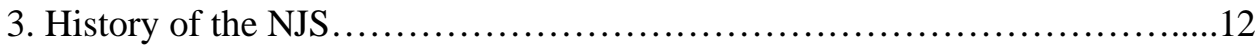

4. Criminalization Procedures for NJS Participants........................13

5. Legal Implications of the NJS....................................14

6. Overview of the NJS Program......................................... 16

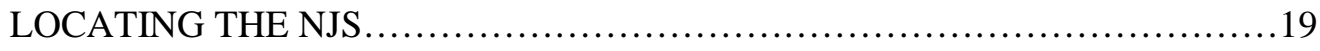

1. Economic Determinism: Supply and Demand..........................19

2. Problematizing Economic Determinism.................................22

3. Defining Prostitution: Problematizing the "Market" Paradigm.................24

4. Historical Approaches: Regulationists and Abolitionists..................26

5. Contemporary Theoretical Camps.....................................29

5.1 Neo-abolitionists................................................29

5.2 Non-abolitionists................................................. 30

6. Legal Frameworks for Prostitution.....................................33

6.1 Criminalization..................................................... 33

6.2 Legalization and Regulation......................................... 34

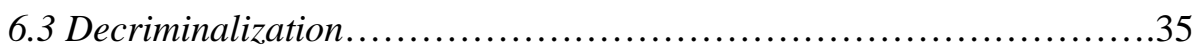

7. Locating the NJS: Legal and Theoretical Models.........................36

7.1 The Destructuring Movement......................................37 
7.2 Deterrence and Crime Prevention....................................41

7.3 Reintegrative Shaming............................................48

8. Shame-Guilt, Embarrassment-Exposure, and Unresolved Shame.............55

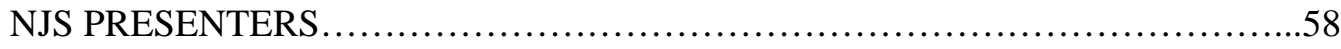

1. Kenny: "You're just trying to get your needs met".......................58

2. Brad Beasley: "Protect yourself first and your partner second"................61

3. District Attorney's Office: "Do you want to be a part of that?" .................62

4. Eliza: "I'm out there giving love to get love and you're paying for it".........65

5. Sexaholics Anonymous: "Sex is optional" .............................66

6. EST: “Stop adding to demand, okay? And tell others!”....................67

7. Stigmatization Versus Reintegration..................................69

7.1 Labeling and De-Labeling......................................69

7.2 Reintegration Through Ritual..................................... 71

7.3 Education and Moralistic Appeals.................................72

7.4 Processing Expressions of Dissent: Non-Domination......................75

7.5 Respected Others........................................... 84

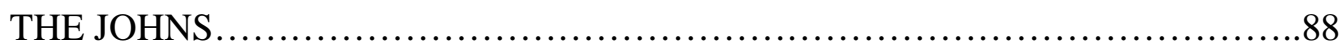

1. Shame-guilt.................................................... 89

1.1 Consensus............................................................ 90

1.2 Awareness of Danger and Risk...................................91

1.3 Empathy........................................................93

1.4 Acknowledgement of Wrongdoing..................................94

1.5 Hostility....................................................... 96

1.6 Reintegration.................................................... 98

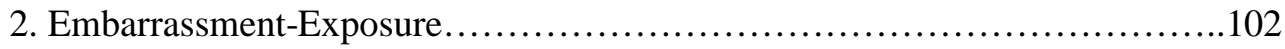

2.1 Lack of Consensus..................................................102

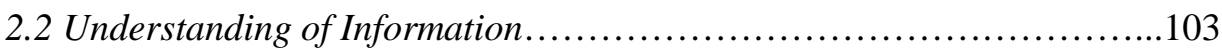

2.3 Hostility ..................................................... 104

2.4 Empathy......................................................... 105

3. Unresolved Shame............................................ 106

3.1 Lack of Consensus...............................................106

3.2 Understanding of Information....................................108 
3.3 Indecision Regarding Wrongdoing ...............................112

3.4 Empathy........................................................ 115

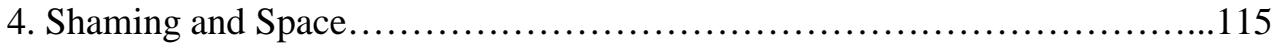

5. Exceptions to the Shaming Paradigm..................................117

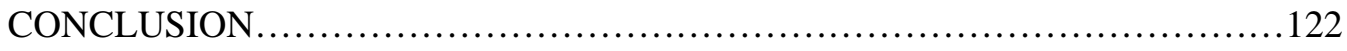

REFERENCES......................................................... 130

CURRICULUM VITAE........................................................ 134 


\section{INTRODUCTION}

In response to the purportedly growing demand for commercial sex, prostitution has persisted as a nuisance to city neighborhoods, as a threat to public health, and as a potential stimulant to sex trafficking. Governments, NGO's, and law enforcement agencies often conceptualize the issue through a "market" lens, contextualizing the dynamics of commercial sex within the framework of "supply" and "demand." Historically, attempts to curtail prostitution have targeted the "supply" by criminalizing and stigmatizing sex workers while virtually

disregarding sex consumers or venue owners. Recent shifts in public policy, however, have transferred the focus from sex workers to sex consumers. Such policies theorize that targeting the demand for sex consumption will effectively deplete supply and cause the industry to fold. One component of this approach is a diversion program offered to those arrested for attempting to purchase sexual services. While only offered in select states or provinces, these programs have become increasingly popular as an approach to curtailing "the demand". Through this program, sex consumers known as "johns" are not simply criminalized—-they are also reeducated and reintegrated. For this reason, the prostitution offender diversion programs are casually referred to as “john schools."

This ethnography explores how each of the program presentations, the program duration, and the program design construct john school participants in the Nashville, TN John School Program through a process of stigmatization, reintegrative shaming, or both, and how, in turn, participants feel in response to such constructions. To what extent do participants own or reject 
culpability for wrongdoing? To what extent do participants feel empathy towards potential victims or community members adversely affected by their participation in commercial sex? Do participants express feelings of dishonor and remorse over their entire personhood or solely their participation in commercial sex? Are participants angry or hostile towards law enforcement officers, program presenters, or the State?

This thesis later concludes that the Nashville John School (NJS) program, through reintegrative shaming and deterrence education, can induce feelings of shame-guilt in some offenders, lower feelings of hostility towards sanctioning and enforcement officials, and increase empathy for potential victims of sexual exploitation or violence. This is most effective for offenders that already maintained beliefs condemning prostitution as legitimately illegal and morally wrong. The NJS also avoids stigmatizing practices that foster hostility and exclusion and encourage deviant subculture formation, thereby rendering it a positive alternative to harsher punitive measures or shaming campaigns.

This ethnographic approach to john schools contributes to a growing body of scholarship that questions why men purchase sex (Frank 2007), how sexual commerce has adjusted to "the late capitalist market" (Bernstein 2007), and how virtual john subcultures serve to reinforce conceptualizations of prostitution as normative and acceptable (Blevins and Holt 2009). Additionally, the ethnographic approach assumed in this study diversifies the approaches of more quantitative studies that analyze the demographic profiles of johns (Kennedy et al. 2004), their pre and post-program attitudes towards topics related to sexual commerce (Wortley et al. 2002)(Sawyer et al. 2001), and the so-called effectiveness of john schools in reducing recidivism amongst participants (Roe-Sepowitz et al. 2011). By lending voice to john school participants and presenters, this thesis depicts the manner in which reintegrative shaming is both mobilized and received. While this ethnography only examines the immediate, self-proclaimed reactions of participants to the NJS program, it does contribute an important on-the-ground perspective to 
literature that questions how "effective" john school programs can be in changing attitudes and affecting behavior.

\section{Methodology}

During the early stages of my research, I developed an interest in the NJS program as a potential site for my investigative study. After contacting both Kenny Baker of Behavioral Treatment Providers and Cary Rayson of the Magdalene Program in late 2011, I received permission to attend the program as a silent observer. I began attending and observing the NJS program in January of 2012, and continued visiting the program until June of 2012, when research officially commenced. Initial observations of the program proved helpful, not only for establishing relationships with program presenters, but also for observing the general dynamics and flow of the program itself. Through this process I developed important research questions for both program presenters and program participants regarding the design, structure, duration, and impact of the program.

In addition to engaging in various discussions with Cary Rayson regarding the NJS program, restorative justice versus "shaming" campaigns, and the Magdalene program, I also attended an Open House at the Magdalene Program. This opportunity enabled me to take a tour of the Magdalene Program facilities, learn about Magdalene's social enterprise model from Founder, Reverend Becca Stevens, and interact with Magdalene Program participants.

After officially beginning my research in June of 2012, I continued attending the program each time it was offered. During June, July, September, October, and November of 2012, I conducted participant observation in the NJS program, focusing on elements of the individual presentations as well as apparent participant reactions. Prior to each session, I was allotted time to directly address program participants as a group in order to explain my presence, my research goals, and the opportunities available for participation in my research. In addition to explaining my research and fielding questions from participants, I also distributed unsigned consent forms in 
both English and Spanish. All participants were offered the option of declining involvement in participant observation, private interviews, or focus groups, or selecting isolated aspects in which to participate.

Altogether, all john school participants attending the sessions in which I was present gave their consent for me to conduct participant observation. Ten participants total volunteered for individual, face-to-face interviews with me during the course of my research, though no participants chose to engage in virtual interviews or focus groups. At no point did I collect any demographic or identifying information for participants, instead focusing upon the general dynamics present between the "shamers" and shame recipients within the john school program. While this study does utilize the actual names of certain john school program presenters, it maintains the confidentiality and anonymity of all participants through usage of pseudonyms.

In order to tease out the dynamics of shaming and emotional reception present within the john school program, I posed the following questions to frame participant observation:

1.) What is the tone/discourse utilized by each presenter? Are there key words, or phrases that the presenter uses to refer to prostitutes, johns, law enforcement agents, human trafficking victims, etc.? Is the general tone harsh, casual, formal, familiar, etc.?

2.) How does the presenter communicate with participants? Does he or she allow for questions or request that participants remain quiet? Does he or she challenge participants to engage in role play or prove a point? Does he or she walk among the group or stand in one spot the whole time? Does he or she dress formally or informally?

3.) How does the presenter balance accountability with care for participant wellbeing? Does he or she address issues of legal culpability or moral/ethical culpability? Does he or she explicitly communicate messages of care or concern about participants' health, well-being, safety, or potential sexual addiction? 
4.) What information does the presenter emphasize during their presentation? Are there segments that the presenter repeats or reiterates? Does the presenter offer a summary of the high points or most significant aspects of their discussion?

5.) How many participants ask questions during the presentation? What types of questions are asked?

6.) How many participants are asleep or using their cell phones during the presentation? How many seem to be paying attention (making eye contact, nodding, etc.)

7.) Do participants approach the presenter after the conclusion of the presentation or take any information pamphlets, business cards, etc.? Do they clap for or thank the presenter?

In addition to participant observation, semi-structured interviews with both program presenters and participants were conducted. Interviews with program presenters took place inside St. Ann's Episcopal Church following the john school program or over the phone. During these recorded interviews, presenters were questioned about their personal objectives for participating in the program; their opinions on the program's overall purpose; their ideas regarding program structure and duration; their expectations for program impact, their preferences regarding penal approaches to prostitution-related offenses; their presentation styles; their opinions regarding reintegrative and stigmatizing shame; their opinions regarding reasons why men engage in sexual consumption, and how they believe the john school responds to those reasons; their ideas regarding prostitution prevention; and, their ideas for potential program improvement. Interviews were conducted with Kenneth Baker of Behavioral Treatment Providers, Brad Beasley from the Davidson County Health Department, Rachel Thompson and Antoinette Welch of the Davidson County District Attorney's office, a member of Sexaholics Anonymous, and Derri Smith from EST.

In order to offer options for anonymity, group discussion, and individualized discussions, I established various channels through which john school participants could engage in the research. First, all participants were offered an opportunity to participate in one-on-one, semi- 
structured, semi-private interviews with me following a given john school session. Participants were granted immediate compensation in the amount of 20 dollars for partaking in these interviews. All interviews took place on the premises of St. Ann's Episcopal Church, either outside of the chapel that hosts the program, or immediately outside the front door of the building. Generally, these interviews occurred within the distant vicinity of a church office where staff members worked. This provided a layer of privacy and also visibility for both me and my interview participants during our face-to-face interactions.

During interviews with program participants, I questioned participants about whether the offense prompting their participation in the john school was their first time engaging in sexual consumption. I also asked about their preference of sexual service venues; their opinions regarding prostitutes, law enforcement agents, and human trafficking victims; their motivations for purchasing sexual services; their opinions regarding "shaming" campaigns; the degree to which they felt culpable, remorseful, or entrapped; their notions of costs/benefits and risks associated with sexual consumption; their thoughts on recidivism and sexual addiction; their ideas regarding the legalization or criminalization of prostitution; their reactions to the presentations, design, duration, and venue of the NJS program; and, their plans to participate in sexual consumption in the future or discontinue participation altogether.

Program participants were also offered the option of engaging in an online interview through a private chat room. All participants were informed of the process of establishing a chat room account, logging on, and engaging in a private virtual discussion with me. Participants were also informed of associated confidentiality and security policies prior to subscribing to this option. Although no program participants elected to engage in virtual interviews, this opportunity provided a discussion outlet for those interested in contributing to research in a meaningful way without feeling overly exposed or visible. Internet interviewing was also offered as a means of reducing discomfort associated with my presence as a female researcher, given that cyberspace offers some degree of anonymity. Also, a generic Internet chat room represents an imaginary, 
non-politicized space that does not carry the same symbolic overtones as a church building, for example. Knowing this, I had believed that subjects would be induced to express themselves more openly and honestly without fear of judgment, manipulation, or reproof-let alone participate in my study at all. Surprisingly, however, all participants that volunteered to partake in individual interviews rejected this option, mentioning either their discomfort using technology, or the desire to complete the john school program and an interview pertaining to it in the same fell swoop—and then "be done with it for good."

A final facet of my research involved focus groups for john school participants.

Originally, I anticipated three focus group meetings to address broad questions regarding the john school components, the players involved in prostitution, and the overall crime of prostitution. Rather than "leading" the group discussion, I planned to pose general questions to spark discussion and debate amongst group members, thus allowing me to draw deeper conclusions regarding the manner in which subjects construct themselves in social settings and how such constructions are potentially informed by program curriculum and structure. This group approach allowed johns to engage in dialogue with each other within an insulated environment, and appealed to those that might not feel comfortable in one-on-one social situations. In spite of this provision, no john school participants elected to participate in this option.

During the course of my research, many john school participants and program presenters, having observed my singular presence as a female within a large group of "sexually deviant" men, questioned me about my interest in the Nashville John School program (NJS). Why would $I$ be interested in studying a diversion program for sexual service consumers? Why was I drawn to Nashville's program in particular? More importantly, what were my preconceived notions about this population of offenders and what was I hoping to gain through my research? In answering such questions, I reveal the unique position that such a program occupies between harsh deterrence and restorative justice strategies. On the one hand, the john school program has gained widespread approval from various cities and provinces that have boasted reduced re-arrest 
rates for prostitution-related offenses after program implementation. Moreover, the john school model has received praise for enabling successful collaborations between law enforcement agents, non-profit organizations, legal services personnel, health care services, and localized community groups. On the other hand, the john school model has proven confusing and potentially problematic for some neo-abolitionists (those who want to abolish the sex trade), prosex work advocates, and proponents of traditional criminal justice penalties who skeptically question: is it really enough? How can a program resembling the design and duration of traffic school possibly deter sexual service consumers from engaging in prostitution-related offenses again? How can it effectively catalyze profound behavioral changes within an eight-hour period? Do john school graduates simply learn how to better avoid law enforcement detection by pursuing more covert methods of sexual consumption? Most importantly, what does the program design and duration suggest about societal opinions of prostitution-related offenses?

Within the contemporary human trafficking movement in particular, growing attention has been paid toward lowering the demand for sexual services, thus weakening profit potential for sex traffickers. For advocates of this line of attack, the john school program represents an innovative and yet uncertain approach to an age-old phenomenon. Out of this skepticism, a parallel approach to deterrence has developed—one that seeks to deter offenders through public shaming rituals, such as posting johns' pictures in the local newspaper or billboard signs; charging exorbitant fines for prostitution-related offenses (fees in the thousands of dollars); confiscating property utilized to purchase prostitution (i.e. cars and computers); and sending letters home to the spouses or intimate partners of johns, warning them of the potential risks of STDs/HIV contraction due to their partner's commercial sex activities. Cities such as Denver and Aurora, Colorado, Orlando, Oklahoma City, St. Paul, and Kansas City, are among those that have utilized such tactics to deter prostitution. In 2002, Mayor Wellington Webb of Denver, Colorado launched a program entitled, "Johns TV," in which a local television station aired the mug shots, birthdates, names, and conviction dates of local "johns" as a means of discouraging men from 
purchasing prostitution. The Johns TV program lasted approximately 30 minutes and was aired twice daily, once in the morning and once in the evening. Supplementing the TV show was a website featuring the same information, accessible through the Denver.gov homepage.

According to former Mayor Wellington, engaging in prostitution entails an active acceptance of risk, therefore, "If you choose to risk being arrested for prostitution, if you choose to risk catching a sexually transmitted disease, you now also choose to take the risk of having your picture appear on TV and on the city's Web site for the whole world to see" (Isaacs 2002).

Others like Norma Ramos, Executive Director of Coalition Against Trafficking in Women, believe that public shaming tactics will challenge societal perceptions of prostitution that normalize sexual service consumption, thus creating greater consensus for anti-prostitution campaigns. She asserts: "The idea is to discourage men from the notion that they have the right to buy the bodies of lesser privileged women and children for sexual gratification... We have to move away from the 'Pretty Woman' model and towards understanding that prostitution's pretty ugly" (Neumeister 2012).

Despite their popular appeal, shame tactics spark controversy for their stigmatizing impact, which punishes offenders (and their family members) without imparting any information or resources that they might utilize to modify their behavior. In addition, labeling offenders as deviant encourages societal exclusion and creates barriers for reintegration. In response to the Denver Johns TV program, Albany Law School professor Laurie Shanks notes how shaming publicly humiliates offenders prior to trial in a way that is disproportionate to the gravity of their offense: "The chance of a completely innocent person having their life destroyed was astronomical...It was worse than the scarlet letter. At least the scarlet letter happened after the trial. It's closer to branding, where you can't take it off once the harm has been done" (Neumeister 2012). Nevertheless, hard-core shame tactics remain prevalent as a deterrence strategy for prostitution offenders. 
As a case manager for human trafficking victims during the outset of this research project, I personally witnessed a confusing blend of skepticism and praise about the john school program within my professional circle. Arguments supporting and condemning labeling rituals and restorative justice strategies have circulated and re-circulated in task force meetings, conferences, and private conversations, especially regarding whether or not Jefferson County, Kentucky should also establish its own john school program. Consequently, I became curious about the possible "effectiveness" of the diversion program with respect to its ability to truly influence recidivism. More specifically, I wondered about the concept of shame wielded in varying degrees as a deterrent strategy. How does the program curriculum and structure construct "the john"? How, in turn, do these constructions shape subjects' perceptions of the risks associated with their participation in the sex industry? How does the restorative justice model compare with hard-core penal measures that seek to deter johns through stigmatizing shame?

In order to explore these initial questions, I began researching john school programs in the vicinity of Louisville, KY. Each program features slightly different characteristics, including the fines, the presentations offered during the program, and the criteria for enrollment. ${ }^{\mathrm{i}}$

Ultimately, I decided to concentrate my efforts on a john school program that offers a wide variety of presentations while narrowing the requirements for program enrollment ${ }^{\mathrm{ii}}$. The NJS program consists of six different informational presentations designed to educate participants about the risks associated with participation in sex industry activities. Each of the presenters works as a program volunteer and receives no direct benefit from their participation. Altogether, the presentations address behavioral/psychological motivations to engage in high-risk activity; health risks to consumers and providers; legal implications for crimes associated with prostitution; sex addiction; connections between commercial sex and sexual exploitation; and also, the life struggles associated with sexual service provision. Additionally, offenders receive packets of information containing a program questionnaire, a prostitution facts test, a copy of prostitution-related laws, a sexual addiction screening test and subsequent explanation of sex 
addiction, information about sexual compulsives anonymous, and a schedule of local Sexaholics Anonymous meetings. Also, offenders' pictures, names, and citation numbers are posted on the Nashville Police Department website for 30 days following their arrest. While this form of exposure does recall the shaming tactics detailed previously, identifying information is restricted to the police website only (rather than billboards and TV programs directed at the general public), requiring potential viewers to specifically seek out such information. Also, the availability of such information is temporally limited.

John school participants must also submit to HIV/STD testing and pay a $\$ 300$ fine to attend the john school program. All of these stipulations must be met in order for offenders to dismiss their cases in court, and later, expunge them. Because of the diversity of the presentations offered, the strict restrictions for program enrollment, and the geographic proximity to my hometown, I selected the NJS program as a solid program of study.

\section{Origins of the John School Diversion Program}

The first john school program, or First Offender Prostitution Program, emerged in San Francisco in 1995 as an approach to combat the ills associated with commercial sex. The program resulted from collaboration between the San Francisco Police Department, the District Attorney, and a non-profit organization aiding victims of sexual exploitation, SAGE (Standing Against Global Exploitation). Rather than utilize traditional penal channels alone, the FOPP seeks to educate johns about the legal, medical, and crime victimization risks associated with their participation in the sex industry while increasing empathy for sexual service providers and community members adversely impacted by the presence of commercial sex activities (Shively et al. 2008). The john school was also designed to serve as a revenue stream for continual police decoy operations; program administration costs; court processing costs; and most importantly, social services for survivors of sexual exploitation. In response to the reportedly low recidivism (re-arrest) rates in San Francisco following the program's inception, many states and provinces 
throughout the world have emulated this model and developed john school programs of their own. While each program sets its own parameters, including fee amounts, material presented, and legal conditions, most closely resemble the original model and boast equally low recidivism rates for prostitution offenders while remaining cost-free for taxpayers.

\section{History of the NJS}

In the mid-1990s Reverend Becca Stevens, an Episcopal priest on Vanderbilt's campus, grew tired of witnessing women trapped in a vicious cycle of homelessness, prostitution, and substance abuse that inevitably resulted in prison sentencing, only to return them to the streets with no alternatives or assistance. Becca decided that the time had come to act. Realizing that the target population's needs were not being met, she contacted Nashville's mayor, who then convened a special task force consisting of the District Attorney's office, the Davidson County Community Correction's chaplain, and a few members of local faith congregations. Through this task force, the Magdalene program, a residential program for survivors of homelessness, addiction and prostitution, was founded. This program currently provides free housing, food, medical/dental assistance, therapy, and education \& job training to Magdalene residents for two years while building their sobriety and stability. The program does not rely upon government funding; rather, it has developed alternative revenue streams. One of these stems from Thistle Farms, an original bath and body product social enterprise that the Magdalene program developed in order to assist program participants (especially those with felony charges) with employment opportunities. Magdalene residents employed at Thistle Farms gain work experience in manufacturing, packaging, marketing, sales, and administration while earning money in a supportive work environment. Currently, Thistle Farms products are sold at over two hundred stores within Tennessee and throughout the United States.

While Thistle Farms provides both a valid employment opportunity for program participants and profit for the Magdalene program, it is not the only source of revenue supporting 
Magdalene's residents. In 1997 the NJS program was developed as an additional component of the Magdalene program. The program represents a collaborative effort between the Magdalene program and the District Attorney's office to draw greater attention to the other side of the prostitution equation: buyers. For the Magdalene founders, the john school program not only represents a more equitable social justice model by calling attention to both parties involved in sexual service transactions, but also provides additional revenue for their non-profit program. Unlike other john school programs, the NJS channels all of its proceeds to benefit survivors of prostitution and exploitation, rather than dividing proceeds between law enforcement, legal services and social service providers. As such, through a one-day educational intervention for first-time offenders, sexual service consumers pay directly into a program that supports the ongoing treatment and recovery of women once walking the streets.

\section{Criminalization Procedures for NJS Participants}

Participants in the NJS program are the product of reverse sting operations in which female law enforcement officials work as decoys to attract potential sexual service consumers. Such decoy operations occur either through "streetwalking" transactions in parts of town notorious for prostitution, or through Internet-based sting operations in which a buyer contacts an online advertisement and arranges to meet a consumer at a hotel or motel.

According to 2010 Tennessee Code, Section 39-13-512, "Patronizing Prostitution" refers to the act of "soliciting or hiring another person with the intent that the other person engage in prostitution, or entering or remaining in a house of prostitution for the purpose of engaging in sexual activity." For decoy officers, this law indicates that intent is the minimal element necessary for arresting and successfully prosecuting an offender for patronizing prostitution. Decoy officers need not negotiate a price or provide any sexual services to potential buyers; they need only demonstrate that the person's aim was to purchase sex. According to Antoinette Welch, an ADA in Davidson County and former law enforcement agent, intent is not difficult to 
prove. In fact, a person becomes prosecutable upon demonstrating some of the following behaviors: presenting themselves in a part of town notorious for prostitution, especially without just cause (i.e. their home or workplace are nowhere nearby); circling the block two or three times, as is commonplace for buyers "scouting" a potential purchase; talking to a "known prostitute" (a person with a history of prostitution-related arrests); and sometimes, a direct or indirect offer for paid sexual exchange. As a former decoy agent, Welch identifies some common approaches from interested buyers that demonstrate intent. She reveals these in a phone interview, saying,

They'll just pull up and say anything from 'Hey, do you need a ride?' 'Hey, do you want to party? 'Hey, what are you doing?' 'Get in the car!' I mean it doesn't take a whole lot to show intent. Sometimes they'll just straight up ask for something, or ask us a question like, 'Do you party?' I'm like, 'Yeah I party! You got 20 bucks? What do you want to do with it?' Stuff like that, sometimes they'll tell you something, sometimes they'll just say 'yes' - that kind of thing.

Welch also acknowledges how easy it is to prosecute buyers that utilize online ads or escort agencies to procure providers: "The internet is real easy, because the guys will either call or type back and forth, you know, 'hey, I'm looking for such and such'...the ads are always written and it's clearly for someone's sort of sexual act... and you know if they show up - that's real easy! Especially if they have money in their pocket, I mean, it's real easy! if they show up, I'm like, boom! It's in!" While creating remarkable flexibility for prosecutors and law enforcement officials, the law on patronizing prostitution proves confusing and frustrating for johns, who often do not comprehend how they have violated a prostitution law when neither sexual services nor money were actually exchanged. This thesis will later elaborate on the notion of entrapment, and how the manner in which prostitution laws are written constructs perceptions of wrongdoing for program participants.

\section{Legal Implications of the NJS}


Upon arrest for patronizing prostitution (and associated charges), sexual consumers receive a citation requesting them to appear in Davidson County's criminal court, where they are given an option as to how they would like to plea. If proven guilty, those with prior prostitutionrelated convictions are automatically sentenced to 30 days in jail. First-time offenders, however, have various options available to them. Should they plead guilty, they can either go to jail for 30 days, or pay $\$ 300$ to participate in the john school program (which also mandates that participants get tested for STDs/HIV). Those that elect to attend the john school program may enter an Under Advisement plea, in which the judge officially delays his or her ruling until the offender brings proof of john school completion, at which point the judge will dismiss the case. Others may choose to utilize the 40-35-313 statute, which enables offenders to have their case dismissed and their arrest expunged after completing a probation period of six to twelve months (depending on the severity of the charge). As a part of their probation, offenders must also complete the NJS program and fulfill all of its stipulations_-paying a $\$ 300$ fine and submitting to STD/HIV testing. This 40-35-313 plea, which the Davidson County District Attorney's Office fondly refers to as the "do-over statute," is one that anyone can utilize once in their lifetime for misdemeanor offenses and even some felonies charges. For either plea, not showing up for the assigned john school session will automatically result in a 30-day jail sentence.

Most sexual consumers that participate in the john school program have been charged with patronizing prostitution, which qualifies as a Class B misdemeanor. However, as ADA Rachel Thomas, explains, most johns actually commit a more serious offense, but arrest officers are generally "nice enough not to charge for it." Following Tennessee Code Section 39-13-513: “Prostitution committed within one hundred feet (100') of a church or within one and one-half (1 1/2) miles of a school, such distance being that established by Sec. 49-6-2101, for state-funded school transportation, is a Class A misdemeanor." Given the number of churches and schools in the Davidson County area, many offenders commit Class A misdemeanors even if they are charged with a lesser offense. On the other hand, those that enter an innocent plea for patronizing 
prostitution receive another court date on the "bond docket." However, according to Antoinette Welch, many offenders "add up the court costs at that point and end up taking the deal [john school diversion program] anyway." As such, each john school session generally contains between 25-40 offenders - all of whom result from reverse sting operations through both the Internet and known areas of prostitution.

Offenders that plead guilty and complete the john school program not only qualify to have their cases dismissed; they can also pay to have them permanently expunged from their record. For an additional fee, participants can remove any evidence of involvement in prostitution from their criminal records, thus allowing them to avoid questioning or disqualification from employment or housing opportunities due to a flawed background check. Offenders may file for expungement as soon as their case is dismissed by the judge.

\section{Overview of the NJS Program}

The NJS program is held in St. Ann's Episcopal Church, a small, contemporary-looking building on the corner of a busy intersection within sight of downtown Nashville. One Saturday morning each month, participants form a line in front of an informal card table where they register and receive their packets before filtering into the chapel where the program is held. Two female volunteers, one of whom works as a Spanish language interpreter during the course of the program, and another who spearheads administrative responsibilities throughout the day, greet the participants with a cheerful smile. The program begins around 8:30am, allowing participants to gradually trickle through the door, even if arriving a few minutes tardy.

As participants quietly fill out paperwork and await their number to be called by the administrative volunteer (in order to turn in registration information), Kenneth Baker, a Cognitive Behavior Therapist at Behavioral Treatment Providers and the NJS Program Director, kicks off the session with an informal discussion about the psychological elements that mold behavior. $\mathrm{He}$ encourages participants to non-judgmentally explore the underlying reasons that motivated their 
decision to purchase sexual services. Following his discussion, participants receive a five to ten minute break while awaiting the next presenter, Brad Beasley, from the Davidson County Department of Health. Most participants clear out of the chapel for a bathroom break or quick smoke outside the church. Others remain seated, swapping stories with one another, quietly fixating on their phones, or sleeping in their chairs. Slowly, men return to their seats as Brad Beasley begins his presentation, in which he details the symptoms and treatments of common sexually transmitted diseases as well as HIV/AIDS. Afterwards, either Rachel Thomas or Antoinette Welch of the Davidson County District Attorney's Office enters the session. Both speakers present legal information for program participants, including the implications of prostitution-related offenses with supporting examples from their respective caseloads, and the particulars of case dismissal and expungement. Following the legal presentation is an hour-long lunch break for participants and facilitators, all of whom vacate the building to find food nearby. Upon returning, participants attend another presentation - this time by a former prostitute that has received assistance from the Magdalene program. Although the actual speaker may vary from session to session, most recount their painful childhood home lives, histories of abandonment, domestic violence or sexual abuse, and lifelong search for love and acceptance. They discuss how the Magdalene program has helped to educate them and create opportunities for stability, and remind the participants how the $\$ 300$ john school fee benefits ex-prostitutes and substance abusers. Participants then receive another five to ten minute break while awaiting the next speakers-volunteers from End Slavery Tennessee (EST), a local anti-human trafficking agency. In their presentation, EST presents facts and statistics about human trafficking, explains how human trafficking and prostitution intersect, and encourages participants to stop fueling the demand for sexual services, thereby creating a market for human traffickers. Finally, two or three members of a support group known as "Sexaholics Anonymous" give individual testimonies of their respective sexually addictive behavioral patterns. SA members encourage program participants to examine their behaviors and seek out support services should they suspect 
themselves of having sexually addictive tendencies. The program officially concludes as the administrative volunteer hands out certificates of program completion, which each participant must present to the judge at their show-cause hearing in order to have their case dismissed. Participants then make their way out the chapel doors and into the lobby area, perhaps picking up additional materials on sex addiction or pausing to speak with SA members on their way out.

\footnotetext{
${ }^{i}$ The programs that I considered for my study, along with their respective characteristics, are as follows:

- Cincinnati, Ohio: Features an eight-hour class with presentations from the Cincinnati Police Department, Central VICE, the City Prosecutor, STOP AIDS, a concerned community member, a sex addictions counselor, and two prostitution survivors. The program charges a $\$ 500$ fee that participants can pay in installments. The program is not exclusive to first-time offenders and does not require participants to undergo STD/HIV testing (Shively et al. 2008).

- Columbus, Ohio: Features an eight-hour class with presentations regarding STDs, neighborhood crimes related to prostitution, and survivors' experiences in the sex trade. The class must be completed on top of probation, jail time, or a fine. Convicted offenders may also receive one hundred and eighty days in jail, a \$1,000 fine, or a possible suspension of driver's license (Shively et al. 2008).

ii While the Cincinnati john school program provides a multi-faceted array of presentations, it allows both first-time and prior offenders to enter the school, therefore rendering it difficult to gauge the program's potential impact on recidivism. The Columbus program also problematizes my exploration of excluding versus reintegration by combining both approaches. Also, the presentations offered in the diversion program are more limited than others.
} 


\section{LOCATING THE NJS}

The john school program's design and purpose-to combat prostitution through reeducation and reintegrative shaming-occupies a unique position within a larger context of social movements, state intervention, and crime control models. In order to conceptualize how the program and its presenters construct prostitution through stigmatizing and/or reintegrative shaming, how society condemns and/or condones participation in sexual commerce, and how johns respond to these factors through expressions of shame-guilt, embarrassment-exposure, or unresolved shame, it is critical to locate the john school program within various sociopolitical and historical approaches to sex work. First, it is important to explore how the economic determinism paradigm constructs neo and non-abolitionist attempts to curtail prostitution through the establishment of certain legal and theoretical frameworks, namely criminalization, legalization, or decriminalization. Such approaches reflect historical methods to establish and to govern sexual morality and normativity, as well as to manage public health. Furthermore, it is necessary to examine the NJS' precarious position between draconian deterrence measures and reformative justice models by reviewing the destructuring, deterrence, and reintegrative shaming approaches that have shaped it.

\section{Economic Determinism: Supply and Demand}

First, in order to locate the john school program within a larger sociopolitical context, it is important to review the dominant market paradigm under which sexual service consumption has long been subsumed. According to this framework, the consumption of erotic services is 
inextricably linked to the principles of the free market—supply and demand. As such, the general drive for sexual services forms various niches for sexual service provision, thus fueling the sex industry as a whole. This model conceptualizes the sex industry as a mere business, guided by the same market principles as any other product or service offered in the global economy, with the end goal being maximized profits. The principles of supply and demand encapsulate all forms of sexual service, both legal and illegal, as well as all forms of participation-whether voluntary or coerced. The economic determinism employed through this framework does not account for the specific motivations that compel individuals to participate in the sex industry. Rather, it privileges a macro perspective that reduces all sexual commerce transactions to exchanges of sex for money.

Conceptualizing prostitution in the United States as a lucrative industry driven by an ever-present demand for sexual services is not a new model. In fact, the 1902 Committee of Fifteen states that "A community, it is said, will have as much vice as it is willing to pay for. 'Demand will create a supply"' (1902:7). Though the report critiques the notion that the buyers - the men who merely respond to their biological "need" for sexual pleasure—are culpable for stimulating the growth of the sex industry, it does refer to the prominence of the dominant economic model for conceptualizing it. Additionally, cities across the United States have recognized the importance of the revenue generated by prostitution in their local communities. Jeff Rettmann describes how prostitution in Spokane, Washington proliferated in spite of its official condemnation. He writes, "Since prostitution was a major attraction, city officials and businessmen had a big stake in making sure that prostitution continued with as few regulations as possible" (1998:78). As such, prostitution has long been envisaged as a profitable business, governed by the same principles of the "invisible hand" as any nonsexual industry.

However, the emergence of human trafficking as a hot topic amongst government officials, NGOs, religious organizations, and feminist activists has altered the long-standing market paradigm, situating it within a human rights discourse. The 2011 Trafficking in Persons 
Report, an annual report published by the United States Department of State, concluded that, "The economic reality is that human trafficking is driven by profits. If nobody paid for sex, sex trafficking would not exist...Increasingly, anti-trafficking actors are looking to combat modern slavery from the demand side rather than focusing on arrests and prosecutions (the supply side) alone" (2011:21). This suggests that the demand for sexual services fuels sex trafficking, by creating particular niches for service provision within the sex industry that traffickers exploit for profit. It also assumes that sexual service consumers ("johns") cannot or do not distinguish between victims of human trafficking and voluntary, consensual sex workers when purchasing sexual services. According to this theory, the increasing demand for sexual services not only bolsters participation in prostitution, but also the potential for sexual exploitation.

Furthermore, radical feminist organizations such as the Coalition Against Trafficking in Women or Prostitution Research and Education conflate sex trafficking and commercial sex, claiming that all forms of participation in the sex industry represent forms of sexual exploitation. According to CATW (N.d), "Sexual exploitation includes sexual harassment, rape, incest, battering, pornography and prostitution. All prostitution exploits women, regardless of women's consent. Prostitution includes casual, brothel, escort agency or military prostitution, sex tourism, mail order bride selling and trafficking in women."

Neo-abolitionist organizations that make no distinctions between consensual and nonconsensual participation in the sex industry insist that "the demand" must be eradicated before exploitation can cease. As Ted Bunch, the cofounder of A Call to Men, a national organization working to end violence against women and girls, states, "Men feed the demand, and men have to eradicate the demand" (Bennetts 2011). Hence, abolitionists promote various measures for educating and penalizing sexual service consumers, regardless of whether their sexual transactions are legal or illegal, consensual or coerced. It is within the context of "eradicating demand" that the john school program is located. Rather than simply relying upon hard-core penal consequences, such as imprisonment, to deter sexual service consumption, many states 
have adopted a softer approach. This approach assumes that if commercial sex consumers knew about the dangers associated with participation in the sex industry, they would not choose to engage in such activities in the future. For this reason, the john school program addresses a wide variety of risks presumed to deter sexual service consumers from recidivism.

The state-endorsed "attack on demand" has not only been informed by the global human trafficking discussion, but also by hygienic and moralistic concerns. Such concerns have long since supported anti-prostitution campaigns in the United States, claiming that prostitution increases risks for STD/HIV contraction and threatens traditional and "ideal" expressions of monogamous, conjugal, and reproductive sexuality. Moreover, the sex industry is implicated in the spread of the HIV/AIDS epidemic (Middleberg 2006:3-4). In this sense, the hygienic concerns surrounding prostitution still play an active role in the policies enacted in the United States and abroad. Such concerns have also been mobilized by neo-abolitionist groups as a supportive argument for their rationale - that sexual commerce is inherently harmful.

The john school program is situated within a complex intersection of old and new theories, all of which inform the current "attack on demand." Abolitionist theory that subsumes all participation in sexual commerce under the paradigm of sexual exploitation has majorly influenced the state-endorsed movement to eradicate demand. This movement is also bolstered by long-standing arguments against sexual commerce as a hygienic and moral danger to society. As such, the john school diversion program represents one method among many of curtailing demand for sexual consumption, positing that an eradication of the "demand" will necessarily eliminate the "supply," thus destroying the entire sex industry.

\section{Problematizing Economic Determinism}

While many allude to economic determinism to illustrate the dynamics of the sex industry, this model has received criticism for reducing all sex industry participation into mere sex-for-money exchanges. For Elizabeth Bernstein (2007) and Katherine Frank (2007), "the 
invisible hand" does not entirely encapsulate the commodities that are truly exchanged during a commercial sex transaction. For Bernstein, contemporary commercial sex exchanges entail more personalized, time-consuming investments in which sex workers simulate "the girlfriend experience." She writes, "In contrast to the quick, impersonal 'sexual release' associated with the street-level sex trade, much of the new variety of sexual labor resides in the provision of what I call 'bounded authenticity'-the sale and purchase of authentic emotional and physical connection (2007:103).” Frank supplements this observation, concluding that contemporary sexual exchanges also engage sex consumers" "touristic gaze," in that they "foster feelings of belonging, connection, intimacy, self-expression, and self re-creation (2007:166).” In this sense, sex industry transactions may not be easily condensed into a capitalist paradigm that discounts the complex emotional, social, psychological, and spatial-temporal factors that influence their dynamics.

For some presenters at the NJS, johns represent an incorrigible demand for sexual services that exacerbates human trafficking. Consequently, the john school program serves to reeducate and reintegrate offenders, thus deterring them from sex industry participation and reducing demand overall. In a phone interview with Executive Director of End Slavery Tennessee, Derri Smith, she described how johns perpetuate human trafficking, "sometimes by buying, unawares or awares, minors or people who were victims of human trafficking." She insisted, "the money they're giving is going into the systems that feed human trafficking potential and the business and everyone in it and the products that sell...Demand drives trafficking and prostitution, so anything we can do to lessen the number of people who are demanding sex for pay, the more we're addressing those crimes." For Smith, the irrefutable link between prostitution and sexual exploitation demonstrates that prostitution is not, as johns might believe, a victimless crime. Davidson County ADA, Antoinette Welch, agrees with this assertion, boldly declaring to the program participants, "A lot of people think prostitution should be legalized because it's between 'two consenting adults'...almost 99 percent don't want to be there! They're 
not there by choice! This sex trafficking thing is finally getting the attention it deserves...everyone says prostitution doesn't hurt anyone, but first of all, it hurts women."

Understanding the impetus of the john school program, and all other prostitution deterrence efforts for that matter, also necessitates a historical exploration of State-sponsored efforts to define sexually normative behaviors and boundaries, to curtail the spread of STDs and HIV, and to establish legal frameworks that effectively manage these factors while simultaneously shaping societal perceptions of sexual morality. While social and political efforts to curtail prostitution and its related hazards are not new, the erotic service industry has greatly diversified over time, thus raising new questions. For example, how does the law define prostitution, thus differentiating it from other types of erotic work? What do legal definitions of prostitution indicate about societal perceptions of sex work and how do such definitions reinforce them? In other words, what makes prostitution unacceptable while other erotic services like erotic dance or massage remain tolerable? Which legal frameworks for prostitution best encapsulate these ideas? Such questions remain problematic due to the variety of ways in which "sex work" and "prostitution" are constructed and politicized by various groups. This ethnography later examines how different sociopolitical groups formulate their own definitions of prostitution, proposing legal models to establish and reinforce such conceptualizations. In spite of these efforts at legal categorization, boundaries between different forms of erotic service provision and even traditional feminine roles within patriarchal society, remain slippery.

\section{Defining Prostitution: Problematizing the "Market" Paradigm}

Hastings Donnan and Fiona Magowan describe the spectrum of sexualized relationships and the fluid boundaries between them: "Images of erotic enticement have led some writers to speak of prostitution as a vocation in which sex is an erotic art and prostitutes are mistresses of that art... Others speak of prostitution as an effect of being in a patriarchal society in which no distinction can be made between prostitution and other forms of sexual relationships" (2010:73). 
They also discuss the difficulties in assigning reductionist definitions to various sexual service activities, illustrating the cross-cultural and contextual variability that influences notions of sex work and commoditized exchange. Instead, they propose a continuum of sexual expression within monogamous and extramarital relationships (ibid:73). Here Donnan and Magowan emphasize the complexity of commoditized sexual exchanges within the context of marriage and outside of it. They caution against essentialist binaries that position marriage and commercial sex in opposition to one another, arguing that cultural and sociopolitical contexts must be taken into consideration before any attempt at categorization takes place. On the whole, Donnan and Magowan conclude that, "What constitutes 'sex work' is uncovered from the perspective of what men and women believe they are doing when they engage in monetized sexual exchanges" (72).

Tove Pettersson and Eva Tiby (2003) share a similar opinion, exploring how law enforcement agents, social service providers, sexual service consumers, and healthcare professionals constitute prostitution in ways that challenge reductionist legal definitions. In their conclusion, Pettersson and Tiby note that prostitution represents "a clear example of the way those with power, the members of established mainstream society, define what is to be designated as deviant, and thereby what is to be sanctioned" (2003:168). Thus, Pettersson and Tiby avoid simplistic definitions of sex work or prostitution, citing the inevitable variability of such phenomena according to context. Additionally, they emphasize the importance of considering power relations, which necessarily influence conceptualizations of sexual deviance and social norms. For some participants in the NJS, the manner in which Tennessee prostitution laws define sexual deviancy reflects dominant conceptualizations of sexual morality and normativity, established by those in power. For those that reject such conventional conceptualizations, the NJS may not successfully generate feelings of shame-guilt.

For the purposes of this thesis, I utilize the term "sex work" to refer to the collective sexual activities that can occur within commoditized exchange, understanding that not all of these activities are objectionable to various groups of people. As previously mentioned, "prostitution" 
is the sex industry sector that features most prominently in debates regarding preferable legal models. Because of this, I also utilize the term "prostitution" to more accurately identify the particular sex industry activity that so many activists find controversial. While I agree with Donnan and Magowan, Pettersson and Tiby that prostitution definitions tend towards reductionism and are often constructed by those in power, I employ the term "prostitution" in reference to its popular and dominant conceptualization as a sex-for-money exchange defined by law. While boundaries between different types of sex work or traditional feminine roles, such as prostitution, fetishism, domination, erotic dance/massage pornography, or marriage are more fluid than legal definitions imply, laws impose reductionist categories on complex phenomena by establishing what is legal, moral, or socially acceptable, and what is not. In turn, legal models that criminalize, legalize, or decriminalize prostitution reflect societal perceptions of sexual morality and normativity. Each of these frameworks possesses historical significance in antiprostitution campaigns following the Civil War and still remains highly controversial around the world.

\section{Historical Approaches: Regulationists and Abolitionists}

Mark T. Connelly outlines the history of prostitution within the United States, exploring how prostitution became an especially salient issue in the aftermath of the Civil War when women's groups, former abolitionists, temperance organizations, and church officials collaborated in a "purity crusade" for the restoration of American sexual morality (1980:5). Emerging from this controversy were two opposing ideological camps: regulationists and "purity forces" (ibid:5). On the one hand, regulationists (generally physicians, public health officials, and government officials) maintained that sexual commerce was an inevitable fact of life that can never be eradicated. Rather than create laws to abolish prostitution, regulationists promoted the legalization and government-sponsored regulation of certain sex industry venues. By implementing frequent and compulsory medical inspections for prostitutes as well as imposing 
spatial boundaries for sex industry activities, regulationists asserted that immoral sexual behavior and venereal disease could be effectively contained. This is evident in a 1902 report published by a committee of citizenry from New York City that convened to address the rapidly growing "vice" plaguing their communities. In their report, the Committee of Fifteen acknowledges prostitution as "a phenomenon coextensive with civilized society" (1902:1) without hope of eradication. This recognition of prostitution as a permanent fixture in the social fabric constitutes the foundation of regulationist ideology, which questions, if prostitution cannot be abolished, how can it be effectively minimized and contained?

In response to this question, the Committee of Fifteen regards prostitutes as liable for the spread of infectious diseases (1902:77). As such, the committee recommends improved access to healthcare for prostitutes suffering from venereal disease. Additionally, it calls for more funding for medical care directed at the sex industry population. Moreover, spatial confinement is also proposed as a means of controlling hygienic risks and immorality, especially for minors that have been "notoriously debauched" (ibid:176).

While venereal disease can best be controlled through regulation and containment, restricting "immorality" necessitates further attention. The report recommends two important measures for ensuring society's moral purity: improved "moral education" for high school and college-aged young men and societal condemnation of prostitution and mobilizing a stigmatizing discourse that unceasingly reviles "the evil itself" as a "sin against morality" (1902:175).

In reports such as this one, prostitutes are constructed as societal pathogens. On the one hand, the Committee of Fifteen advocates for improvements and expansions to the healthcare system for prostitutes. On the other, while the Committee acknowledges that both clients and providers can transmit venereal diseases, only prostitutes are subjected to mandatory health screenings or detainment due to infection. Furthermore, prostitutes—not clients—are spatially confined as a means of containing the spread of sexual immorality and corruption. These measures, along with recommendations to condemn and stigmatize sexual service providers, 
pathologize the prostitute. In this sense, regulationists during the Progressive Era privileged the mobility of sexual service consumers while comparatively limiting the mobility of "pathogenic" sex workers. Regulation served to contain these mobilities and protect the sexual purity and health of society as a whole.

On the other side of the post-Civil War purity campaign were the "abolitionists" that sought to criminalize prostitution. Under this model all prostitution venues would be outlawed. Those that knowingly employed prostitutes, operated commercial-front brothels, or directly provided sexual services would be subject to punishment. This approach became especially popular during the Prohibition era when other forms of public vice—namely alcohol consumption-were disputed and eventually banned. In 1911 the Vice Commission of Chicago published a report analyzing the sex industry in Chicago and recommending changes to law enforcement practices, legal frameworks, and public education in the city in order to eradicate the "Social Evil Problem" (1911:1). In order to effectively reduce and eventually eliminate infectious diseases and vice, the Vice Commission campaigned for the enactment of laws that would declare prostitution a "public nuisance" as well as a public health hazard (1911:56-57). Underlying these suggestions is the notion that prostitution can be effectively abolished, provided that a zero-tolerance policy is implemented. If harsher penalties for sexual service providers and proprietors were enacted, the dangerous promulgation of sexually transmitted diseases and societal corruption would come to an end. However, much like the early regulationist approach, criminalization essentialized sex workers as dangerously pathogenic and immoral while largely disregarding male clientele.

The arguments outlined in post-Civil War discourse still exist in pro and anti-prostitution campaigns today. Presiding over these debates are representatives from two opposing theoretical camps, the neo-abolitionists and the non-abolitionists. Janie Chuang distinguishes between these two ideologically opposed stances and their respective legal proposals for prostitution reform. Succinctly stated, neo-abolitionists maintain that all forms of sexual commerce are inherently 
exploitative and degrading (to women in particular) and therefore epitomize violence.

Conversely, non-abolitionists "insist on a distinction between trafficking and prostitution, with the 'trafficking' label applying only to those cases that fit into the paradigm of forced or coerced labor" (2010:1671).

\section{Contemporary Theoretical Camps}

\subsection{Neo-abolitionists}

According to neo-abolitionists "prostitution" and "sex trafficking" are synonymous terms that denote sexual exploitation. Furthermore, since all forms of sexual commerce exploit women, no woman would consciously choose to enter into the sex industry. Instead, most all participation in the sex industry is coerced, either by third parties seeking to sexually exploit sex workers or by structural inequalities that force the economically depraved to sell themselves as commodities. In fact, many women who think they have consented to sex industry activities do not understand their own oppression (Chuang 2010:1664-65).

Though neo-abolitionists agree upon the basic tenets regarding prostitution's harmful characteristics, they are by no means a homogenous group. Indeed, several actors with otherwise opposing agendas, namely evangelical Christians and "radical feminists", converge in their campaign to combat sexual exploitation by putting an end to prostitution. For conservative Christian groups, women's sexuality belongs in the domestic sphere and not in the market. As such, prostitution becomes an issue of morality rather than a question of labor rights or economic hardship for women. Tony Nassif, President and Founder of Cedars Cultural and Educational Foundation, represents this perspective. His organization's 2011 conference, “Preventing Abuse Conference: Protecting Women and Children from Trafficking and Abduction" entailed topics like, "SEXUALIZATION of the American culture: Standards of right/wrong are normalizing abnormal sexual behavior which fuels human trafficking. Conference information shows what can be done," and "ENTERTAINMENT: Sexualizing the culture \& youth by portraying sex 
outside of marriage as recreation," and also "THE FAMILY: How the traditional family is among the greatest protections against child prostitution and cultural collapse." Such topics illustrate the intimate connection that conservative groups draw between traditional religious values and the supposedly exponential growth of exploitation worldwide.

On the other hand, "radical feminists" oppose prostitution as the institutionalization of paternalistic dominance over female sexuality, and thus, rally to end it altogether. An example of this rhetoric can be found in the mission of the Coalition Against Trafficking in Women (CATW), a leading organization in the campaign to end prostitution, which it conceptualizes as any form of sexual violence against women. CATW (N.d) claims, "Sexual exploitation is a practice by which person(s) achieve sexual gratification or financial gain or advancement through the abuse of a person's sexuality by abrogating that person's human right to dignity, equality, autonomy, and physical and mental well-being."

Radical feminists express similar notions about sexual commerce. For example, radical feminist Kathleen Barry discusses the intrinsic problem with all legal models that attempt to manage sexual commerce: each model reinforces male dominance over women and children. Barry declares, "Each patriarchal state system in its own way locks women into prostitution...All legal approaches to prostitution are masculinist systems that yield to the male market demand and concede to the misogynist myth that prostitution is a necessary and inevitable sexual service required by men" (1995:221).

Although radical feminists and conservative religious groups differ in their reasoning to equate sexual commerce with sexual exploitation, both groups comprise the extreme "neoabolitionist" faction of the prostitution debate.

\subsection{Non-abolitionists}

While neo-abolitionists advocate for the abolishment of prostitution, non-abolitionists support a distinction between sexual commerce and human trafficking. As Chuang aptly points 
out, it is difficult to unify all non-abolitionists under a single category other than their opposition to neo-abolitionist theory. As she explains, "They are united in objecting to the neo-abolitionist feminists' assignment of a 'false consciousness' to those who claim they voluntarily engage in prostitution" (2010:1670).

Though non-abolitionists acknowledge women's choices as expressions of agency and not "false consciousness," many within the group adopt various approaches to formalizing prostitution as a viable profession. For example, some liberal, libertarian, postmodern or materialist feminist groups embrace sex work as an expression of women's liberation, selfdetermination, and even empowerment (Chuang 2010:1670). Dossie Easton and Janet W. Hardy, for example, attempt to reclaim the term "slut" from its stigmatizing and demeaning connotation of female sexuality, recasting it as "a term of approval, even endearment" (1997:4). They claim, "To us, a slut is a person of any gender who celebrates sexuality according to the radical proposition that sex is nice and pleasure is good for you" (ibid). Furthermore, Easton and Hardy acknowledge that any consensual sexual encounter "can be a positive, creative force in the lives of individuals and their communities" (ibid). Provided that these encounters are "consciously chosen and mindfully followed" (ibid), they can take place within "the market" or outside of commoditized exchange. As such, Easton and Hardy express an extreme feminist view that acknowledges all consensual sexual encounters as valid—even within the paradigm of sexual commerce. To them, branding unconventional sexual practices as pathological reinforces the patriarchal constructions of female sexuality as inherently dangerous or taboo if not efficiently managed. Liberal feminist Jo Doezema makes this connection when she insists that "The argument that women cannot consent to commercial sexual interactions coincides all too easily with anti-feminist ideas about female sexuality, and particularly with that of the threat of women's sexual autonomy" (2002:21). This comment reveals a similarity between radical and liberal feminist ideals, given that both groups seek to limit the continuation of patriarchal power over female sexuality. However, the groups completely diverge in their approaches to dislodge 
female sexuality from dominant paradigms. Whereas radical feminists seek to end prostitution altogether, liberal feminists seek to open new spaces for alternative representations of sexuality by confronting the traditional social norms that constrain sexual expression.

While Easton and Hardy represent an extreme faction of liberal feminism, others characterize women's participation in the sex industry as voluntary, but often informed by structural inequalities and economic depravity. As such the "decision" to enter into sexual service provision manifests itself as "one constrained option among many, all of which are undesirable or harmful" (Chuang 2010:1670). In her study of topless dancers working in the rust belt, Susan Dewey (2011) explores the reasons that prompted her research participants to enter into the sex industry. First, erotic dancing was viewed as a temporary means of achieving some degree of upward mobility. Additionally, while most of the dancers in Dewey's study could qualify for various types of welfare assistance, each of them rejected this option outright, claiming that accepting welfare benefits would construct them as "lazy." In fact, the dancers "othered" welfare recipients as "welfare queens," a term they associated with laziness, a refusal to adopt self-improvement strategies, and a lack of self-respect. Dewey reveals how her research participants exhibit what sociologist Avery Gordon terms, “complex personhood." According to his phenomenon, "even those who live in the most dire circumstances possess a complex and often contradictory humanity and subjectivity that is never adequately glimpsed by viewing them as victims or, on the other hand, as superhuman agents" (Dewey 2011:393). Rather than deeming all sex workers "victims" she proposes a nuanced approach that recognizes sex workers as decision-makers while still acknowledging their disadvantaged positions.

Altogether, non-abolitionists offer a wide array of conceptualizations of sex industry participation and sexuality in general. These ideologies occupy different positions on a continuum of feminist, religious, and political thought. What unites non-abolitionists, however, is their rejection of neo-abolitionism — the notion that all sexual commerce is sexual exploitation and thus, human trafficking. 
Overall, both neo-abolitionist and non-abolitionist discourse contribute their own characterizations of prostitution, including exactly what conditions shape it. While neoabolitionists adhere to a broad construal of prostitution as sexual exploitation, non-abolitionists distinguish between forced/coerced and consensual sexual exchanges. Both of these movements endorse specific legal frameworks that structure prostitution laws according to their respective interpretations. These legal frameworks attempt to contain the spread of sexually transmitted diseases and human trafficking, as well as communicate and reflect certain societal perceptions of sexual morality and normativity.

\section{Legal Frameworks for Prostitution}

Regulationist and abolitionist arguments from the Progressive Era aimed at controlling, containing, or regulating prostitution, immorality, and the propagation of infectious diseases still circulate in neo-abolitionist and non-abolitionist debates today. Though both camps still concern themselves with the spread of sexually transmitted diseases and sexual immorality, contemporary anti-trafficking campaigns have diversified approaches to combat illicit sexual activities through specific legal frameworks.

\subsection{Criminalization}

Criminalization is the current legal framework utilized in most parts of the United States. Under this model all parties involved in illicit sexual commerce (narrowly defined as the exchange of intimate sexual contact for something of commercial value) are legally culpable.

This includes the client, the provider, and any business proprietor facilitating illicit sexual transactions. In spite of widespread criticism towards this model's supposed inability to control the spread of STDs/HIV or alleviate trafficking in persons, not to mention its tendency to disproportionately penalize sexual service providers while largely ignoring clientele, some still uphold it as the ideal model. 
Though the US government does not explicitly recognize any religious or moralistic agenda underlying criminalization, some criticize its approach for idealizing certain performances of heterosexuality while condemning and censoring those that fall outside of its official construction of appropriate sexual behavior. For example, Anna Carline argues that "the Government provisions simultaneously construct and exclude expressions of sexuality that contravene the matrix of compulsory heterosexuality. Not all performances of heterosexuality are considered to be culturally intelligible, rather the State idealizes certain expressions of heterosexuality" (2011:329). For this reason, Carline views government regulation and censorship of the sex industry as an inherently moralistic intervention. While the anti-prostitution campaign is generally couched in a human rights discourse and not in explicitly moralistic terms, it does privilege certain expressions of heterosexuality while condemning others, thus constructing "appropriate" and "inappropriate" forms of sexuality overall.

Critics of the criminalization model also object to the historically disproportionate number of arrests between sexual service providers and their customers. Unevenly targeting sex workers for their involvement in illicit sexual activity harkens back to historical constructions of prostitutes as essentially pathological and impure. To this day, de facto mobility injustices exist between sex workers and their clientele, especially within criminalization regimes that force sex workers to operate under potentially dangerous conditions. Consequently, campaigns to balance these power and mobility asymmetries by focusing on the "demand" for sexual services, rather than the "supply," have become popular throughout the world.

\subsection{Legalization and Regulation}

An alternative model to criminalization that has been implemented in isolated areas of the United States and throughout the world is the legalization/regulation model. Legalizing and regulating sex work is a protocol that the Netherlands notoriously adopted in October of 2003 as a means of guaranteeing the occupational safety of sex workers while controlling the spread of 
contagions. Under this model the State can license individual sex workers as well as certain commercial sex venues to provide sexual services. As such, the State is ultimately responsible for regulating the supply and demand of the sex industry. As Sally Cameron points out, "Too many or too few workers may result in the development of illegal operators, as too many workers will see pressure on some to agree to lower payment and worse conditions, and too few licensed premises will see workers working outside the legal sector" (2008:97).

For critics of this model, however, legalizing prostitution normalizes participation in commercial sex activities for both buyers and providers. This legal framework suggests some degree of societal consensus for sex industry involvement, at least for interactions deemed consensual. It also alludes to the supposed permanency of the sex industry as an eternal fixture in society. Hence, prostitution in and of itself is not morally wrong; rather, it is a natural and expected part of social interaction. For many participants in the NJS, this model represents an alternative conceptualization of prostitution that does not equate sexual service consumption with wrongdoing.

\subsection{Decriminalization}

A final approach to managing commercialized sexual exchanges is decriminalization. Under this model, sexual service consumers become liable for their illicit practices while sex workers remain innocent. Often referred to as the "Swedish" or "Nordic" model, this approach was popularized by the Swedish Parliament in 1999 (Bernstein 2007:149). For non-abolitionists, the approach literally reverses the pathologizing stigma attached to sex workers by placing full responsibility on sexual consumers. Simultaneously, sex workers can exercise agency and decision-making power without paternalistic forces dictating sexual normativity. For neoabolitionists, the law effectively upholds the image of a sex worker as an innocent victim of oppression whose "choice" to enter into the sex industry has no bearing on their legal culpability. 
Moreover, discouraging consumers from purchasing sexual services decreases the "demand" for commercial sex, causing the entire industry to crumble.

\section{Locating the NJS: Legal and Theoretical Models}

Given the dense history of approaches to curtail or contain prostitution, it is important to situate the NJS program in relation to its historical, theoretical, and legal underpinnings. Altogether the NJS program locates itself at the intersection of diverse social movements, theories, and legal models -all of which seek to contain, control, and define the boundaries of prostitution. First, the program is consistent with former anti-prostitution campaigns dating back to the post-Civil War era. This is evident through its focus on public health and human trafficking, as well as its intent to establish sexually moral and normative behavior. More significantly, the program occupies a unique position within a web of notorious sociopolitical debates concerning the appropriate legal framework for prostitution. While the program exists within a state that criminalizes prostitution for both consumers and providers, the NJS represents a shift in attention from the "supply" to the "demand," thus reflecting the ideology supporting the decriminalization model. At the same time, the program challenges notions of prostitution as normative, acceptable, and permanent, thus opposing the principles that support the legalization model. Because of its precarious position between these models, some remain skeptical about the so-called "effectiveness" of the NJS.

Davidson County, as in most counties in the United States, adheres to the criminalization model, given that any party that either patronizes or solicits prostitution becomes legally culpable for a criminal offense. While prostitutes have historically received the brunt of criminalization efforts, the john school program symbolizes a relatively new effort to reverse dominant paradigms and distribute culpability more equitably. It also employs a degree of economic determinism, assuming that targeting the "demand" side of prostitution with deterrence efforts will inevitably deplete "supply," thus causing the entire sex industry to fold. This outlook 
harkens back to neo-abolitionist views of the entire sex industry as problematic and exploitative, thereby necessitating total eradication. Simultaneously, the "attack on demand" approach attempts to amplify negative attention towards johns, thus shifting prior constructions of culpability—even within a criminalization framework where legal culpability is supposedly shared. In spite of these efforts, a palpable lack of consensus remains regarding the manner in which the john school reinforces prevailing constructions of sexual morality and normativity as well as masculinity. For some program participants, this lack of consensus influences the degree to which they accept blame for wrongdoing, buy into their own culpability, and feel a genuine sense of shame-guilt.

\subsection{The Destructuring Movement}

In addition to the sociopolitical and legal frameworks previously mentioned, the NJS program emerges from a variety of crime control theories, each of which attempts to balance state power and community influence, exclusion, and inclusion. Among these tactics is destructuring-diverting crime control from the institutional power of the State, to communities (Cohen 1985:35). This movement, which originated in the 1960s, stressed distancing crime control from the State by creating agencies to manage "diversion" and "decriminalization, thereby making criminal processes less bureaucratic and more community-based. It also encouraged distancing crime control from "experts," believing that community members are just as capable of classifying and treating deviance as technocrats, and encouraged gravitation toward open communities rather than closed institutions (ibid:30). Underlying these tenets were cognitive, theoretical, and ideological justifications. Proponents of destructuring held that prisons are not only ineffective in deterring or rehabilitating offenders, but even strengthen criminal commitment. Also, community-based alternatives are capable of managing deviants in less costly, more successful, and ultimately more humane ways. While stigmatizing offenders renders societal reintegration difficult, the community itself can address underlying factors that foster 
delinquency (family, economic, school, or societal issues). For these reasons, destructuring advocates pushed for greater community involvement in crime control, positing that reintegration into the community should be the focus, not exclusion (Cohen 1985:30).

In many ways, the NJS program reflects these shifts. While the program does rely upon "experts," or representatives from professional agencies, it also draws from members of the community, such as Sexaholics Anonymous presenters and former prostitutes working with the Magdalene program. Also, the program enables offenders to opt out of jail time, thus preventing further overcrowding as well as the potential stigma that accompanies a criminal record. Rather than receive a permanent, formalized label like "sexual deviant," or "sex offender" as some advocates propose, john school participants can achieve societal reintegration with reduced stigmatization. This message is important for individuals like Dave, a humble and soft-spoken member of Sexaholics Anonymous who presents at the NJS as part of his own "recovery." In a private interview, Dave avowed,

I...believe in second chances. I believe in reaching out to people and asking them if they're ready for a different way, because what I found in recovery too is that... when we start to recover, those people...not only stop their behavior so...they're not harming anyone else, if that's what they're doing, but they're not harming themselves, they're not harming anyone else, and they tend to be a good teacher for the next people coming in.

In spite of its original aims to place "the community" as the center of crime control, Cohen critiques the destructuring model, pointing out that complete destructuring has not completely occurred. In fact, diversion and destructuring have supplemented the criminal justice system without reducing incarceration rates (1985:43). As classification, diagnosis, and intervention measures intensify, new programs are required to re-educate and reintegrate offenders. As in the case of the NJS, such programs do not operate independently from the State, yet work in tandem with it, thus expanding state power overall.

Cohen also details how new constructions of offenders have emerged from the existence of diversion programs. Because criminal justice systems tend to divert first-time or "softer" 
offenders to community-based programs, repetitive offenders thereby become "hardened," pathological deviants that have "failed" preliminary rehabilitative measures and can only be controlled through exclusion. This may ring true for the NJS participants who reoffend after program completion. For many program presenters, this faction represents a select group (namely "sex addicts") that seeks commercial sexual consumption in spite of its associated risks. ADA Antoinette Welch reiterates this, saying, "I think the small percent that reoffend...those are the people that are going to do it no matter what, whether they're arrested or not arrested." For these participants, risk factors outlined in the john school program do not serve as effective deterrents. Cohen highlights the divergence of "hard" and "soft" criminal offenses created through the implementation of diversion programs such as the NJS, commenting, "Almost the entire alternatives, diversion, and community movements can be seen as loops of this kind-new systems being created to deal with the damage caused by the old systems-but then inflicting their own kind of 'damage' from which clients have to be further saved, diverted, delabelled or decategorized" (1985:171). This phenomenon could occur for johns rearrested for prostitution following program completion, who then must contend with a criminal record and a minimal seven-day jail sentence.

Cohen goes on to problematize the tense position diversion programs occupy between public and private intervention approaches - a position that creates difficulties in addressing the wider social contexts underlying pathogenic behavior. For him, such limitations cripple the ability of such programs to sufficiently intervene upon offenders (1985:125). For presenters, the NJS program faces some limitations regarding its ability to significantly affect participant behavior, in spite of its multi-faceted educational approach. Brad Beasley, STD Program Director at the Davidson County Health Department, who adopts a casual, humorous, and yet informative tone during his NJS presentation, reiterated this in a private interview:

The intent of the program is to affect some type of behavioral change. We both know that's not going to happen in four to five hours, so I think a sub context of that would be just to give 
people some information hopefully that they will retain enough to start thinking about it. It may affect behavior change immediately or two years down the road, but you hope that somewhere it will take.

Derri Smith, Executive Director of EST, also recognizes the john school's limitations to address the multiplicity of reasons prompting participants to engage in sexual consumption. In a phone interview, Smith considered some of these reasons, concluding,

Some of them, a lot of them probably, have relationship skill problems, and so it seems simpler to them to go and buy an artificial relationship than to have to really work on a real relationship...they don't have those skills. They've been hurt enough times in the past to not want to try anymore. Other times, I think it's because they've been abused themselves-kind of the mindset they know. Sometimes I think it's men who want, for whatever reason, want some sense of control and power and maybe don't feel that in other aspects of their life...As far as relational skills, I don't really think it [the NJS] does address that. Hopefully, if they get involved with some group, like Sexaholics Anonymous, which is promoted within the school, there will be elements of that addressed further down the line. I don't know how much you can get in the context of the john school.

As this thesis will further explore, the NJS program seeks only to educate offenders on the risk factors associated with their participation in commercial sex, rather than investigate the individual reasons that compel participants to purchase sexual services. Instead, presenters provide information and resources to participants in hopes that they will take personal initiative to address the underlying reasons prompting their behavior. According to Kenny Baker, a Cognitive Behavior Therapist of Behavioral Treatment Providers, "if you tell them and they get the information -if you tell them the truth then they get to choose what they want to do, so that's the goal: give them the information and you tell them the truth and they get to choose and that's it." Given the relatively short duration of the program, as well as the average number of participants per session (generally upwards of 25), the john school program must examine what objectives are feasible. Educating participants about the risky implications of their decisions and providing optional resources for ongoing personal support after program completion are two of the 
objectives expressed by program presenters. This thesis will also examine how program presentations impact johns emotionally, and if eliciting certain emotions seemingly reduces the risk for recidivism overall.

\subsection{Deterrence and Crime Prevention}

For Stanley Cohen, most societies attempt to balance both inclusionary and exclusionary crime control policies in order to efficiently maintain social order. Crime control systems are also burdened with prioritizing "doing good," or engaging in socialist reform to tackle the macro issues propelling deviancy, with "doing justice," or maintaining a sense of rightness and fairness for the public good (1985:253). For Cohen, programs must efficiently prioritize their values in order to be effective. Regardless, preventing and deterring crime must be the principal intent of any program—-more so than "doing good." Given this model, it is important to examine the core theories associated with deterrence and crime prevention.

David M. Kennedy (2009) analyzes a diverse body of theory regarding offender risk perception, sanctioning, and most importantly, the behavior of criminal justice authorities, and how their behavior is interpreted by offenders. Moreover, he recognizes the dialectical relationship between social institutions that administer legal sanctions and societal consensus for sanctioning strategies (2009:1). He further claims that deterrence is a simple matter of reducing the "rewards" gained by engaging in criminal acts and increasing the "losses" associated with being caught (ibid:1). For NJS presenters, Kennedy's deterrence and crime prevention framework represents their principle interest: to clearly convey risks associated with sexual service consumption while decreasing and deconstructing its benefits. Presenters hope that offenders will acknowledge the imbalance between costs and benefits and, if nothing else, will determine that illegal sexual service consumption is too risky—if not immoral or victimizing. In an individual interview, Brad Beasley reveals that heightening a sense of loss occurs through informative and punitive processes. He claims, 
My objective...is just to give them good information. Hopefully that rolls into everything they have learned from legal to everything. Of course, that's the altruistic objective on our end - to affect behavior-but from the legal end, it's punitive, ya' know, hit you in the pocketbook. If you're not going to think about the sociological consequences of it, you're going to feel the economic consequences of it, because it's not an inexpensive thing.

ADA Rachel Thompson agrees with the paradigm of risk education. Talking about her objectives for participants in a private interview, she wants them

to leave with a working knowledge of why what they did was illegal, and how broad the law in the realm patronizing prostitution is, and how none of their little ideas, probably of... sort of playing with fire...like driving up and down some of the roads like Dickerson, Murfreesboro, or things like that...how none of those things are good ideas, and how cases will be made against them even if...they're touching the fringes of prostitution.

Not only do deterrence efforts seek to reformulate offenders' perceptions of risks, they also seek to prevent future offending by shaping and reinforcing the "social and community conditions" that "affect the character and choices of offenders" (Kennedy 2009: 1923). Kennedy indicates that this is one of the most influential factors in crime control and prevention. Is there consistency and uniformity in how certain "deviant acts" are sanctioned? Is there consistency and uniformity in how such sanctions are enforced? Referring to Zimring and Hawkins (1973), Kennedy reiterates three categories of authoritative failure: “(1) a general failure of enforcement, in which enforcement is attempted but does not succeed; (2) the failure to even attempt enforcement for a particular offense, which creates general immunity for that offense; and (3) the failure to attempt enforcement for a particular class of person, which creates status immunity for those persons (2009:54)." Failures like these create barriers for officials seeking to reshape social and community conditions that deter criminal behavior. In fact, as Kennedy boldly alleges, "there are a number of important ways in which official behavior can encourage offending and, in particular, can undercut deterrence" (2009:54). An example of this occurs when offenders experience situations in which authorities witness their crimes and do not act, thereby conveying 
"permission to offend" (ibid:59). When officials do take action, offenders perceive enforcement as unpredictable, inconsistent, and worse yet, illegitimate and unfair. Additionally, offenders may attribute inconsistent enforcement to official corruption, especially when particular groups of offenders believe themselves to be targeted inequitably (ibid:59). In contrast, those who feel they were treated reasonably and fairly are more likely to legitimize sanctioning and enforcement, even if they disagree with the outcome (ibid:60). While this study does not explore or critique law enforcement practices, it does address the manner in which conceptualizations of such practices crop up during the john school program and influence participants' understanding of their own behavior. For the NJS participants in this ethnography, perceptions of enforcement and sanctioning patterns proved extremely influential in the emotional responses they underwent during the program. These responses played a major role in determining how offenders qualified their own actions, the degree of hostility they felt towards officials, and any feelings of empathy for those adversely affected by their actions. This affirms Kennedy's conclusion that "Internal informal sanctions, such as feelings of guilt and shame, and external informal sanctions, such as community and peer disapproval, may be triggered by official action, such as arrest, but only if the predicate norms already exist in the offender and in a given social setting and only if subsequent processes bring those norms into play" (2009:119).

For officials to consistently and equitably enforce sanctioning, Kennedy (2009) also suggests preventative approaches, noting that deterrence efforts are not solely reactionary. Alluding to a 1990s gun control initiative, Operation Ceasefire, Kennedy observes that most offenders possess a weak comprehension of the risks associated with their behavior, as well as the stipulations of the laws they violate. In this example, probation partners ordered members of Boston's drug crews, who happened to be on probation, into a series of face-to-face meetings or "forums." Drug crews were informed that business would be handled in a new way in Boston: If anyone in their crew killed someone, law enforcement would go after the entire crew for any crimes they were committing. This included drug sales, drug use, gun carrying, outstanding 
warrants, probation and parole violations, unregistered cars, or anything at all. Crews also heard from community members-ministers, parents of murdered children, neighborhood residents, etc.- that violence was wrong and that the community could no longer tolerate it. Crew members were ordered to leave the forum, return to their crew, and deliver the clear message that there would henceforth be collective accountability for the violence. The intent was to create peer pressure in the group to refrain from violence. Offenders were also informed that if they wanted help getting off the streets they could receive it from streetworkers, social service agencies, probation and parole officers, churches, and nonprofit organizations (Kennedy 2009:3). This model, which utilized information rather than outright enforcement, created a remarkable reduction in street violence in the aftermath of the Operation Ceasefire campaign. For this reason, conveying information about legal implications and other risk factors may prove effective in deterring criminal offenses (ibid:4-5). Education should also incorporate both special and discretionary initiatives, meaning that officials should inform offenders about heightened interest or "crackdowns" on particular offenses or particular areas, as well as special attention paid to certain instances of a given offense (first-time offenses, next offenses, etc.) (ibid:5-6). Transparent communication in which offenders are enlightened as to the policies being followed and enforced, and the rationale behind enforcement, may encourage societal consensus around formal sanctioning strategies, as well as support informal sanctioning practices overall.

The NJS echoes this framework by responding to the call for comprehensive education regarding the variety of risks associated with purchasing prostitution. Kenny Baker, for example, incorporates a "bucket of shit" metaphor into his presentation in order to illustrate notions of risktaking associated with illegal sex consumption. Casually dressed in flip-flops, khakis shorts, and a ball cap, he nonchalantly engages the sleepy and often cranky participants in an informal discussion about undertaking risk. Rather than rely upon notes or a memorized script, he informally walks among the rows of participants, addressing the group as "fellas" or "guys," and occasionally punctuating his speech with profanity. In his relational approach to participants, 
Kenny utilizes a metaphor to illustrate how purchasing prostitution can incite negative

consequences. He explains,

The world is like a checkerboard where buckets of shit occasionally crash down from the sky, and even being near the vicinity of one of these squares is putting yourself at risk, because it's only a matter of time before a bucket of shit will hit. Some squares get hit more than others because of what they are and where they are...so what would be an example of putting yourself in a high-risk situation that could lead to a bad position in reference to being arrested again for patronizing prostitution?

In this segment of the presentation, Kenny encourages participants to consider their actions—not from a moral standpoint—but from one of risk. His metaphor acknowledges that regardless of individual opinion regarding the validity and morality of current prostitution laws, committing illegal behavior can be dangerous and may result in individual loss.

Following Baker's presentation, Brad Beasley of the Davidson County Health Department, a laid-back, bald man with a full beard, details ways in which johns could contract sexually transmitted diseases or HIV. Speaking from his long-term experience working with STD-infected patients as an STD Director, he warns, "If someone finds you attractive enough to have sex with you, they might not tell you what they have!" He proceeds to graphically, and sometimes wittily explain risks for men and women that unknowingly contract venereal diseases like chlamydia, gonorrhea, and syphilis. In his explanation of gonorrhea and chlamydia he claims, "If a guy hasn't been treated, the bacteria move up the urethra and into the body. It irritates and creates scar tissue that restricts urine flow until you can't pee!" He discusses syphilis in a similar way, stressing the symptoms associated with primary, secondary, and tertiary phases. For example, during the secondary syphilis phase, patients experience symptoms like hair loss and a highly contagious skin rash. Beasley recounts his personal interactions with syphilis patients, exclaiming, "I've seen people with secondary syphilis reach up and pull their hair out! This is permanent hair loss—it's not growing back!" Beasley repeatedly underscores such details throughout the presentation, highlighting how men and women may be unknowingly contagious 
for several weeks while still remaining sexually active, and how sexual intercourse is not the only mode of disease transmission. Through his presentation, johns are spared few grotesque details with respect to the health risks associated with sexual activity. For him, the presentation serves as a scare tactic for participants. In a private interview, Beasley professes, "That's the intent actually. That's the intent. This is in your face. This is what's really happening."

The District Attorney's office also discusses risk by informing johns of the laws regarding patronizing and promoting prostitution, recounting stories of offenders that were convicted for felonies they unknowingly committed, and detailing the legal consequences should participants reoffend. For example, ADA Rachel Thompson alerts johns about how easy it is for sexual service consumers to commit a class E felony for "Promoting Prostitution for a Patron" and what legal ramifications follow. Posed stiffly in front of the group in business-like attire, reading directly from a thick law book, she emphatically explains a typical scenario in which two buddies encounter a couple of prostitutes. One man expresses preference for a particular prostitute while directing his buddy towards the other one. Under Tennessee law, an occurrence as seemingly innocuous as this one could be construed as promoting prostitution-an offense that prevents offenders from voting, owning firearms, or even owning a boat.

ADA Antoinette Welch also focuses upon risk in her presentation, describing how johns make for "perfect victims" for prostitutes wishing to commit robbery, given their reluctance to contact police while engaging in illegal activity. In a scathing and no-nonsense tone, she reports only four incidents in which police were called for help during a sexual service encounter. According to Welch, "two were stabbed, the other was shot, and the other guy was unable to call because his brains ended up on the wall!" Additionally, Welch mentions the likelihood of a john unknowingly purchasing sexual services with a minor, the penalty for which entails a prison sentence of seven years, eleven months, and twenty-nine days.

Other program presenters also highlight risks during the course of their presentations, such as becoming a sex addict or unknowingly buying into human trafficking. Aside from risk, 
however, program facilitators also emphasize harsher penalties tied to reoffending. For example, ADA Rachel Thompson reinforces this in her presentation at the john school, proclaiming: "I'm sure there are some of you who have had a difficult time lying to your wife or girlfriend about where you would be today, but as hard as it was today, it's even harder to explain seven days!" Here Thompson reiterates the seven-day jail sentence imposed on those that choose to reoffend and how reoffending can generate interpersonal controversy between offenders and their partners. Others like Antoinette Welch remind participants that they have already been granted a second chance. Upon beginning her presentation, Welch makes this point very clear. Penetrating the crowd with a shrill and authoritative voice, she declares, "You are here as a gift from the state of Tennessee! If I see you texting and making me act like a third grade teacher it won't be good for anyone! You are here because you plead guilty, so you're guilty as far as I'm concerned!' The hard-hitting spotlight that presenters place on subsequent offending alerts participants to the thorny consequences they will encounter should they reoffend.

Overall, the NJS program responds to David M. Kennedy's theories of effective crime prevention through direct, comprehensive risk education that incorporates the rationale behind legal enforcement and sanctioning, as well as a clear-cut crackdown on recidivism. Unlike the gun control initiative, Operation Ceasefire, however, the NJS deters offenders after they have already been arrested and charged with patronizing prostitution, rather than targeting the initial offense. For many program participants, the experience of being arrested, having their photo posted temporarily on the Nashville Police website, and going through a criminal process in court, stem from unjust prostitution laws and underhanded enforcement tactics. For these offenders, deterrence efforts enter into the equation only after they have developed an adverse emotional reaction towards enforcement and sanctioning authorities. For some participants in this study, the lapse between arrest and deterrence may influence the emotional response they experience during the program, and the degree to which they feel they have committed wrongdoing, harmed others, etc. In response to this viewpoint, which may prove 
counterproductive to effective deterrence, David M. Kennedy points out that mass media campaigns targeting the population at large can provide an initial layer of deterrence (2009:139). For him, "Nonoffenders can have direct influence on offenders; their views of official actions can influence how offenders view those actions. If community members view, for example, focused enforcement of street drug dealers as a continued expression of official racism, informal sanctions and community norms are unlikely to align with official intent" (ibid:135). In this sense, increased communication regarding enforcement tactics and rationale, as well as sanctioning policies, may increase societal consensus underlying particular policies, thus bolstering informal sanctioning overall. For offenders in the john school program, adding a primary echelon of deterrence via mass media campaigning may decrease feelings of "blind-sightedness," and therefore, the degree of hostility and blame felt towards law enforcement or legal officials. Given the funding and resource limits of the NJS program, however, such campaigns may prove unrealistic at this time.

\subsection{Reintegrative Shaming}

A final context in which the john school locates itself is within Australian Criminologist John Braithwaite's "reintegrative shaming" model (1989), a form of restorative justice in which particular shaming techniques are wielded to generate feelings of "shame-guilt," with the design of creating behavioral change. Most importantly, Braithwaite stresses that effective shaming be "reintegrative," not stigmatizing. This model recalls Michel Foucault's theory of discipline, in which the body is molded into a submissive subject of the State through subtle and constant forces of institutionalized coercion (1995:138). Hence, individuals can be systemically controlled by even the most mundane rituals embedded in their daily routines-often without even realizing it.

Underpinning the theory of reintegrative shaming is the notion that deviancy is a social construct, determined by societal disapproval for a given action. For Braithwaite, knowingly 
choosing to engage in behaviors regarded as "deviant" distinguishes criminal choices from other types of social action (1989:2). As such, the degree to which society at large condones or condemns certain activities shapes what is considered criminal, and what is not. In turn, social institutions, such as the criminal justice system, exist to concretize differences between acceptable and unacceptable behavior, and to enforce these norms. In so doing, social institutions dialectically reproduce the norms they were established to uphold. Braithwaite asserts, "Crime is reproduced as something real by repeated sequences of interactions...Similarly, shame, conscience, the power and authority of the police and the judge... are structural and psychological constraints upon crime which are themselves reproduced as real by the very encounters in which the crime construct is reproduced" (1989:3). Thus, crime control efforts should not concentrate on individual motivations or capacities to commit deviant actions, but rather, informal social support for the institutionalized disapproval of the criminal law: shaming (1989:4). For him, crime control is most effective when community members become directly involved in informal rituals that shame offenders. At the same time, Braithwaite acknowledges the limitations of community structures. Rather than construct offenders as passive social actors, the theory of reintegrative shaming conceptualizes offenders as "making choices—-to commit crime, to join a subculture, to adopt a deviant self-concept, to reintegrate herself, to respond to others' gestures of reintegration—against a backdrop of societal pressures mediated by shaming" (ibid:9). Here Braithwaite reflects Emile Durkheim's notions of social constraint and inhibition. In "Rules for the Constitution of Social Facts" (1895), Durkheim posited that societies are more than mere extensions of individuals; in fact, societies assume a power of their own which exceeds the collective power of individuals. Also, social pressure can act upon individuals in ways they do not even realize. He writes, "The authority to which the individual bows when he acts, thinks, or feels socially dominates him to such a degree because it is a product of forces which transcend him...Inhibition is, if one likes, the means by which social constraint produces its psychical effects, but it is not itself that constraint" (quoted in Lukes 1982:128). 
Like Durkheim, Braithwaite maintains that individuals can, through their own will power, make individual decisions. However, such decisions occur within a complex social milieu that structures and reinforces individual behaviors and choices. According to Braithwaite, informal shaming is the most significant type of social constraint concerned with crime control. Not only does shaming serve as an intangible boundary that restricts deviant behavior, it also calibrates individual consciences to endorse particular social norms. For example, Braithwaite indicates that while sometimes the benefits of committing crime do outweigh the costs, not all individuals choose to commit crimes. Such decisions reflect the presence of an individual conscience attuned to uphold certain moralistic and social norms. If community members actively and systematically participate in informal shaming, individuals will develop appropriately conditioned 'learned consciences.'

Because Braithwaite identifies the dialectical relationship between individual conscience and the social institutions that uphold and reproduce social constraint, he restricts his theory of reintegrative shaming to dealing with crimes underpinned by societal consensus. Shaming can only occur when the community at large agrees that a particular act violates moralistic and social norms, and is therefore deviant. For Braithwaite, the most apparent subset of crimes widely deemed unsavory is predatory crime, in which an individual perpetrates actions that directly and adversely affect others, the victims. Given the degree of social consensus around constructions of deviancy for murder or assault, for example, collective community shaming tactics can be effectively launched. However, Braithwaite makes an important distinction between predatory crime and victimless crime. While predatory crimes, such as murder, entail "doubtless consensus," other minor criminal offenses, like marijuana usage in democratic societies, are not consensually legitimized or justified. For this reason victimless crimes do not fit neatly within the reintegrative shaming paradigm.

Braithwaite's predatory/victimless crime binary is a useful framework for conceptualizing the degree of social consensus around deviancy. Crimes such as soliciting or 
patronizing prostitution occupy a controversial space between "predatory" and "victimless." While a large faction of "neo-abolitionists" regard prostitution as synonymous with human trafficking, pro-sex work activists seek to legitimize prostitution as a formalized profession. This contentious divide indicates a general lack of social consensus around prostitution as an act of deviancy. For many, purchasing prostitution is a social norm, especially when it closely corresponds with the mores of their masculine socialization. For others, prostitution is not a victimless crime, but perpetuates structural violence against women in particular, and feeds the demand for human trafficking. How, in turn, can shaming take hold within a broader social context of "doubtful consensus"?

This thesis argues that the NJS program in and of itself serves as a deterrent to some offenders, not only by educating participants on high-risk factors associated with participation in commercial sex, but also by fostering feelings of embarrassment and shame-guilt through a process of exposure and reintegrative shaming. This was most effective for offenders that already held beliefs condemning prostitution as immoral, prior to entering the NJS. The program also avoids stigmatizing practices that increase hostility, exclusion, and subculture formation, instead relying upon restorative justice practices that reeducate, forgive, and ceremoniously de-label. Yet, the NJS situates itself within a broader social environment of "doubtful consensus," thus weakening its ability to morally resonate with all offenders and elicit feelings of shame-guilt. Moreover, dominant gender socialization mores paint a seemingly contradictory background to the social norms the john school seeks to promulgate. As this ethnography will later explore, the shaky degree of social consensus for constructing sexual consumption practices as deviant proved problematic for some program participants, who viewed crackdowns on prostitution as contradictory to dominant gender norms and even Constitutional liberties. In fact, many professed that they had been condemned for acting on the very impulses society would otherwise condone as gender-appropriate. Such observations problematize Durkheim's theory of social constraint versus inhibition, implying that constraint may operate in contradictory, overlapping, 
and indistinct ways. An individual may receive mixed messages from their social environment with respect to what is acceptable, moral, or normative. For many offenders, this clouds individual capacities to exercise self-restraint or self-determination in certain circumstances.

Not only does Braithwaite limit the scope of his theory to predatory crime, he also painstakingly establishes the difference between "reintegrative" and "stigmatizing" shame, drawing attention to the significance of how shaming should be performed so as to be restorative, not retaliatory. On the one hand, disintegrative (stigmatizing) shaming practices "divide the community by creating a class of outcasts" (1989:55). Braithwaite points out that too much intention is paid to labeling deviance and constructing entire personhoods as morality inept, rather than emphasizing forgiveness, de-labeling, and reintegration. On the other hand, reintegrative shaming, or "expressions of community disapproval, which may range from mild rebuke to degradation ceremonies, are followed by gestures of reacceptance into the community of lawabiding citizens" (1989:55). For Braithwaite, appropriate shaming should emulate the "Family Model" of punishment. In this model, children commit naughty offenses and are punished, although not in such a way that transforms their status as members of a family unit. In fact, wrongdoing, while intolerable, is treated with love and respect; occasional wrongdoing is normative (ibid:56). Additionally, the child's actions become the focus of shaming and sanctioning, not the child's personhood. Rather than approach children as inherent deviants that lack a moral compass, health families appeal to children's moral consciences to discern their own behavior as shameful and wrong.

Healthy shaming can also occur indirectly. John and Valerie Brathwaite discuss “indirect methods of confrontations that seek to elicit volunteered remorse," such as "dialogue where those who have been hurt discuss consequences of an act; others owning their share in the responsibility; others telling stories of their remorse for similar wrongdoing in their past," and so on (2001:45). By selecting former prostitutes and sex addicts to share their histories with participants, the NJS program emulates this approach. Participants hear about the tribulations 
former prostitutes experienced throughout their lives, including the harmful and abusive treatment they received from johns. Sex addicts explain the way in which innocuous fixations progressed into full-blown addiction and compulsive behavior. Through the unassuming narratives of fellow community members, participants are indirectly confronted with the potential ills caused by their own behavior.

On the other hand, stigmatizing shame--such as the shaming tactics promulgated by many anti-prostitution advocates - encourages offenders to join criminal subcultures. Braithwaite explains this process, claiming, "Subcultures of deviants arise from the fact that society creates similar types of outcasts with a common fate that face the same problems" (1989:21). When this occurs, criminals form social ties with other deviants, often fulfilling the prophecy of labeling theorists like Tannenbaum (1938) by becoming "the thing he is described as being" (quoted in Braithwaite 1989:16). For Braithwaite, when criminals become the target of stigmatizing shame, they are denied restorative reintegration via de-labeling. Henceforth, no incentive exists for offenders to conform to social norms - they will always be deviants regardless of their choices. With respect to prostitution offenders, the danger in shaming tactics that attach permanent labels to johns without providing opportunities for reintegration is that it creates an outcast class of sexual deviants. For Braithwaite, the stigmatizing process will push deviants further into a criminal self-concept, thus encouraging subculture formation. Given the vast array of virtual subcultures that already exist for sexual consumers, or "hobbyists" as they refer to themselves, stigmatization could present a real threat to anti-prostitution efforts. In turn, the NJS program endeavors to avoid stigmatizing shame practices by directing disapproval at participants' choices, rather than personhood, and by offering a de-labeling through expungment. Through this process, "johns" can detach themselves from their former label and remove the charge from their permanent record. This enables participants to fully reintegrate themselves into society without fear of exclusion or retribution. For many supporters of restorative justice models, formal sanctioning measures are less preferential than community-based, diversion-style programs. 
Whereas formal sanctioning practices "erect barriers between the offender and the punisher through transforming the relationship into one of power assertion and injury," reintegration approaches rely upon the interconnectedness between the parties (Braithwaite 1989:73). By extension, the act of repentance and forgiveness holds more symbolic power than mere denunciation. In fact, while formal punishment denies confidence in the offender to discern right from wrong, reintegration reaffirms the offender's inherent morality by appealing to it directly (ibid:72). John Braithwaite also observes that shaming is most effectively achieved within a communitarian environment in which interdependent groups with strong cultural commitments participate in informal shaming rituals. He further observes that confrontations are most likely to induce the ideal "shame-guilt" emotion when conducted by those the offender highly respects (Ahmed et al. 2001:32). For the NJS program, the distant relationship between offenders and program presenters may reduce the degree to which offenders respond to reintegrative shaming tactics through feelings of shame-guilt. For many, the arrest procedure and subsequent diversion program exposed and embarrassed them, but did not penetrate their morality. The differentiation between embarrassment-exposure and shame-guilt will be further addressed in later sections of this ethnography.

While John Braithwaite and other theorists hail restorative justice approaches to crime control as preferential and effectual, they also recognize its limitations. Some offenders do not respond to shaming tactics, regardless of how restorative they may be. In these cases, a harsher echelon of deterrence is necessary to effectively control crime. Nathan Harris comments on this progression: "Nevertheless, just as shaming is needed when conscience fails, punishment is needed when offenders are beyond being shamed. Unfortunately, however, the shameless, the remorseless, those who are beyond conditioning by shame are also those who are likely to be beyond conditioning by punishment...”(Ahmed et al. 2001:73) In such cases where offenders do not respond to shaming, harsher and more formalized deterrence measures are necessary. However, harsh formalized punishment may be, John and Valerie Braithwaite argue that 
deterrence should never incorporate stigmatization (ibid:36). Here, the escalation of deterrence measures from diversion to formal sanctioning (without stigmatization as deterrence), is replicated in the NJS program. Rather than send prostitution offenders directly to jail, the State enables them to participate in a diversion program and to expunge their records, thereby emphasizing forgiveness and de-labeling. However, harsher deterrence measures exist for those that reoffend.

\section{Shame-Guilt, Embarrassment-Exposure, and Unresolved Shame}

According to Eliza Ahmed, Nathan Harris, and John and Valerie Brathwaite, one of the most important facets of inducing shame is managing the emotional response that offenders experience. Effective shaming should not only elicit certain feelings in offenders, but should also concern itself with "helping wrongdoers to acknowledge and discharge shame, rather than displace it into anger" (2001:17). For this to take place, confrontations between authorities and offenders should avoid stigmatization as much as possible. This can take place by emphasizing a disapproval of the wrongdoer's choices, not personhood; allowing offenders to process their emotions during the confrontation, even if this includes expressions of dissent or uncertainty; incorporating individuals whom the offender "highly respects" into the reintegrative shaming process; and lastly, symbolizing reintegration through ritual (Ahmed et al. 2001:32). By completing shaming practices in this manner, it is hoped that offenders will experience a rejection of their own wrongdoing - though not their entire personhood; feelings of concern for others who may have been adversely impacted by their wrongdoing; feelings of disgrace associated with their wrongdoing; feelings of anger at themselves; loss of honor among family and friends; feelings of remorse; feelings of empathy for potential victims; and lastly, a lack of hostility towards sanctioning and enforcement authorities (ibid:7). These sentiments compose what Nathan Harris terms "shame-guilt," a label that reflects the emotional response induced by both internal and external shaming forces (ibid 2001). Here, he acknowledges how effective shaming occurs both 
inwardly—in which an individual's wrongdoing violates their own moral principles—and outwardly, in which individuals respond to criticism and disgrace imposed by others. Rather than differentiate between these forces, he claims that both internal and external forces contribute to an individual's feelings of moral failure. Furthermore, for Harris, shame-guilt is the target sentiment that reintegrative shaming tactics seek to educe. Only a feeling of utter moral failureif properly discharged — can hope to induce lasting behavioral change. This emotional reaction is different from embarrassment-exposure, the feeling of "social discomfort or social consciousness resulting from a social situation" (ibid:126). Essentially, embarrassment-exposure encapsulates the feelings of awkwardness and awareness that offenders experience upon becoming an object of the public gaze, while not necessarily incorporating an internal remorsefulness about one's wrongdoing as a violation of their own moral values. Embarrassment-exposure, therefore, frames a unidirectional flow of shame in which the offender responds to external forces of disapproval without feeling a strong, internal sense of wrongdoing. Harris (ibid 2001) points out that shameguilt and embarrassment-exposure may bleed together as emotional responses to certain social situations. For example, a prostitution patron may feel internalized guilt or shame for having engaged in sexual consumption-a practice that may violate his or her own ethics. Afterward, the same patron may experience feelings of humiliation and exposure upon being arrested, booked, and sentenced. Cases such as these blur boundaries between internal and external shaming forces. Nonetheless, Harris concludes that while feelings of moral failure may be accompanied by embarrassment-exposure, the reverse is not true. Those that respond to external shaming forces through sentiments of humiliation, self-awareness, or "the feeling we have when our nakedness, or some other feature of ourselves we do not want displayed, is exposed" (ibid:8), may never conceptualize their offense as moral wrongdoing nor feel inherent remorse for having committed it.

A final emotional response that Nathan Harris explicates is "unresolved shame," characterized as "ongoing feelings that issues and emotions have been unresolved" (Ahmed et al. 
2001:11). In other words, this sentiment refers to an offender's liminality, a suspension of subscription to any one identity. During this period, the offender remains uncertain as to whether he or she is truly a deviant, or whether he or she has been unfairly judged. Also, Harris observes a high correlation between unresolved shame and hostility towards sanctioning and enforcement authorities (ibid:123). In spite of this, he notes that hostility for authorities and empathy for potential victims do not necessarily occur in opposition. Rather, many offenders that express unresolved shame also feel empathy for others adversely affected by their actions. Offenders in Harris' study that expressed embarrassment-exposure, however, did not communicate empathy for others, focusing instead on their own feelings of self-consciousness (ibid:123). Harris' framework of emotional responses to shaming provides a helpful foundation for conceptualizing participant reactions to the NJS program (and the sentencing process in general). While this paper analyzes participant emotions through the lens of shame-guilt, embarrassmentexposure, and unresolved shame, it views these categories as fluid and overlapping. For example, NJS participants may communicate anger or hostility towards the legal system or enforcement authorities while still admitting moral failure. Additionally, participants may express moral failure while still questioning whether purchasing prostitution should truly be framed as wrongdoing. As will later be explored, normalizations of "masculine" social behavior often appeared alongside moral condemnations of the same behavior, thus problematizing categorizations of emotional response. 


\section{NJS PRESENTERS}

This ethnographic study of the NJS seeks to examine the role of shaming in crime control and deterrence. Shaming is a bilateral process involving the shamer(s) and the shamed.

Considering its potential impact on behavioral change necessitates an exploration of the dynamics between shamers and shamed individuals, including the emotional responses elicited by shaming measures. This approach gives rise to various questions regarding the manner in which NJS presenters engage in shaming practices and generate specific emotional responses in program participants. How do presenters address societal consensus? Do they believe that prostitution is a "victimless" crime, or that it victimizes others? Do they normalize prostitution as part of masculinity or condemn it as immoral? Also, how do presenters carry out deterrence and shaming measures? More specifically, how does their tone (casual, formal, etc.), discourse (labeling or constructing personhood versus crime), communication style (including direct or indirect shaming, blaming or appeals to morality, informative), and social role (enforcement authority, community member, etc.) construct johns as objects of shame?

\section{Kenny: "You're just trying to get your needs met"}

Kicking off each NJS session is Kenneth Baker, a thin, informally dressed Cognitive Behavior Therapist that casually paces throughout the room as he speaks to the drowsy and often irritable program participants about the purpose of the NJS, and encourages them to confront the underlying reasons that prompted them to purchase prostitution. Baker assumes a nonchalant, 
off-the-cuff approach to his presentation, often pausing to take a sip of his coffee or remove his baseball cap. As he reveals in an individual interview, assuming the lead-off role is a calculated maneuver to "get guys talking" and usher them to a point in which they can "understand what exactly they did and either choose to not do it again or choose to do it again." Describing this role, Kenny claims, "That first 30 or 45 minutes when I do that talk-I do that on purpose because some of that stuff really relates to those guys and shakes them up! And it kind of just puts the rest of the day in a better position a lot of times."

Rather than characterizing prostitution as immoral or inherently predatory, Kenneth Baker captures it under the paradigm of "unhealthy behavior," telling johns, "I'm not getting into morality but if it's a situation that puts you at risk, it's unhealthy behavior." Utilizing his interactive "bucket of shit" metaphor, Kenny explains the risks associated with engaging in prostitution - the proverbial "buckets of shit that occasionally fall from the sky." If johns place themselves in certain social situations, or "squares," they position themselves in situations that could lead to adverse consequences. Kenny then calmly questions participants, "Hey guys, what would be an example of putting yourself in a high-risk situation that would put you near a square that gets hit by shit?" And, "What would you be if you repeated the same thing over again?" During each session, Kenny receives similar answers to these questions, as some participants perk up enough to make the connection between sexual consumption and high-risk behavior. Participants reply that it would be "insane," "stupid," "crazy" or "addictive" to repeat their behavior after getting caught the first time-especially since risk factors increase following the first arrest. Through this exercise, Kenny suspends moralistic judgment on sexual consumption, instead painting it as personally dangerous, harmful, and therefore unhealthy for program participants.

On the other hand, sexual consumption is no different than any other high-risk behavior. In an individual interview, Baker stressed this point to me, claiming, "It's all the same stuff I mean...it's all the same things...food, sex, alcohol, drugs, candy, sugar, caffeine, you name 
it...it's all you have a choice." In this sense, Baker depicts prostitution as fairly normal behavior, since everyone fails to make healthy choices while seeking self-gratification and fulfillment. Throughout his NJS presentation, he reiterates this theme to program participants. He explains, for example, the widespread movement that seeks to deter "the demand" from sexual consumption using harsh shaming tactics. Sighing and raising his voice emphatically, he angrily declares, "There are folks that want to charge you $\$ 10,000$ fines, take your cars, give you a felony and put you on the sex offender registry-I don't agree with that. You can do that, but you may be arresting your husband, or your boyfriend, or your son! Society needs to be careful about how judgmental they are!"

Kenny also reassures johns that he completely understands their behavior, that "sex is a normal, natural, and carnal thing," and that "you're just trying to get your needs met." By employing normalization and a relaxed, familiar tone, Kenny hopes to break down boundaries between himself and program participants, claiming that "we are all a lot more alike than we are different." Using himself as an example, Kenny recounts how he reacted to his late wife's passing in May of 2010, after she was misdiagnosed for a serious illness: “The point that I'm trying to make is that I gave myself an identity, a label, that I'm this wounded guy, and I gave myself permission to do what I wanted...this shit is no different! The point that I'm trying to make is that I became unconscious, just like you became unconscious in a way that's not you!" Through constant reassurance of his perceptiveness and understanding, Kenny constructs illegal sexual consumption as rather ordinary-yet unhealthy behavior. Supporting this is a casual, often profanity-laden tone that renders Baker more approachable to johns as "a guy" and less intimidating as a licensed professional.

When questioned about the ethics of engaging in prostitution, Baker simply reminds participants of its illegal nature, regardless of individual moral principles. In one example, a flustered participant raised his hand and asked, "Hey Kenny, how do I get past the rationalization of two consenting adults, aside from those who might be exploited?" Smiling, Kenny succinctly 
replied, "It's against the law...I don't question what is. My life will be easier if I live my life within the bounds of the law. It's freer. But I respect that and I understand that." Here, Kenny disregards issues of morality or ethics justifying prostitution laws. Instead, he shifts the focus to healthy behavior, noting that living as a law-abiding citizen provides opportunities for liberty and personal gain.

Throughout his presentation, Baker encourages johns to consider the personal ramifications of their own behavior. Rather than justifying the criminalization of prostitution because of its dangerous and unhealthy nature, he focuses on the converse: prostitution is unhealthy because it is dangerous and illegal. Overall, he constructs prostitution as normative, yet unhealthy behavior that is objectively and unquestionably illegal. With respect to consensus, Kenny discourages johns from fixating on whether prostitution should or shouldn't be tolerated, while redirecting them towards a consideration of the adverse personal consequences that could ensue for those that reoffend.

\section{Brad Beasley: "Protect yourself first and your partner second"}

Like Kenny, Beasley assumes a casual approach to his presentation. Dressed informally and maintaining a light-hearted, often humorous tone, Beasley nonchalantly strolls around the chapel as he speaks. Though his presentation is packed with detailed information, Beasley maintains a natural, almost conversational flow.

In his discussion, Beasley concentrates on safe and unsafe sexual practices occurring both within and outside of the commercial sex paradigm. He clarifies his motives, stating, "I'm not going to tell you what you should or should not do. We're all adults and can figure that out for ourselves." However, he hopes that his presentation will encourage johns to consider the health risks so that "the next time you find yourself in sexual situation you will protect yourself first and your partner second." Again, the objective neutrality he assumes neither condemns nor condones sexual consumption — only unsafe sexual practices, which could occur within or outside of "the 
market." He normalizes sexuality as innate and carnal, claiming, "We're animals, and we're hardwired for sex." At the same time, unhealthy sexual practices carry potentially heavy consequences, such as venereal disease contraction or death. Here, Beasley normalizes a biological, animalistic sex drive while constructing unsafe sex as personally harmful. Though neither presenter attempts to justify its illegal nature or depict it as a moral violation, both frame prostitution as potentially dangerous and personally harmful.

\section{District Attorney's Office: "Do you want to be a part of that?"}

Upon entering the NJS program for her segment on the legal implications of patronizing prostitution, Antoinette Welch ushers in a palpable mood change. Though her attire is casual, she commands a professional level of respect as she strides assertively towards the front of the group, abruptly interrupting the general murmur of johns chatting amongst themselves or making brief calls on their cell phones. Before beginning her discussion, Welch demands the undivided attention of the group. Rather than walking around the room, she remains firmly planted at the front of the chapel, scrutinizing audience members with a glaring gaze and piercing tone, and occasionally, a sarcastic smile.

In contrast to prior presenters who address sexual consumption as unhealthy, unsafe, and high-risk due in part to its illegal nature, Welch draws attention to the opposite: prostitution is illegal because it is high-risk, unsafe, and unhealthy. Welch also expounds upon the adverse consequences that accompany sexual consumption, detailing how offenders facilitate human trafficking and corrupt communities. Altogether, she asserts that prostitution is not only dangerous, but morally wrong and legitimately illegal. She also confronts issues such as the legalization of sex work:

A lot of people think prostitution should be legalized because it's between consenting adults... but almost 99 percent don't want to be there! They're not there by choice! This sex trafficking thing is finally getting the attention it deserves...If you thought it should be legalized, why would you hide it? Everyone says 
prostitution doesn't hurt anyone, but first of all, it hurts women...Do you want it in your neighborhood? Do you want your boss to find out? Your wife? Your church? Your kids?

Welch pushes further, warning,

At this point I hope you're thinking, 'wow! That's the worst decision I've ever made! I could be having sex with a child! I could be paying for sex with someone who doesn't want to be there!' Again, she's smiling, but she's being forced to have sex for five years! Do you want to be part of that? If it weren't for all these men buying sex there wouldn't be all these girls! That's sick! Do you want to be part of that? I'm going to prosecute you as a predator and I won't lose a moment's sleep! Some might think that's harsh but I don't. Spend a day with these women and you'll see! Think about what your choices are doing to these people, and to yourself!

Here, Welch assumes a neo-abolitionist standpoint, connecting participation in prostitution to exploitation. Not only does she illustrate the unsavory consequences that could befall johns should they reoffend, she also casts sexual consumption as victimizing-even predatory. Furthermore, Welch refers to these factors to justify the illegality of prostitution. In this sense, Welch puts forward a strong view against sexual consumption that Beasley and Baker do not. While all three presenters uniformly construct unhealthy sexual practices (both within and outside of the market) as potentially dangerous, they do not all express consensus on the appropriate legal framework for prostitution or its inherently immoral influence.

ADA Rachel Thompson also lectures on the ills associated with prostitution. As a youthful, statuesque, and professionally dressed blonde, she also captures attention at the NJS. Walking assertively to the front of the class, Thompson pulls out a bulky law book, opens it, and reads from it loudly and confidently. Like Welch, she assumes an authoritative and no-nonsense approach to her presentation, incorporating hints of sarcasm and cutting remarks to stress important points in her discussion. Using examples from her own caseload, she recounts occurrences in which she "felt sorry for some good, decent men whose lives are ruined by this." In one of these examples, Thompson relates how a man, "Richie," checked in at a Hilton hotel, 
having arranged to meet a prostitute there that he met through the Internet. The man had only hired the prostitute to satisfy a unique fetish—sucking his toes. However, upon answering the door to his hotel room, Richie discovered that the prostitute was accompanied by two male counterparts, who subsequently stabbed him and robbed him. Ultimately, Richie not only experienced a traumatic near-death experience, but his wife also discovered his indiscretions. Thompson concludes this narrative by warning johns not to "play with fire." Such anecdotes serve to illustrate the personal risks that johns undertake when they choose to engage in prostitution. This theme resonates with Baker and Beasley's summation of prostitution as potentially hazardous and unsafe.

Thompson conceptualizes prostitutes in such a way that indirectly constructs prostitution as potentially immoral. Thompson describes the stereotypical female prostitute that johns may encounter, naming them as "drug addicts, pitiful, broken people." She further adds that "they're not Girlscout, girl-next-door, good, whole women." She questions why participants would elect to purchase sexual services from providers that inevitably possess such traits. In so doing, Thompson implies that prostitutes may be vulnerable and in need of social support--not their next trick. At the same time, prostitutes are corrupt and dangerous, thus endangering those with whom they share sexual contact. Through these constructions, Thompson inadvertently constructs johns as both heartless (for willfully engaging in sexual services with vulnerable women), and as vulnerable (for putting themselves in situations with corrupt and potentially dangerous strangers). Overall, she depicts prostitution as a dangerous affair, not only because it is against the law, but also because it involves potentially seedy and unpredictable players-prostitutes. At the same time, she draws attention to the vulnerable positions from which many prostitutes operate, thus suggesting the inherent immorality of sexual consumption. As such, Thompson joins Beasley and Baker in her construction of prostitution as personally perilous while adding her own dichotomous conceptualization of prostitutes as both vulnerable and dangerous. 


\section{Eliza: "I'm out there giving love to get love and you're paying for it"}

Immediately following an hour-long lunch break, the NJS resumes with a brief presentation by a former prostitute from the Magdalene Program. While the individual presenter may differ from session to session, the same presenter attended each of the NJS sessions that I observed during the course of my research. This young woman, "Eliza," walks briskly to the front of the chapel facing the group. Still clutching her purse, chewing gum, and periodically checking her cell phone, she introduces herself and hurriedly explains that she is still on her lunch break at work. She then details her personal history of childhood sexual abuse, domestic violence, homelessness, and rejection, staring boldly into the faces of the johns as she talks. She also explains how she fell into a life of prostitution and drug addiction during her aimless quest for love and acceptance. Throughout her presentation, Eliza makes no direct mention of prostitution's legal framework, nor does she name it as immoral. Yet, her narrative illustrates the harmful nature of prostitution, given the personal damage it produces. However, rather than wholeheartedly blame johns for their participation in sexual consumption, Eliza equates her status as a former prostitute with that of the program participants, claiming that, "we are more alike than not...'cuz I'm out there giving love to get love and you're paying for it." In this way, she links her own brokenness to that of her clients, thus signifying that both the buyer and the provider share responsibility for moral wrong. Rather than view herself as a victim of exploitation, Eliza assumes a non-abolitionist perspective, declaring, "I believe in cause and effect...this is what I chose and I deserve this because I chose...it's about choices. I'm not ashamed of my past—it's a choice that affected me and helped me to become the person I am today."

In addition to her construction of prostitution as a vice that buyers and providers contribute to equally, Eliza also highlights the increasing danger it presents. She recounts being hung, stabbed, shot, pistol-whipped and raped during the course of her life as a prostitute, warning johns, "All the stuff I did I'm paying for it now! Some of you think it's a joke-it's not. 
The people that are on the streets now are ruthless_-it's not a joke!" As such, Eliza reiterates the same construction as other presenters - that prostitution is personally hazardous to participants.

\section{Sexaholics Anonymous: "Sex is optional"}

The penultimate presentation in the NJS often includes a small contingent of speakers, each of whom narrates his history of sexual addiction, and his respective process of recovery through Sexaholics Anonymous. The speakers varied from session to session, each recounting a different narrative of sexual lust and compulsiveness. For some speakers, "acting out" on their sexual impulses did not involve illegal sexual consumption practices. Rather, some presenters described habitual obsessions with fetish, fantasy, masturbation, and pornography. Others mentioned being "peeping Toms," engaging in extramarital affairs, fondling women in public, voyeurism, sexual tourism, homosexuality, or general promiscuity. Through their presentation, Sexaholics Anonymous members discuss the personal losses they have suffered due to their addictive behaviors, thereby reiterating how hazardous unhealthy sexual practices can be. One speaker, a middle-aged, Caucasian man with a hunched posture, discussed how he grew up as a "peeping Tom," even taping a mirror to his shoes that enabled him to look up women's skirts. In spite of his efforts to beat his "disease" through prayer, spirituality, and ministry, his behavior worsened. While working as a church counselor, he claimed to have had affairs with over 30 women. His addiction continued until one of his clients reported him to authorities, after which point he lost his family, his marriage, and his ministry. In reflection, the man assured johns, "If you think you're invisible, you're not. When you get caught it feels like the worst day of your life. It could be the first day of a turn-around. I hope that happens to you."

In spite of their message of hope and recovery for those that struggle with sexual addiction, Sexaholics Anonymous speakers embody the message of Baker and Beasley-that engaging in unhealthy sexual practices (inside the market or outside of it) could result in damning personal consequences for program participants. 


\section{EST: "Stop adding to demand, okay? And tell others!"}

The final presentation in the NJS is also composed of a circulating volunteer base, all of whom read off of a fact sheet pertaining to human trafficking. Speakers explain that human trafficking is "just a fancy name for modern-day slavery." They proceed to detail the profit human trafficking purportedly generates each year; the manner in which minors are lured into pimp control; the "red flags" to look for in potential human trafficking cases; the connection between prostitution and human trafficking; and finally, the reasons underlying male participation in prostitution. During their talk, speakers present prostitution as inherently immoral, given its alleged role of feeding the demand for human trafficking. Many speakers assume a neoabolitionist standpoint, such as the following presenter-a critical, gray-haired woman that narrowed her eyes, threw her hands in the air, and laughed sardonically as she read specific points off the fact sheet:

You're not going to know if someone's 18 years old or not! Anyone who has frequented porn or paid for sex has contributed. At some point you have given yourself permission to seek sex outside of your relationships! 'I'm the kind of person that needs a lot of sex'...'I have the right to have sex whenever I want to'...All of these at the end of the day sound like excuses! You've been involved in a particular way in the sex industry. Stop adding to the demand, okay? And tell others!

Another volunteer speaker-this time a youthful photographer that had recently learned about human trafficking through a film project—reiterates this notion, questioning, "Can anyone guess how much money human trafficking brings in each year?” After allowing participants to register a few guesses, the volunteer alerts johns that "part of that money is YOUR money!" Unlike previous presentations, EST does not allude to the negative consequences that could befall johns for participating in commercial sex. Rather, they focus entirely upon the negative impact that sexual consumption has on others-especially sexually exploited minors. Volunteer speakers urge participants to show empathy for others by stopping their sexual consumption practices-- 
which may be due to lack of healthy coping skills, lack of true understanding of intimacy, problems with fantasy, controlling tendencies, or sense of personal entitlement. In this way, EST expresses an extreme view of prostitution as inherently immoral, justifiably punishable, and hazardous for others - a view that other program presenters do not necessarily convey.

Altogether, the NJS program represents a continuum of viewpoints regarding the predatory or victimless nature of prostitution. On one end of the continuum, presenters like Antoinette Welch and EST construct prostitution as inherently immoral, due to its contribution to the greater demand for sexual services and subsequent facilitation of human trafficking. This viewpoint resonates with neo-abolitionist theories that conceptualize prostitutes as victims of sexual and structural violence.

On the other end of the spectrum, some presenters do not directly name sexual consumption as morally wrong or attempt to justify its illegal status. In fact, presenters like Brad Beasley, Kenneth Baker, and Sexaholics Anonymous do not specifically target commercial sex practices at all, focusing instead on unhealthy sexual practices at large. Such practices could occur both within and outside of the market paradigm. Presenters that take this approach also incorporate normalizing and validating constructions of sexual desire within their discussions, reassuring participants that sexuality is natural, carnal, animalistic, and part of human hardwiring.

In between these theoretical poles are presenters like Rachel Thompson and the former prostitute from the Magdalene Program. Though neither presenter makes overt statements about the inherent immorality of prostitution or its ideal legal framework, both construct it as a dangerous activity for potentially vulnerable players.

Altogether, NJS presenters construct prostitution as either dangerous for program participants, dangerous for prostitutes, morally wrong, or justifiably legal. Though differing in their neo and non-abolitionist approaches, presenters uniformly infer that illegal sexual consumption practices (such as prostitution) can be construed as unhealthy behavior, which may result in adverse consequences for both buyers and providers. While not achieving unvarying 
consensus with respect to the appropriate legal framework for prostitution or its intrinsic morality/immorality, presenters do engage in deterrence efforts by portraying prostitution as more costly than beneficial.

\section{Stigmatization Versus Reintegration}

Central to John and Valerie Braithwaite's theory of shame management (Ahmed et al. 2001), and to this ethnography of the NJS program, is the stigmatization/reintegration binary. Examining the degree to which shame is managed responsibly and reintegratively within the NJS program calls for a review of the tone, discourse, communication style, and social role of program presenters, and in turn, a qualitative assessment of the ensuing participant responses. Guiding this examination are the following considerations: To what extent do presenters label or de-label participants? Do presenters allow for clarifications of wrongdoing or expressions of dissent? Do they confront offenders directly or shame them indirectly? Do they acknowledge johns' moral consciences, or treat them as inherently immoral? Does the NJS program symbolize reintegration through ritual? To what extent are "respected others" involved in the shaming process? Through these questions shame induction and management can be differentiated as either stigmatizing or reintegrative, or even a combination of the two.

\subsection{Labeling and De-Labeling}

According to Kenneth Baker, labeling offenders as johns, batterers, deviants, criminals, or sex offenders inadvertently assigns them an axis of identity through which future behavior is dictated. This notion resonates with labeling theorists like Braithwaite and Geis (1982:300-1) who maintain, "A major risk in apprehending the traditional criminal is that the stigmatizing process will push him further into a criminal self-concept." Kenny describes the same prospective danger for johns: 
If you...have established the identity that 'I have to have sex in order to be okay'... underneath that is something that you're not okay....They don't really understand why they're doing it. We give them a label or an identity around it, we reinforce it through society - that they are a john... and they judge themselves.

Society judges them as well. I look at the fear that comes along that 'you're not made whole', that 'you have to have it to be okay', that it's 'where your power comes from.'

In essence, Kenny and other labeling theorists posit that negatively constructing deviants encourages them to adopt the self image they have been ascribed. For johns who may already struggle with feelings like social anxiety, fears of rejection, and an inability to relate well to others (which may relate to the original decision to engage in sexual consumption), labels depicting them as innately immoral or perverted could exacerbate these feelings. In what becomes a vicious cycle, offenders experiencing social alienation may turn to "unhealthy behaviors" (like sexual commerce) to cope with underlying fears of 'not being made whole' or 'needing sex to be okay.' An example of this theory manifested itself when a particularly outspoken participant refused to fill out the participant questionnaire in his folder. An older man in jeans and a plaid shirt, sitting towards the back of the chapel, he raised his hand and hollered his objections to program presenters. He continued to create conflicts with program presenters throughout the day, protesting against the legal system, law enforcement, and neo-abolitionist conceptualizations of prostitution. Though not all of his comments were audible due to the echoing acoustics of the chapel, he created a distraction by engaging in disruptive chatter with fellow participants and mumbling derisive phrases under his breath. In response to this participant, Kenny observes,

That guy—-that's normal, that's par for the course. I mean, he's just thoroughly lying to himself about the situation...but he's a likely candidate to be arrested again because he even identifies with being delinquent. That's his identity - that he's actually a victim of the police. That's the bigger problem with a guy like that; he's established an identity, and I'm not even talking about the behavior! 
For Kenny, the axis of identity around which offenders formulate their choices and behaviors is more important than the behaviors themselves. Accordingly, he seeks to target the underlying issues that offenders face while refraining from judgments or labels. At the same time, Kenny notes how labels can be beneficial to healing and recovery, provided that offenders adopt them for themselves. He notes how members of Sexaholics Anonymous, for example, gravitate towards a "sex addict" label that outlines their identity and structures their recovery. Upon assuming this identity, sex addicts can embark on a 12-step program that equips them with the necessary tools for achieving "sexual sobriety." This message of recovery for self-proclaimed sex addicts is clearly transmitted by members of Sexaholics Anonymous during their program presentation.

\subsection{Reintegration through Ritual}

Although the NJS presenters abstain from directly assigning labels to program participants, the term "john" is embedded in the program in various ways. First and foremost, the program itself is officially titled, "The NJS," thus explicitly labeling all program participants as sexual service consumers. In addition, presenters such as EST informally reinforce this title by reading excerpts from a book called The Johns. In one such excerpt, a former sexual service consumer, who refers to himself as a "whoremonger," speaks of the misconceptions he previously held about prostitution. By applying this passage to john school participants, the presenter reiterates constructions of participants as johns. Given the casual circulation of this term within the program, it becomes important to examine the manner in which such discourse constructs participants.

Victor Malorek contrasts terminology associated with sexual service providers versus that which is associated with consumers: "While the women are stigmatized with terms laced with opprobrium and distaste—prostitutes, hookers, whores, harlots, and sluts- the users of prostituted women are benignly tagged clients, patrons, customers, and johns" (2009:xiv). Accordingly, the 
term "john" sidesteps any negative undertones that degrade moral character. While masculine, the term remains nonsexual, faceless, and even generic, underscoring the idea that anybody can be a john. In a phone interview, Derri Smith of EST draws attention to this point, claiming, “There are no stereotypes in the john school. I've seen the silver-haired, distinguished-looking gentleman, the people who drive up in their Mercedes or Lexus. I've seen teachers, pastors-the whole gamut! I think it crosses every educational line, every socioeconomic line, every racialethnic line." In this sense, being a "john" implies both commonality and ambiguityconstructions that normalize sexual consumption while maintaining an obscurity about the moral identity of individuals that engage in it. The implicit facelessness associated with "johns" diverges from constructions of female prostitutes that morally condemn them as dirty, impure, or corrupt.

Although program participants may experience some degree of labeling while undergoing the criminal justice process and subsequent diversion program, such identities like "john," "offender" or "criminal" are temporally restricted. With the allowance of expungement, participants can permanently erase any evidence of criminal behavior, including any discursive constructions accompanying it. With respect to John and Valerie Braithwaite's theory of shame management (Ahmed et al. 2001), expungement provides a ritual through which shaming formally concludes. In traditional Anthropological literature, ritual refers to a broad category of religious and nonreligious behaviors that are carried out on socially prescribed occasions, and that convey significant social messages (Hicks 2010:xvii). For program participants, case dismissal and expungement remove evidence of potentially stigmatizing histories while allowing for societal reintegration. As such, they represent an important de-labeling ritual that aligns with Braithwaite's theory of reintegrative shaming.

\subsection{Education and Moralistic Appeals}


The central focus of the NJS is to educate offenders about the risks associated with sexual consumption. Through realistic discussions of medical, psychological, legal, safety, and interpersonal risks, offenders receive information that will hopefully deter them from reoffending. Within these discussions, participants are regarded as possessing an inherent understanding of "right and wrong," along with the cognitive ability to make appropriate choices. Conversely, punishments based solely upon exclusion or incapacitation carries a different connotation. Braithwaite discusses this distinction, claiming, "Moralizing appeals which treat the citizen as someone with the responsibility to make the right choices are generally, though not invariably, responded to more positively than repressive controls which deny human dignity by treating persons as amoral calculators" (1989:9-10). Here he brings to light an important question regarding the extent to which NJS presenters appeal to the moral consciences of participants. For him, this approach makes offenders actively responsible for their indiscretions, thus increasing the possibility of eliciting shame-guilt.

Kenny Baker approaches his discussion casually, employing a relaxed tone and informal presentation style. While normalizing and validating participants' sexual impulses, he also implores them to examine where they went wrong. During his NJS segment, he reviews the thought process that many participants may have employed when engaging in sexual commerce: "I see someone and then... almost unconsciously, I'm engaging in behavior I know deep down inside of me what's going on, that it is a mistake, but I'm still going to do it. The majority of the men in this room know what was going on—the knowing in you did anyways." In this discussion, Kenny acknowledges that participants understand basic concepts of right and wrong, given that they knowingly made an inappropriate decision to engage in sexual consumption. $\mathrm{He}$ also reprimands participants for their decisions in a manner reminiscent of John and Valerie Braithwaite's theory of shaming "as a means of making citizens actively responsible for informing them of how justifiably resentful their fellow citizens are toward criminal behavior which harms them" (Ahmed et al. 2001:10). Kenny balances this reproof with an 
acknowledgement of his personal investment in their wellbeing: "I definitely think you need to shape up! This is suffering! You're going to the john school! No one wants this shit! I don't care, and I think you guys know that! I get it! Underneath that I do care about you doing the right thing and where you are in your life...Don't let your ego let you brush this off-that's another way of giving yourself permission."

Welch also echoes Braithwaite's theory of shame management by challenging offenders to weigh their actions in light of the negative impact they may have on others, as well as themselves: "It hurts your business! Do you want your kids riding their bike near someone who's getting it on in the car? Why don't I start with your family? If you told your wife I bet she's crushed! What if the only person you care about is you? You want your neighbors to know? Does that blow job sound worth it now? Don't fool yourselves!" Such moralistic appeals attempt to recalibrate participants' consciences rather than deny their existence altogether. She also employs deterrence strategies promoted by David M. Kennedy (2009), explaining the rationale behind enforcement and sanctioning procedures.

Volunteers from EST also employ moralizing approaches to participants, highlighting how offenders actively chose to participate in sexual commerce. Presenters emphasize the fallacy of such actions in an effort to level with offenders and re-establish appropriate social mores. In the June 2012 john school session, for example, a volunteer presenter pointedly reminded participants, "You are here because at some point you gave yourself permission to solicit sex for money...The problem is you are paying to use someone who may have been trafficked" (emphasis added). In the following July session, another volunteer presented a letter from a former Sexaholics Anonymous graduate, reading it aloud to the group of john school participants. In the letter, the former john names his consumption practices as "dehumanizing, demeaning, hurtful, and selfish. He also claims that he was "sick and diseased," and that he had "no regard for others" when participating in prostitution. Through these materials, as well as through direct 
petitions to participants, EST embeds informal moralizing features within shaming practices-a method that Harris recommends for inducing feelings of shame-guilt in offenders.

\subsection{Processing Expressions of Dissent: Non-Domination}

An interesting feature of the NJS and the diversion program model in general, is the forum it provides for offenders to clarify legal expectations, question social norms, and process their own misunderstandings or emotional responses. Naturally, the time and latitude allotted for "respectful moral reasoning" is limited, given the program's overall educational and deterrence goals. Nonetheless, restorative justice programs award a unique opportunity for offenders to process their feelings directly with shame-inducers, thus developing a better comprehension of why their actions have been deemed morally wrong. For John and Valerie Braithwaite, this space is crucial to reducing feelings of unresolved shame, in which offenders leave the criminal justice systems without a clear-cut understanding of their wrongdoing. As they conclude,

A state of being unable to make up one's mind as to whether one has done anything wrong is destructive and anger-inducing. Thus we need institutions of justice that allow respectful moral reasoning in which the defendant is not dominated, and can think aloud with those who can help her to think. Part of the idea of this undominated dialogue is that the defendant will jump from the emotionally destructive state of unresolved shame to a sense of moral clarity that what she has done is either right or wrong (Ahmed et al. 2001:17).

Given this model, it is important to examine to what extent the NJS facilitates 'respectful moral reasoning' in such a way that enables johns to manage and discharge shame. To what extent do presenters allow for questions, clarification, or discussion? Do participants respond to these opportunities through questioning, expressing misunderstandings, or emotionally processing? Exploring these questions reveals the degree to which offenders express hostility, misunderstanding, or transitions from unresolved shame to shame-guilt.

An example of this process in action occurred during the October 2012 john school session in which a couple of participants openly shared their misunderstandings, hostility, and 
feelings of unresolved shame with Kenny and the group. One participant, an outspoken, middleaged man wearing sunglasses and athletic garb protested aloud: "I ain't done none of this shit! Police said I was trying to buy pussy! They just judged me! I shouldn't be here! I shouldn't be paying no $\$ 300$ ! Forreal it's bullshit!! You don’t understand until you get put in this position!"’ Another participant, a tall, polished man in a heavy gray overcoat and dress pants chimed in: “There is an assumption that everyone is guilty... Most of us know where this $\$ 300$ is going! And it seems like a money-making venture! They've got police officers hiding behind bushes and trees and not solving crime! (points to man next to him) This guy told me he didn't even have the money to pay—he couldn't have bought anything, even if he wanted to!"

In response to these assertions, Kenny attempts to clarify typical law enforcement procedures while honestly admitting that systemic flaws do exist. He continually reassures participants that he does understand their position, that he "gets it." Even so, he urges them to examine their potentially risky behaviors so as to prevent further offenses.

In an example of positive responsiveness to the program, one participant openly shares the thought process he undergoes when purchasing sexual services. Sitting attentively in the front, nodding periodically and giving consistent eye contact, Ronald (who later participated in an individual interview), raises his and hand and engages Baker in a conversation. Kenny offers a space for this, capturing the participant's story under his paradigm of identity and "psychological time." Ronald acknowledges: "It becomes an out-of-body experience...for me there were times when I had no job, no vehicle, and then I wasn't doing it, but then I $d o$ have a job and a vehicle and then I did it—so I don't have to do it." Kenny responds, “Let's look at that! You've created in identity that you have to do this or you're not okay. Society tells me this. It's not doing any favors, although you own your shit—we all have to own our own shit (Kenny shakes the participant's hand). Right there! You just engaged me and we are present, conscious, right now!"

Ronald continues, "Part of me says to patronize prostitution, I know is wrong...I'm ignoring the harm it's doing to the community. Then when I do justify it I think if I do take a girl 
out, then I have to deal with the girl's four baby daddies!! (laughs) So I use that to justify it. I use that approval because when I was not in the position to do it I don't do it!"

While Baker provides an open forum for discussion and emotional processing, other presenters set firm boundaries around the types of interactions they will and will not allow. This is particularly salient during the ADA's presentation on the legal implications of prostitutionrelated crimes. Rachel Thompson, for example, informs participants that she cannot answer questions regarding individual cases. However, she does inquire as to whether participants feel as though they were "entrapped." This question generally elicits controversial responses amongst the participants, some of whom willfully engage in a role play exercise with Thompson, through which she attempts to clarify culpability under the law. During one such interaction, Thompson explains that entrapment is a legitimate defense, but that "you have to be able to show that you have no predisposition." In these interactions, john school participants verbalize feelings of confusion and hostility—often towards enforcement and sanctioning officials. Thompson challenges their ideas regarding culpability and even social normativity. She asks, "How many of you have heard of entrapment? It is an effective defense." A younger participant with a sarcastic grin calls out from the back, "Is it enforced? It's one thing to have it in a book!" Reading from the law book, Thompson replies, "You have to be able to show that you have no predisposition. If you show up at a hotel room you have predisposition. Why did you go? Normal people don't do that! And who talks to strangers in the street?" Another participant, leaning forward in his seat and waving his arm wildly exclaims, "I feel like I was entrapped! I live on Murfreesboro, and I was out of the club. I see a girl I want to talk to...it's 1:30 am, so I'm like, I wanna talk to her! She tells me she's a prostitute, and I'm like, 'you are too good to be a prostitute!' I'm talking to her for the hell of it because she's pretty...I tell this girl, 'I don't buy sex!' I repeated this!' To this Thompson replies, "Okay, you've been convicted like four times already... Once she tells you she's a prostitute you should have rolled up your window and left! You willingly stayed and 
talked to her even after she told you she was a prostitute!" Frustrated, the participant fires off, "You work for the State don't you? Oh, well you're not a real lawyer though!"

A third participant, Craig, (who later agreed to an individual interview) also takes this opportunity to speak up. A tall, youthful, Caucasian man with a southern drawl, Craig inquires, "What about freedom of speech? What about constitutional rights? "How come the hypocritical legislature can make legislation they violate?" Thompson shruggs and definitively responds,"That's life, and also, legislature also gets convicted."

During these exchanges, participants express hints of hostility directed at the legal system and those that enforce it. Another participant further illustrates this when sharing his experience with law enforcement. He tells Thompson that he had purchased sexual services through the Internet and subsequently met with the prostitute at a hotel. The participant describes hearing a knock at the door of the hotel room. Upon going to lock the door, suddenly, police officers "charged in and attacked." He claims that excessive force was used, and insisted to Thompson that "it's not football!" Thompson reassured the participant that police officers should wear brightly-colored vests and avoid using excessive force whenever possible while conducting sting operations.

In yet another example, Thompson reviews the fines associated with patronizing prostitution, including court fees and expungement. Participants groan in response to the high figures Thompson announces. Rachel strategically reminds them, "Hey, it's expensive to commit crimes ya'll!" One participant seated in the middle of the chapel comments flippantly, "Someone has to keep the government running!" Comments such as these frequently surfaced during Thompson's presentation, thus enabling participants to discharge shame within an open dialogue. At the same time, these isolated interactions do not entirely reveal whether participants have transitioned from feelings of unresolved shame or embarrassment-exposure to feelings of shameguilt. 
Another area in which participants utilize opportunities to express dissent is the EST discussion on human trafficking. During a particular NJS session, the volunteer speaker that was supposed to present was unable to do so. At the last minute, an EST volunteer-in-training who had never before presented at the NJS, was asked to read from the fact sheet. An older gentleman with graying hair, the speaker introduced himself as a veteran that had formerly participated in sexual commerce before discovering the issue of human trafficking. He expressed how hearing about trafficking changed his world view and influenced him to become an activist. Although he approached participants with an honest, gentle, and familiar tone, one of the participants became extremely upset. Slouched against the back wall of the chapel, a middle-aged African-American donning glasses and a ball cap spoke up. He challenged the notion that purchasing prostitution fuels demand for sexual exploitation, and warned the speaker, "Don't put that on me!" Other participants nodded in agreement and began to chat amongst themselves. Through the general murmur, another participant raised his hand and skeptically inquired as to where the statistics from the fact sheet originated. The EST volunteer clarified that the statistics came from recent government reports. As the noise level in the room escalated, one participant raised his hand and noted, "Part of the problem is that now the fear of the law is against the women, and that's why they don't report!" He then made reference to the legalization model, asserting that if prostitution were legal, women would more likely report violent crime. Other participants continued to engage in rowdy side conversations until NJS administrators cut off opportunities for commentary and proceeded to the next presentation.

While all presenters allowed for at least some degree of commentary, questioning, and feedback, participants did not always utilize these spaces to publicly discharge shame. In the instances in which participants narrated their experiences, processed their emotions, or expressed hostility and frustration, presenters responded by explaining culpability, clarifying social norms, and recalibrating understandings of right and wrong. Whether this 'undominated dialogue' aided in reducing feelings of unresolved shame and/or increasing shame-guilt remains unclear, the NJS 
program emulates John and Valerie Braithwaite's model of shame management by allowing a space for verbalized dissent. This may prove advantageous over penal models that simply sanction offenders without providing them education or clarification of their wrongdoing.

Not all presenters in the NJS confront participants directly. Instead, some opt for an impartial and less condemning approach that highlights the destruction resulting from wrongful behavior, which as John and Valerie Braithwaite suggest,

Indirect methods of confrontation that seek to elicit volunteered remorse...will be more effective in bringing about desistance from predatory crime than direct verbal disapproval of the act. Where indirect methods of eliciting confession, remorse, apology, and recompense fail, direct verbal confrontation with disapproval of the act (while approving of the person) will be necessary (Ahmed et al. 2001:45).

Altogether, the NJS exercises a variety of shaming approaches ranging from impartial and indirect to increasingly targeted and hard-hitting. Three of the presentations in particular assume the least confrontational approach, either by delivering objective information without specific mention of sexual commerce, or through personal testimony. The first of these presentations is Brad Beasley's. As previously discussed, his presentation covers various sexually transmitted diseases, their symptoms, effects, and transmission. Instead of directly identifying johns' practices as potentially harmful or risky, he details the ease with which sexually active individuals that do not take appropriate precautions can contract and transmit sexually transmitted diseases. Despite the lack of a confrontational or accusatory approach, he hopes that johns will critique their own unhealthy sexual practices, and thusly understand the inherent danger embedded in them. Beasley expressed these intentions during a private interview, commenting, "I think that's the objective and the intent of the program...to affect some type of behavioral change...I think a sub context of that would be just to give people some information hopefully that they will retain enough to start thinking about it. It may affect behavior change immediately or two years down the road, but you hope that somewhere it will take." 
For many participants, the information Beasley presents comes as both a shock and a reality check, thus functioning as a scare tactic for participants. During individual interviews, many participants mentioned the possibility of contracting an STD or HIV as a major deterrent for them to engage in commercial sex. Deshawn, a middle-aged, self-proclaimed family man and dedicated husband, commented, "I think they got the point across for me...I don't know what the rest of them got...but I think with the herpes thing and stuff like HIV—-that'll keep my ass in line." Another participant, Michael, an articulate and allegedly religious man, who later identified himself as a sex addict, expressed a similar sentiment:

You know law enforcement, certainly STDs, I think those two by far would be...the bigger issues at hand when I am soliciting for sex. I've had unprotected sex...I guess God is merciful that I didn't contract anything...I took a test in order to come to the john school today, so... who knows? But I'm hoping. I feel healthy; I haven't had any symptoms whatsoever, even though there are types of STDS where there are no symptoms.

Ronald also mentioned the fear of contracting venereal diseases, noting how such an event could negatively impact his life:

I don't want to become HIV...I have other health issues. I have hepatitis, I have herpes, but I don't want to become HIV! What I understand is constantly getting diseases shuts your immune system down to become HIV. Not to mention, it's going to make it harder for me to find a partner when you have all these issues. So when you can't find someone because you have all these issues, it kind of limits your options on who you can deal with. And then you look at going back the same way you was going, because my mind will say 'ain't no women's gonna want me.' Shit! I got herpes, I got hepatitis C, I'm 49 years old, I only make 10.24 an hour... the jail, my health, my recovery, those are pretty high risks!

Here, participants reflect on their own sexual behaviors and the potential consequences that could arise should their health become compromised. In these examples, Beasley's presentation seemingly impacts participants enough to generate contemplation and deterrence.

On a more profound level, some participants expressed feelings of remorse, regret and anger at themselves-feelings consistent with shame-guilt. In an individual interview, Michael, claimed, 
“I would say 85 percent of the time I did use protection, but uh that 15 percent I didn't...yeah...I would say that was crazy and stupid. And I wouldn't classify that as naïve either; it's just crazy and stupid." In cases such as these, indirect shaming can work to elicit feelings of shame-guilt without stigmatizing participants or inflating hostility towards sanctioning and enforcement officials. While not all participants experience an emotional response from this information, Beasley's presentation does aid in explaining part of the rationale behind enforcement of prostitution laws.

Other presentations that embody indirect shaming are those of former prostitutes from the Magdalene Program and of Sexaholics Anonymous members. In each of these presentations, former participants of sexual commerce or otherwise addictive sexual practices give their personal testimonies. Not only do these presentations attempt to elicit feelings of empathy for potential victims, they also offer an axis of identity around which participants can potentially rehabilitate themselves. While not all participants construct prostitutes as deserving recipients of compassion, many express a desire for prostitutes to receive help, and also communicate satisfaction that their john school fees contribute to a humanitarian cause. During individual interviews, some john school participants revealed such views when questioned about their opinions of prostitutes. Matt, an overweight, soft-spoken, and noticeably self-conscious participant reflected, "They're probably on hard times. I imagine they would have to make means, you know, their finances...you never know what people are involved in or what they're going through, so I really can't judge anybody for that." Rusty, an army veteran that began frequenting brothels while overseas on active duty, also revealed an empathetic attitude towards prostitutes: "Well my views changed a little bit today. But before today I probably would have thought drug abusers, alcoholics, that kind of stuff...people who have brought problems on themselves. And after this...talk today I realize that that may not be the case. They may have...just grew up in a crap life." Andy, a participant in his early twenties, wired from downing energy drinks during breaks at the NJS, emphasized that he was not a "dumb guy," and that he 
already knew about the risks of prostitution. Connecting his own behavior to that of prostitutes, he remarked, "You see stuff on TV, you know? Stuff like them walking around, and part of you has to feel for them because you know something is wrong. And then here I am today, you know? Something was apparently wrong. So, I mean, you see both ends of it." Daniel, who approached the NJS program with apparent enthusiasm and humility, commented, "When I'm actually level-headed and not in the frame of mind that I was in, I actually very much feel for them...would really like to see them get their lives squared away... and get becoming productive members of society, not necessarily perpetuating the cycle that they're in." A final participant, Jeremy, a tall, soft-spoken man on the brink of retirement stated, "I think of them as humans. I think of them as dysfunctional—-they have dysfunctional problems. I think they're just lost souls that needs to be helped, you know? They try to put them in jail and all that, but really instead of doing programs, I'm thinking it would be helpful to find out what is the mental make-up of it to make them do that."

In these cases, participants express empathy for prostitutes and their harsh circumstances or grim upbringings. Others also contemplated their own behaviors within the context of sexual addiction. After a long pause of self-reflection during an individual interview, Craig professed, “Well I don't know if it's addiction or a dream...I got to learn to question the difference between dream and reality...it's like you build a super-model in your head...that's like what you want in your life, that's what you want to tell your kids...that's what, you know you want your whole to-you know you want that happiness...I don't know why I got that fear." Michael and Ronald also admit to sexual addiction during individual interviews. According to Michael ,"When $I$, you know, purposefully get in my very own car, you know, at all hours of the night and decide to peruse the city... what else can I call it...other than sex addiction? I mean, I'm going out specifically to engage in sex...It's sex addiction!" Ronald claims, "I do not look down on prostitutes, because I know the same way I have a problem that's why I'm doing it—I have a deeper problem. I know I'm a sex addict and I have deeper problems. I know that the women out 
there have deeper problems too...so what you have is just sick people taking advantage of each other."

For some participants, hearing the personal testimonies of sex addicts seemingly impels them to contemplate their own capabilities to exercise self-control over their sexual behavior. According to both Baker and John Braithwaite, this process of self-exploration is essential to discovering the underlying basis for choosing to engage in risky behavior. As such, indirect shaming may be a more successful strategy for cultivating shame-guilt than more punitive approaches that stigmatize participants and heighten feelings of hostility.

\subsection{Respected Others}

John and Valerie Braithwaite's theory of shame management and reintegration offers a helpful framework for examining how the NJS program imparts and manages shame. One salient aspect of his theory, however, remains problematic for restorative justice efforts directed at this particular population of offenders: private case conferences in which the offender, the victim(s), shame management facilitators, and the offender's reference group discuss the wrongdoing at hand. John and Valerie Braithwaite further stress the importance of involving "respected others" in the case conferences, asserting, "The number one design principle for restorative justice processes is therefore that coordinators must work hard at finding out who are the particular people offenders have the highest respect for and spare no expense in getting them to attend" (Ahmed et al. 2001:32-3). With regards to prostitution offenders, this model presents challenges to restoration and reintegration, given the complex web of intimacy and identity conceptualizations that individuals often attach to their sexuality. According to Baker, revealing details about johns" commercial sex practices with "respected others" (a group that could include spouses, girlfriends, parents, bosses, coworkers, etc.) could backfire, causing greater personal loss for offenders. Such losses could assume the form of divorces or breakups (especially if a john's intimate partner was formerly unaware of their participation in commercial sex), loss of a job, or 
other forms of exclusion. In the face of this personal misfortune, johns may plunge further into the very behavior that harmed them in the first place. John and Valerie Braithwaite also describe this process, adding, "If perceived outcasting persists, the wrongdoers may opt to forge an outcast identity collectively in a community of those who have been similarly outcast... When this happens, the direct confrontation has backfired, exacerbating the wrongdoing (Ahmed et al. 3132). Such "communities of outcasts" may resemble what one interviewee, Craig, described when questioned about his strategies for managing various risks associated with commercial sex. In an attempt to orient me with his process for purchasing sex on the Internet, he directed me to "Just sit down on the computer, pull up Bing, and put yourself in a guy's mindset. Say that you want a female escort, you know, in whatever city that you're in...Just look at all the forums that pop up and then you can start...You'll see reviews." Craig goes on to explain, “Angie's list gives you a referral. It's also there on Better Business Bureau, you see what I'm saying now? There's also a thing called Tear, Big Daddy, Big Dog...four or five that you go through and they run background on you. You say who you are and what you are, and all your information-same thing for the escort, they do the same thing. So then...that's a safety precaution if you go that route."

Craig's reference to the layer of safety and support that online communities can theoretically provide through reviews, recommendations, and background checks, alludes to a virtual subculture of sexual service consumers. Kristie R. Blevins and Thomas J. Holt (2009) explore the norms and values of this subculture by examining forum postings from three different websites. They discover that the virtual john subculture possesses its own argot, through which sexual service consumers exchange information pertaining to their sexual encounters with sex workers in a given city, offer recommendations or post complaints, or warn other johns about the potential presence of law enforcement in certain venues or areas. The researchers observe that the Internet provides a public, yet anonymous space in which such information can be shared with reduced risks of exposure, shame, or embarrassment (2009:620). For some participants, like 
Craig, virtual subcultures already provide the normalization, solidarity, and support for their sexual behavior that they cannot locate in other settings. These elements are subtly communicated through the very discourse, or "argot" that johns utilize in the forums. This discourse not only serves to indicate membership and identification with the subculture, but also "functions to conceal deviant or criminal activities and communications from outsiders" (Blevins and Holt 2009:622). Blevins and Holt identify popular terms that circulate in online john forums, like "hobbyist," "mongerer," or "troller," which johns utilize to describe and normalize their own behaviors.

The same jargon emerged in an individual interview with Craig, who also manipulated verbiage to justify his participation in sexual commerce. He asserted,

A lot of people...it's like a trophy or a notch on their belt or something. Like they do it as a hobbyist. It's their hobby... I mean you've got people who make moonshine. That's a hobby. You've got people who grow pot. That's their hobby...I haven't heard of or read about people growing coca plants to make cocaine but I guess that could be their hobby too. My greatgrandfather was a moonshiner and a gun builder. He was a gunsmith, so I mean, I guess everybody's got their own thing that floats their boat.

Here, Craig's rationalization illustrates a lack of consensus regarding the supposedly immoral or pathological nature of sexual commerce and, therefore, a lack of shame-guilt. While online forums may not exacerbate an individual's criminal activity, they may aid in circumventing law enforcement detection and generally counteracting ideologies regarding "normative", "healthy", or lawful sexual behavior. In this sense, virtual john subcultures work against the ideals promoted within the NJS program, thus rendering it increasingly difficult for johns to experience feelings of shame-guilt over their actions. Because deviant subcultures undermine dominant ideologies, John and Valerie Braithwaite and Baker caution against implementing potentially disintegrative protocol that push johns towards them. Perhaps for this reason, the NJS program does not involve 'respected others' in the shaming process, despite the 
fact that this may hamper the program's ability to elicit feelings of genuine shame-guilt in participants. 


\section{THE JOHNS}

In light of the extensive efforts of program presenters to inform, deter, and reintegrate participants, it is necessary to examine the emotional responses that individual participants experience. This study employs Harris' framework as a loose template for categorizing participant reactions as shame-guilt, embarrassment-exposure, or unresolved shame. While these classifications serve as a useful tool for analyzing participant experiences, they risk oversimplification of truly complex emotional reactions. Rather than adhere to rigid categorization, this thesis recognizes participant responses as fluid and overlapping. For this reason, various facets of participant response are gauged, thus illustrating the flexibility of boundaries that distinguish shame-guilt, embarrassment-exposure, and unresolved shame. Do participant comments reflect an accurate understanding of the information presented in the john school program? Do they admit wrongdoing? Is this wrongdoing qualified as illegal, immoral, or both? Do participants express consensus regarding the construction of prostitution as inherently unhealthy, immoral, dangerous, or pathological? To what extent do participants normalize their participation in sexual commerce? Do they express empathy towards community members, prostitutes, or human trafficking victims? What about resentment or hostility towards sanctioning and enforcement officials? Do they express feelings of guilt, regret, anger at self, humiliation, exposure, or concern about others' opinions? Do participants feel labeled, stigmatized, or otherwise treated unfairly? Lastly, what impressions do participants articulate regarding the space in which the program is held? Posing these questions reveals nuances in the emotional responses 
to shaming, which often challenge and contradict the dominant ideologies imparted within gender socialization.

Altogether, ten john school participants elected to engage in individual interviews, during which individual experiences and reactions were shared. Of these ten, five participants seemingly exhibited sentiments consistent with Harris' conceptualization of shame-guilt, one participant exhibited embarrassment-exposure, two presented with unresolved shame, and the other two participants' experiences fell outside the bounds of any of these categories. Before synthesizing individual participant reactions to shaming, it is useful to outline the loose parameters distinguishing one category from another. While disparities certainly exist between theoretical classifications and on-the-ground participant experiences, framing offender responses to shaming may prove useful in predicting potential recidivism or subculture formation, and thereby improving crime control methods that manage shame in a more restorative and effective way.

\section{Shame-guilt}

Shame-guilt is an emotional response that encompasses the dialectical relationship between awareness of external rebuke and internal consciousness of moral violation. For the purposes of this study, shame-guilt is perceived by a participant's expression of consensus regarding the inherent wrongfulness of prostitution; their accurate depiction of information presented within the john school program, including the intrinsic danger or risk associated with patronizing prostitution; acknowledgement of empathy towards potential victims, including prostitutes, human trafficking victims, and/or community members; acknowledgement of moral wrongdoing; acknowledgement of guilt, regret, or anger at self; lack of hostility or anger directed at enforcement or sanctioning officials; fear of others' disapproval of their actions; and lastly, feelings of restoration—not stigmatization or labeling. Though participant accounts did not necessarily epitomize all of these indicators, they fundamentally embodied the reciprocal relationship between internalized guilt and externalized shame. 


\subsection{Consensus}

As previously discussed, societal consensus regarding the inherent immorality or social inappropriateness of crime is imperative for informal shaming to elicit feelings of shame-guilt in offenders, and subsequently generate behavioral change. During individual interviews, five participants explicitly referred to prostitution as inherently wrong, immoral, and/or justifiably illegal. Matt, for example, gave a sigh of relief and declared, "I think for me it's lucky it is a misdemeanor, because I'm sure if it were a felony I would probably lose a lot-my job, probably, if they found out about it, my family...so yes, it should be a crime, but I think the way it is now, I think it's giving individuals the opportunity to get themselves together." Andy, on the other hand, admitted, "I wish it wasn't a crime for me, but I mean, yeah, it's obviously a crime. I mean, these people know the risks too... Yeah, it happened to me. I hate it...but, it happened to me, so it kind of affects me then. But I think you got to have some laws, and some laws have to protect people who can't protect themselves."

Ironically, despite knowing that prostitution's illegal status negatively impacts them as offenders, participants that experience shame-guilt uphold conceptualizations of prostitution as immoral and/or socially unacceptable. Michael demonstrated this in an individual interview when, maintaining a firm expression and serious tone, he professed, "First off I would say on the record that it's [prostitution] wrong, and I would recommend any and all persons to-to stay away." Ronald also expressed an unwavering anti-prostitution stance, claiming, "I think it should be considered a crime because it enables other crimes. If it did not enable other crimes I think it should be legalized, but due to the fact that it enables other crimes, it should not be legalized."

In these excerpts, participants seemingly prioritize their considerations for prostitution's potentially adverse effect on others over the negative consequences they personally endured due to its illegal status. This mentality not only serves as evidence of internalized beliefs that 
prostitution is unethical and unacceptable, but also that participants have violated their own moral consciences by patronizing.

\subsection{Awareness of Danger and Risk}

Another aspect of shame-guilt is an accurate understanding of key points addressed within the john school program—namely the intrinsic risk associated with participation in illegal commercial sex, or otherwise unhealthy sexual practices. According to Kennedy (2009), participants that grasp the reasons underlying sanctioning and enforcement practices may be more effectively deterred from offending than those lacking this background information. Harris concurs with this assumption, concluding that "Shaming will produce unresolved shame to the extent that it creates uncertainty" (Ahmed et al. 2001:190). For this reason, participants that reflect a clear-cut understanding of the rationale underpinning prostitution laws and their enforcement may not experience unresolved shame to the same extent as those with a lesser grasp of information presented in the john school. At the same time, those experiencing embarrassment-exposure may also possess an in-depth understanding of the information presented in the program while simultaneously denying any moral wrongdoing. Nonetheless, a salient trait distinguishing participants with shame-guilt or embarrassment-exposure and those experiencing unresolved shame is an apparent confusion over basic facts discussed in the john school program.

During individual interactions, some participants identified various risks associated with patronizing prostitution as well as dangers existent for prostitutes. Commentary concerning these dangers referenced information presented within the john school program. For example, in a moment of reflection, Andy grimaced and shook his head, admitting, "When you're on the street it could be anybody! When you're on the internet, it can definitely be anybody on the other side...Ever since I did all that, and I was thinking about it...I was like...if it wasn't cops, it could 
have been people there to kill me! You know, steal what I had... and I don't have a lot! Every night I got to bed I think about stuff like that."

This general understanding of danger bodes well for risk deterrence- the core purpose of the NJS. At the same time, however, misunderstandings of other presentation components also manifested themselves during individual interviews—even amongst offenders that reflected overall sentiments of shame-guilt. For example, when Michael was questioned as to whether he believed a prostitution patron could possibly distinguish the difference between a prostitute and a human trafficking victim, he replied with the following explanation: "I see no gratification in watching or even wanting to participate in...child pornography...Kids? You know, 18 or under? You know to me that's hands-off! I guess I should count my lucky stars, that I wasn't that unlucky individual...that ran across this young female that happens to look of age but wasn't...I can walk just out-and-about in the general public, and I can readily identify, you know, an underage teen girl." Michael's assertion in this statement is that human trafficking and child pornography are synonymous terms and that human trafficking only involves minors. Instead of reiterating information presented during the EST program segment, which emphasizes the inability of buyers to differentiate between "consenting" prostitutes and human trafficking victims, Michael indicates that distinguishing minors from adults has prevented him from purchasing sexual services from human trafficking victims. These notions reflect a miscomprehension of the very definition of human trafficking (which includes adults and children), as well as the principle objectives of the EST presentation-to convey to participants how their participation in prostitution fuels the demand for sex trafficking, and how they could mistakenly purchase services from a human trafficking victim without realizing he or she was not consensually prostituting. In this case, Michael's misinterpretations of program information did not overthrow his ability to experience shame-guilt in regards to his own behavior. For other participants, however, such misconceptions may hinder their abilities to grasp the rationale 
underlying sanctioning and enforcement of prostitution laws, and therefore, their capacity to experience and discharge shame.

\subsection{Empathy}

An illuminating aspect of emotional response embedded within the shame-guilt framework employed in this study, is the degree to which participants communicated empathy for those negatively impacted by their actions. In the case of commercial sex participation, potential recipients of empathy included prostitutes, community members, and/or individuals exploited via human trafficking. Though not all participants roused by shame-guilt expressed empathy for all of these parties, each participant conveyed sympathy and compassion for some Other adversely impacted by their actions. For example, Matt, Andy, Daniel, and Ronald all expressed empathy for prostitutes, acknowledging that many may be "on hard times" or experiencing "deeper problems" for which they needed benevolent intervention—not judgment or abuse. Participants like Daniel also empathized with victims of human trafficking. With a wide-eyed expression and earnest voice, he remarked, "I think it's a horrible thing. I definitely think there needs to be more to stop that! As far as how it relates to prostitution...it's a huge trend within the business... which is even one more reason why prostitution should be illegal — exactly like it is." Here, Daniel's

comment — that the risk of directly or indirectly contributing to human trafficking legitimizes the illegality of prostitution—reifies the notion of consensus discussed previously. Because Daniel understands the potential dangers of prostitution, as well as the negative consequences it may hold for innocent others, he can more readily accept accountability for his actions and healthfully discharge shame. Ronald also exemplified this through his concern for community members adversely affected by his actions. In a candid explanation of his guilt, he confessed, "It bothers me because in reality I know I'm harming my community, and I don't like that because...most of the behavior is associated with criminal activity...It enables people to get killed, and I know I'm assisting in that, even if I'm not directly pulling and triggering... The only way I can do it and 
block that out is focus on my own selfish needs, and just make that more important than almost anything else." Here, his awareness of the potential "ripple effect" of his actions reiterates the stance that EST assumes during their presentation. Ronald also communicates an intense level of accountability, labeling his own behavior as 'selfish' and incorrectly prioritized.

Altogether, most participants that reflected shame-guilt sentiments articulated some degree of empathy for others unfavorably impacted by their commercial sex practices. Such parties included prostitutes, human trafficking victims, and even the community at large. While others emerging from the program with feelings of unresolved shame or embarrassment-exposure also expressed empathy for potential victims, they did not link their own transgressions as contributions to the victimization of others. For this reason, another key element of shame-guilt is the admission of moral wrongdoing, often accompanied by feelings of guilt, regret, and/or anger at self.

\subsection{Acknowledgement of Wrongdoing}

The five participants that experienced shame-guilt universally accepted blame for their actions, identifying them as moral or ethical violations and not simply illegal offenses. This distinction emerged as a significant factor in determining differences between shame-guilt and embarrassment-exposure. While embarrassment-exposure entails an awareness of others' disapproval and reproof, shame-guilt incorporates a deeper sense of having violated one's own moral conscience. This sentiment surfaced in individual interviews with Matt, Andy, and Michael, who openly held themselves accountable for wrongful behavior. With a slumped posture, nearly inaudible voice, and lack of direct eye contact during our interview, Matt distraughtly explained, "You know I'm not a bad guy. When I was arrested I apologized to this girl...Even when I went to court I apologized to the judge and to the court...I really still can't see why I did that. It bothers me every day. Why would I even approach somebody like that? Most people I associate with, I don't think would do that." Andy also expressed both regret and 
accountability for his decision, claiming, "I made the dumb decision, so you either own up to it or run from it...Probably 99 percent of the time when people say they're entrapped they're just running scared from it...I think it's better to face it now instead of lying for the rest of my life about it, so there's only one way to learn from it. Well, there's two: there's the hard way and then the other way." Michael even utilized our interview as a demonstration of his guilt and accountability, saying, "I'm culpable because it's about accepting reality and taking responsibility for what transpired...So me being here today and having this interview with you is just accepting reality that I have a problem that I need to address, and it could be much worse at some point in the near future, and I hope not."

For these individuals, feelings of shame, regret, guilt, and anger at self emerged from a sense of moral failure. For Michael, in particular, voluntarily submitting to an interview with me acknowledged his willingness to openly admit wrongdoing and discharge shame. He even took this a step further by critiquing my approach to the interview, insisting that I probe him and other participants further by asking hard-hitting questions to challenge moral consciousness: "I guess if there's one question that you want to throw in to someone like me to interview me, just ask, 'Do you enjoy what you're doing?' I mean, 'And if you enjoy it, how much do you enjoy it?' You know, just ask, 'Do you enjoy it?' 'And if you enjoy it, why?' 'Do you think that it's healthy?' I mean sometimes you have to dig a little deeper!" Michael proceeded, advising me, "If you're trying to get inside of our minds, you've got to ask some hard-cut questions where you're trying to unravel us in a sense! You know you need to interrogate in a sense, in a hospitable sort of way...'Why is it you do what you do?' And try to peel away as much layers as you can." Michael then continued to add to the list of questions that I needed to pose to interviewees, including why they would knowingly break the law, why they did not consider the negative consequences of their actions (especially imprisonment) prior to committing the offense, and why participants would think that prostitution could possibly be acceptable behavior. His critique of the interview, which he considered to be too "soft," performatively and ostensibly reified his own moral 
consciousness. While Michael clearly demonstrated the most eagerness to accentuate his moral awareness and accountability, other participants ridden with shame-guilt also underscored their regret, remorse, and anger at self, in addition to feelings of humiliation and exposure to external disapproval. In this sense, many participants that experienced shame-guilt also experienced embarrassment-exposure, thus illustrating the fluid boundaries between emotional realms. Matt, for example, emphasized this point in his interview, explaining, "Well if you've never been through this experience of being arrested, it's really humiliating — the word humiliating, okay? To be asked to get out of your car, put your hands behind your back, and handcuffed in the backseat of a car, that's - that was really a shocking experience that I've experienced, which I never want to do it again!" Daniel relayed similar sentiments regarding his experience of being arrested and diverted to the NJS, remarking, "It was incredibly shameful for me, but then again, like I said, I'm kind of that guy that never gets in trouble so it was incredibly shameful for me."

While feelings of embarrassment or exposure arose for many participants as a result of their involvement with the criminal justice system, experiences of internal moral violation served as a significant symptom that distinguished shame-guilt from other categorical reactions.

\subsection{Hostility}

Alongside outpourings of empathy for individuals potentially victimized by their actions, participants in the shame-guilt category also conveyed minimal resentment or hostility towards sanctioning and enforcement officials. Only one participant, Andy, begrudged his encounter with arrest officers during the reverse sting operation, though this did not encumber his capacity for shame-guilt overall. These positive, accepting, or objective viewpoints contrasted with other participants, who insisted that they had been "entrapped" by corrupt law enforcement agents or financially exploited by crooked government officials. Matt, for example, brightened up at the mention of law enforcement in our interview, declaring, "We need our law enforcement and I respect them very much...I think law enforcement needs to be available in all cases everywhere." 
Michael maintained a similar attitude towards law enforcement, denying the notion that he was entrapped through disreputable crime control tactics. During our interaction he confidently asserted, "The bottom line is, I put myself in that position, so I'm the person to blame, and so I can't point fingers at any law enforcement... I put myself in that situation... It all comes back to me. So in other words, I have to take accountability, so they're doing their job. You know, whether I may see it as entrapment or not, it still comes back to me and I should not have been in that environment to begin with."

In these comments, none of the participants reveal animosity, hostility, or blame towards law enforcement officials. In fact, the attitudes conveyed are altogether positive, and reinforce personal accountability for wrongdoing. At the same time, both Andy and Ronald acknowledged unsavory aspects of their encounters with legal officials and law enforcement agents. Andy recounted, "One guy who was doing the paperwork really made me mad. It was my first time and he was berating me like, 'Oh yeah, I bet it is!' And it's like, 'It really genuinely is this time!' So it really made me mad. Ever since then I've kind of been angry...I was feeling bad, got caught, and was feeling like this is the end of the world, and he's over here making fun of me." Even as he spoke, an already restless Andy acknowledged feelings of renewed anger brought up by remembering his experience.

Ronald also alluded to shady law enforcement tactics in his personal account, saying, "I understand that they're bending the law to try to preserve life. You know now when I got caught I said, 'This is entrapment! And 'this is wrong!' But I understand that they've been allowed to go to the extreme measure, 'cuz you know, when I'm with a prostitute...I'm not considering how this is affecting the community, so they are trying to preserve life in their community."

In spite of their disapproving reactions to the ridiculing attitudes of law enforcement officials during arrest, participants simultaneously understood the reasons prompting official action. Even Ronald, who undermined the legitimacy of law enforcement tactics by claiming that police "bend the law to catch us any way they can," counterbalanced his unsavory interpretation 
of reverse sting operations with an overall understanding of the rationale behind enforcement. Again, a salient characteristic present amongst participants with shame-guilt was their ability to discharge resentment or animosity towards system officials while owning up to their own wrongful behavior. This stands in stark contrast to other participants, who believed themselves to be victims of shady investigative practices and groundless sanctioning measures.

\subsection{Reintegration}

A final aspect of the shame-guilt concept outlined in this paper is the extent to which offenders responded to the shaming tactics communicated within the program. To what extent did participants feel stigmatized, labeled, or judged? To what extent did they feel educated and restored? How can their overall impressions of shaming be characterized? At the same time, it is important to clarify that any apparent emotional reactions can only reflect the immediate feelings of participants following the john school program. Such sentiments could change over time after participants leave the program and resume their daily lives. Additionally, although measures were exercised to promote open and honest conversations between me as a female researcher and program participants, it is important to recognize the potential for participants to associate me with the program itself, thereby influencing them to modify their answers to reflect a more positive impression of the program or palpable sense of shame. On the other hand, participants may have found my presence as an invested listener helpful for confessions of guilt, declarations of anger, or other expressions of emotional discharge. Nonetheless, further research must be conducted to gauge the long-term emotional responses participants experience after undergoing the program. The sentiments that participants hold long after program completion may also indicate how effectively the john school elicits shame and deters participants from reoffending.

Each of the five participants experiencing shame-guilt addressed different impressions of shaming, as was conveyed through the design and information included within the john school program, as well as through the tone and content of individual presentations. Matt and Andy, for 
example, described hard-hitting presentations with harsher tones and more intensive critiques of participant behavior. For Matt, Antoinette Welch's assertive tone and graphic narratives created a strong impression of shaming - though not one that made him feel stigmatized, labeled, or outcast. During an individual interview, Matt called attention to Welch's approach, portraying her stern tone, yet also noting her emphasis on decisions, not personhoods: "The last lady that was here, she was just cut and dry, and she wasn't feeling sorry for anyone... 'You screw up you pay the piper!' 'I'm going to tell you exactly the way you screwed up, and face it! Quit being a baby!' That's the way she approached it. Some people might take that offensive, and others will just listen to it and run with it. I did it, I screwed up, you know, let's get it over with. But some of the information she was giving was really helpful." For Matt, the experience of being arrested and diverted to the NJS program was not a stigmatizing process, but a learning opportunity, which increased his awareness of phenomena like human trafficking. In reflection of his shaming impressions he remarked, "I think being stopped and arrested has made me more aware of being more responsible as a person and also maybe just looking and having my eyes open towards other individuals that I see out there and letting them know, to make them aware of that kind of situation too." Here, Matt seemingly reflects a healthy model of shame management in which he recognizes how his actions were dangerous and morally shameful, while understanding that his personhood is not under attack. Because of this, Matt exited the program without feeling confused, unjustly confronted, or stigmatized. Hence, the manner in which Matt interpreted shaming practices within the john school program influenced his capacity to arrive at shame-guilt.

Andy depicted a similar reaction to the shaming practices exercised during the john school program. While he admitted feeling sensitive to components of the Magdalene program presentation, he ultimately expressed feelings of restoration and de-labeling. During our conversation, Andy commented, "I'm glad she's better and all that stuff, but some of the remarks she said just stabbed and turned. And I'm like, 'That's not me!' So I'm trying not to take offense to it." While the shaming tactics utilized by this speaker clearly made him uncomfortable, they 
did not induce him to believe himself a victim of stigmatization. In fact, he ultimately concluded, "I guess they get it that we're not all evil, you know? That's good to know, honestly, when you're afraid that everybody who looks at you is thinking so." This was particularly significant for him, since he had earlier express grave concerns about being labeled, saying, "I don't want people I know to find out because it's embarrassing! I was out of my head and that's embarrassing. That's not who I am all the time but that's what you get labeled as! People, if they find that out about you, they'll label you that and you can never come back from it! Because it doesn't matter, even though you spend your whole life-you mess up one time, so...that would suck a lot."

Other participants, like Ronald, also appreciated the valuable information they learned in the program and commended presenters for their perspective. Smiling and clapping his hands together, Ronald declared, "I'm grateful for john school program—-that I was able to come here and not to jail. And then, I'm grateful to get the information because I didn't know I could be locked up...there's a lot of information I got today I didn't know." Ronald's gratitude for the existence of the john school program as an opportunity to avoid harsher penal measures was also reflected in statements Michael made, especially in reference to expungement. He states, "I'm grateful. Of course, I wouldn't want this on my record, but it is what it is and I've accepted it. But to be given an option to expunge it and put it behind me-I think that's nice." Here, he reiterates the significance of expungement, which not only allows offenders to clean up their criminal record, but also serves as a ritual for de-labeling. This process enables offenders to utilize the program as a means of receiving and subsequently discharging shame. For many participants, feelings of shame-guilt and embarrassment-exposure ceremonially ended with expungement.

Despite their universal acknowledgement of moral wrongdoing, as well as their altogether positive response to the reintegrative shaming tactics utilized in the john school program, Matt, Andy, and Daniel believed that stigmatization via popularized "shaming campaigns" directed against johns would be devastating and unfair. According to them, such 
tactics would create an unnecessary degree of personal destruction for otherwise respectable people, thus denying them opportunities to access supportive services that might help them to change their deviant behaviors. Shaking his head in disapproval, Matt comments, "I can only speak from my example, being as stupid as I was...But to have your picture in the paper or to have a letter sent to your house, or something like that, I think that would be devastating to that individual. Not only had that person been already embarrassed by being handcuffed and arrested, but he could lose the family, he could lose his job. I think that would be the wrong decision to be made." Andy, while also noting that his participation in commercial sex was wrong, seconds Matt's opinion regarding the excessive ruthlessness of shaming campaigns, exclaiming, "I made a mistake, yes, but I'm not a pedophile! I'm not peddling drugs, I 'm not killing anybody... I think if someone puts me away for ten years or something like that for that for my first offense ever...I think that's kind of going the wrong way to justice-that's kind of injustice. I mean, when I found out about this, it was a relief because it's a way for me to get this gone and learn from my mistakes."

For both Matt and Andy, harsh penal measures such as imprisonment, posting their pictures and identifying information on local news channels or in newspapers; sending letters to their spouses explaining the criminal offense; or confiscating property utilized to purchase prostitution are ramifications that do not consider the general decency of many first-time offenders. Participants like Matt, Andy, and Daniel anxiously identified all of the ways in which they lived normative, considerate, and stable lives-aside from a random behavioral fluke that was only prompted by extreme emotional distress. Imposing severe punishments that could destroy their interpersonal lives as well as jeopardize their professional lives would be going too far. Daniel also battles with this shaming approach, remarking, "Part of me says I think there should be a harsh penalty, but then another part of me, for people who are in my situation...outstanding citizen, never been arrested, never even had a speeding ticket, made one dumb decision in a severely depressed state, chemically-altered-I think there needs to be 
leniency on that, but then again, I don't know. I'm kind of conflicted on that." In cases such these, stigmatizing tactics run the risk of producing damning consequences for participants that may otherwise benefit from softer deterrence efforts. Rather than treat accountability and compassion as mutually exclusive crime control approaches, reintegrative shaming assumes that both elements can coexist within a single deterrence effort. Derri Smith of EST reiterates this notion, professing, "I just think, like all of us, we don't respond very well to somebody who we feel like is judging us, or if we respond better to someone that cares about us and really wants to help us. But that does not mean there is not accountability."

\section{Embarrassment-Exposure}

A second paradigm of emotional response to the shaming tactics exercised in the NJS is embarrassment-exposure. As previously mentioned, this emotional realm encapsulates a lack of consensus regarding the inherent immorality of prostitution; feelings of anger or hostility towards enforcement or sanctioning officials; feelings of humiliation due to the disapproval and criticism

of others; possible empathy for potential victims; and recognition of legal wrongdoing (but not an internal sentiment of moral violation). While this category represents a slippery middle ground between shame-guilt and unresolved shame, one participant from the NJS program, Rusty, embodied many of these characteristics.

\subsection{Lack of Consensus}

For Rusty, an aging army veteran with a thick moustache and heavy Southern drawl, prostitution is not necessarily an immoral vice, but rather, a public service. During an individual interview conducted on the steps outside the chapel, Rusty assumes a non-abolitionist perspective in which he promotes legalized prostitution as a legitimate care industry sector, commenting, "I think prostitution provides a service. I think there's a certain segment of society that that's the only place they're going to get it. You have people with handicaps and things of that 
nature...You should know in Germany, it's legal...I don't know in particular how their government managed it, but from a customer standpoint it was very clean and very orderly." $\mathrm{He}$ goes on to discuss the other advantages of legalization, explaining, "And then you have your perverts, your sickos, and I want them to have an outlet! I don't want them cruising the Kroger parking lot looking to grab somebody, because that person they grab is going to be our wives, our sisters, our daughters! I want them to know where they can go--a dark hotel somewhere, an empty house." Rusty further glorifies prostitution as a niche for "no strings attached" encounters, saying, "I've said for years...prostitution is the way to go! You go down to the house, pick the girl you want, tell them what you want, put your money down, you go in and get serviced, you walk out, she doesn't know your name, you don't know hers, there's no strings, no ties, no child support, no nothing! No alimony. You walk in, pay for what you want, walk out. But that's very simplistic." In this sense, Rusty does not share consensus regarding the inherent immorality of prostitution, nor does he maintain a viewpoint deeming it unhealthy, harmful, or pathological. In contrast, Rusty argues that prostitution could be legitimized and government-regulated, thereby enabling it to provide important social and relational services. His belief in the benefits of commercial sex, render him incapable of believing himself to have committed moral or ethical wrongdoing. For this reason, Rusty does not convey feelings of shame-guilt for his offense.

\subsection{Understanding of Information}

Another dimension that forms emotional response is the extent to which participants understand the information presented within the program, as well as the underlying rationale for sanctioning and enforcing prostitution. While Rusty comprehended the element of danger present in commercial sex transactions, he also appeared dubious about other program components, such as sexual addiction, questioning, "Where does the addiction start and where does normal end?" He proceeds to explain that "God intended for us to be attracted to male and female and so on, and certainly I appreciate a pretty young lady. But that doesn't mean that every time I see a 
pretty young lady I think, 'Oh I well I'd like to get in her pants.' I can admire a pretty young lady just being a pretty young lady, and I'm attracted to that." Nodding in my direction, he confessed, "I'm attracted to you, but it's enough to sit here and smile and talk to you and spend time with you in that way. And that's not sex, and I don't think that makes me a sex addict. So I would be more inclined to say, no - that the sex addiction crap is - like all men and all women have sex drives. It's—-do you have the discipline and the control?" Here, Rusty apparently struggles to define a boundary between a normative sex drive and a legitimate loss of self-control. Harkening back to his support of legalization, Rusty normalizes expressions of human sexuality and resists framing them in ways that may render them pathological or unhealthy. Again, his firmly rooted belief in the innocuous and normative nature of prostitution interferes with his ability to experience shame-guilt.

\subsection{Hostility}

In contrast to participants that experienced shame-guilt, Rusty maintained that law enforcement officials had unfairly lured him into his arrest. During our conversation, Rusty highlighted how he had been utterly blindsided by arrest officials while approaching a potential sexual service provider. He explained, "I thought for a number of years that if police did a sting, a lot of times the police decoy looks so good that guys that don't normally stop for street prostitution...I have to wonder if perhaps they weren't maybe caused to be inclined to make that choice...I'll say I did it, but I didn't think that was probably above board and fair." Here, Rusty implies that law enforcement officers intentionally position good-looking officers as prostitution decoys in order to tempt innocent passersby to purchase prostitution-even if such men had no prior intent to engage in commercial sex. As such, he admits to having committed an illegal action, but also conceptualizes himself as a victim of law enforcement trickery. Unlike his john school counterparts, who prevented their resentment of law enforcement encounters to hinder feelings of profound remorse, Rusty only expresses feeling embarrassed and exposed. $\mathrm{He}$ 
reveals, “This is the first time I've ever been arrested, and uh, the embarrassment, the humiliation, is very punitive. And it's not necessarily the fact that somebody knows, it's the fact that I think everybody knows, or I wonder, 'well does he know or she know?' And so, you watch yourself." Here Rusty's reaction reflects key elements associated with embarrassment-exposure, such as concern over criticism or disapproval from others, feeling uncomfortable as an object of shaming, and humiliation due to exposure. However, these emotions emerge from a response to external forces of shaming, not a violation of his own moral conscience. This response is reaffirmed when Rusty discusses the deterrent effect that he experienced from the john school program: "If I'm driving down the street and I see somebody on the side of the road...I'm going to have to have to think, 'okay, you know you screw up and you get one too young, you're going to end up on the sex offender registry or federal appearance!' So that's what I'll have to do...what we call 'behavior modification,' where if the pain is severe enough, the behavior will change." While Rusty admitted to feeling fear for the potential repercussions of reoffending, at no point did moral or ethical beliefs enter into his explanation of deterrence. Unlike participants that experienced shame-guilt, Rusty was not seemingly deterred by the notion that his commercial sex practices might be harmful, unhealthy, or immoral. Instead, he described a reductionist cost-benefit analysis in which the threat of harsher penal measures outweighed the benefits of purchasing prostitution. While Rusty's rationale does satisfy the objectives of deterrence theory, it does not satisfy Braithwaite's idealized model of shame management in which offenders recalibrate their moral consciences and refrain from behaviors that violate them.

\subsection{Empathy}

A final element of embarrassment-exposure, salient in Rusty's experience, was his expression of empathy towards prostitutes. While Rusty did not conceptualize his wrongdoing as immoral (only illegal), he acknowledged a transition in his mentality towards prostitutes. At the same time, his sympathy and increased understanding for prostitutes did not induce him to 
consider his own actions as immoral or harmful. Conversely, participants categorized under the shame-guilt paradigm linked their participation in sexual commerce with support for human trafficking — an association that compounded feelings of shame-guilt for some. As such, the extent to which empathy impacted individual constructions of behavior creates another distinction between shame-guilt and embarrassment-exposure.

\section{Unresolved Shame}

The final paradigm of emotional response to shaming is unresolved shame. As previously explained, this category captures participants that do not necessarily conceptualize prostitution as immoral, unhealthy, harmful, or even dangerous. It also includes those that express hostility and resentment towards enforcement or sanctioning officials, a lack of understanding regarding information presented in the john school program, and therefore, indecision regarding their culpability or moral ineptitude. Out of the ten participants that consented to individual interviews, two participants, DeShawn and Craig, identified closely with these characteristics.

\subsection{Lack of Consensus}

Both DeShawn and Craig discussed the issue of prostitution, dismissing conceptualizations of it as immoral, unhealthy, or unsafe. In our interview, DeShawn discusses his apathetic, yet normalizing views on prostitution, claiming, "If somebody want to buy them a little girl for the night, as long as it's not a child, or you're not forced into it, I don't really care... You got a hard-working man, and he ain't got no woman, so later, that urge is going to come up. It might be today, tomorrow, you know? We are human, we do have the nature, so you might want to go out and pick up a girl and just have a coffee." As such, DeShawn normalizes prostitution as an extension of general gender relations. He also detaches himself from this statement, instead referring to "somebody," or "they" as the active agents. For him, prostitution 
is a natural and innocuous occurrence, justifiable for "hard-working" men that opt to act out on their carnal urges. This position directly opposes that of the shame-guilt paradigm, which perceives prostitution as immoral, unhealthy, and dangerous.

Craig also expresses a tolerant and normalizing opinion of prostitution, even referencing historical precedent and widespread social support for its existence.

That's like me asking to wash your car, you know? We're two consenting adults. You pay me cash to wash your car...I have to use my body to wash your car. I mean, I could develop carpal tunnel from it. I mean, yes, you could do sexually transmitted disease, but also you could take precautions to not do that and be tested if you was going to participate in that. Just like, if I was going to paint your car, I'd have to go to school for that. Just the same way if you're going to be a prostitute, you have to get checked every so often, and if you're going to be a john, or whatever it's classified as, you should get tested. That's just common courtesy and protects yourself... You know, it's wrong to a certain degree, but it's the oldest biblical job, even back before Christ types. There's stone ages-I mean the history channel has documentations about it - and there's stone buildings or however you lived back then, about where her bed would be.

Craig likens commercial sex transactions to any other commoditized exchange, thus aligning his views with those of pro-sex work advocates. Though he identifies prostitution as "wrong to a certain degree," he immediately points out its long-standing existence in society. This may indicate uncertainty as to how wrong he considers his own offense, or to what extent it can be normalized or justified. At another point, he refers to the Constitution, implying that laws prohibiting patronizing prostitution violate the rights it establishes. Here he searches for a framework that substantiates sexual commerce as normative and unfaultable, claiming, "I'm kind of a believer in Constitutional amendments about the-I can't remember which one it is—but like the bear arms and stuff. You have to fight for that! And you have to fight for freedom of speech and everything! Just two consenting adults, you know? Getting together...I guess almost like buying a car or something, or renting a car, I mean, whatever you want the purpose of the vehicle to be." While Craig normalizes his participation in prostitution through historical precedent and 
Constitutional provisions, he also identifies it as "wrong to a certain degree," yet struggles to pinpoint how wrong. His wavering viewpoint between conceptualizations of prostitution as right or wrong illustrates a key dynamic of unresolved shame in this study.

\subsection{Understanding of Information}

A prominent component of unresolved shame, which surfaced during individual interviews with both Craig and DeShawn, was a blatant miscomprehension of basic information presented within the john school program. This included misunderstandings of prostitution laws (or the legal system in general), confusion about information from the human trafficking presentation, and most importantly, misinterpretations about the danger associated with patronizing prostitution. Whether these participants allowed their preconceived ideologies to hinder their comprehension during the NJS, or whether they simply did not understand the information presented, both exited the program with a lack of clarity or accurate understanding. This may have influenced their incapacity to feel genuine shame for their supposedly deviant behavior.

For DeShawn, the most significant lack of understanding arose around legal culpability. Part of his misunderstanding stemmed from the circumstances of his arrest. Unlike the participants previously discussed, he was arrested alongside a buddy from work. Throughout the john school program and subsequent interview, he resolutely insisted that it was his friend—not him—who had patronized prostitution. He described his arrest, explaining that law enforcement coerced him into admitting culpability: “They said, 'We've got ya'll for solicitation of prostitution, ya'll offered \$20.' I said, 'there was no money talked about when I was in the car.' Now, when I got out of the car I didn't know what they was talking about then because I wasn't even facing them. 'Yeah, I got ya'll...blah blah,' I said, 'naw, you didn't get me!' So he said, 'if you don't admit to this prostitution we're going to take you to jail!' In his narration of events, DeShawn balks at the idea that he violated prostitution laws, since "there was not money talked 
about" in his presence. Presumably, his friend negotiated logistics with the prostitute while he was inside purchasing pizza. However, DeShawn's interpretation of Tennessee laws against patronizing prostitution demonstrate a poor grasp of information presented within the NJS. In fact, both Rachel Thompson and Antoinette Welch specifically address how easy it can be to arrest and prosecute someone on prostitution charges, given how liberally prostitution laws define "intent." Both presenters review examples in which individuals simply conversed with a "known prostitute" in areas of town notorious for illicit commercial sexual activity, pointing out how such practices legitimately qualify as "intent." Welch and Thompson reiterate that demonstrating a person's "intent" is the only grounds necessary for making an arrest—not negotiating a price. In spite of the ADA's detailed explanation of patronizing, DeShawn denied any legal or moral wrongdoing, thus indicating confusion regarding basic information presented within the john school program.

Craig also demonstrated a misunderstanding of program information. To begin with, he conceptualizes the Internet as a lawless frontier in which conventional legislation does not apply. During the interview, he distinguished between prostitution laws and "Internet laws," claiming, “I guess it goes back to internet law. There's really no laws on the internet...I wasn't really aware of the prostitution laws...If you was two consenting adults, then that was not against the law really_it was almost like meeting someone at a club...or you've got match.com or whatever...If there's no law on the internet, why can you charge someone by posting information on it?" Here, Craig questions how commercial sex transactions differ much from other types of sexual relationships outside of "the market." While this may be a valid point, he clearly misunderstands how laws $d o$ function on the Internet, and therefore, how his own patronizing activities could be considered illegal. Like DeShawn, Craig's misinterpretation of prostitution laws inhibits his ability to conceptualize his behavior as illegal, let alone morally wrong. Compounding this disconnect were his responses to the human trafficking presentation: "I really don't agree with human trafficking...It almost consists of a mail order bride if you think about it, but I mean, 
they're thinking, 'We'll get over here and get a citizenship, I guess, and then...we're in this country legally!' But I'm assuming it's not real big here... I've visited Michigan and Ohio and stuff like that in the northern states where it seems to snow a lot, and it seems like mail order brides is a big thing." As such, Craig paints a picture of human trafficking as an issue concerning foreign nationals seeking citizenship—namely, mail-order brides. He dismisses this phenomenon as "not real big," given the warmer climate in Nashville, which would not be attractive or suitable to mail-order brides. Here, Craig's understanding of trafficking does not reflect the information presented during the EST presentation, in which both international and domestic cases are represented. He also pigeonholes human trafficking cases into that of a mail-order bride syndrome, disregarding other types of cases discussed during NJS. While he opposes human trafficking, he does not make the desired connection between his behavior as a buyer, and the potential for buying into sexual exploitation. When questioned about this potential linkage, Craig responded, "It takes a sick, twisted individual to have sex with a child, it really does. I mean, I've served time in jail and the cho-mos always caught hell, and I always made sure they caught it from me, because I have a little brother and...I would go nuts if somebody wants to kidnap my little brother or something, or any kid...that's just wrong! It's morally wrong, and I don't know what has got us to that point." Thus, Craig expresses a similar misunderstanding to that of Michael, believing that human trafficking necessarily entails interactions with minors. While Craig responds to the thought of child sexual abuse with moral indignation, he also demonstrates a lack of understanding about the definition of human trafficking and the breadth of cases it may encompass. This also may have influenced his inability to connect his commercial sex practices with his potential involvement in human trafficking, thus defying the main objective of EST's presentation.

Most importantly, Craig also reveals a misunderstanding of the connection between patronizing prostitution and risk-taking. While he does acknowledge the presence of certain safety perils for buyers, he also believes that many risks can be adequately managed by choosing 
"higher-class" prostitution venues, "reading people" efficiently, and involving the government in the overall regulation of prostitution.

With respect to the dangers of prostitution, Craig commented, "You always hear about girls rolling guys. And, you know, you could always have a pimp or something in the bathroom or in the room next door, and come in and, you know, grab you and mug you, and whatever, kill you...so I guess without a controlled environment it is dangerous." When asked to clarify what he meant by a "controlled environment," Craig referred to legalized cat houses in Nevada that utilize cameras to monitor sexual transactions on their premises. Like other proponents of legalization, Craig believed that government-regulated sexual service venues would reduce risks for both buyers and providers. At the same time, Craig did not discuss how to fully insulate himself from the dangers he mentioned under a legal framework that criminalizes prostitution.

During our conversation, Craig outlined the reasons that he preferred to pursue indoor sexual service venues, especially those negotiated through the Internet. He indicated that health, safety, and even human trafficking risks could be largely avoided by using a "higher-class" escort agency, for example: "I mean, streetwalkers is usually the drug-addicted ones, or the not-so -likeyourself. You're a high-class lady...they're different-class ladies...They look different, they present themselves different... No one wants to go to a streetwalker because they're usually...crackheads and stuff. I mean, they're going through a very bad time in their life....and sometimes slavery, like they was talking about."

At a later point, Craig also disclosed his strategy for inconspicuously arranging commercial sex transactions without law enforcement detection: utilizing the Internet. For him, this provided a shield of anonymity and secrecy that street-based transactions could not. He explained, "I mean, if you're a streetwalker or whatever, you've got people that pass by-they can see what you're doing! I mean it doesn't take a genius to see, 'Hey! He's fixing to duhdaduhdaduh!'” 
In both of these instances, Craig affirms his preference for indoor sexual service venues, or sexual service transactions arranged through "less monitored" websites. Despite the risk deterrence education propagated during the john school program, or the fact that he was arrested in spite of his risk avoidance strategies, Craig exited the program with the belief that prostitution perils could be avoided. If one is careful to choose the appropriate sexual service venue, he can circumvent law enforcement detection or the possibility of contracting venereal diseases.

Additionally, Craig explains that by studying facial expressions, a potential buyer can "read" whether or not someone is being trafficked: "That's an old military tactic. You can learn a lot by looking in someone's eyes. You can tell if they're saying, 'Help me!' Or, 'I'm being forced to do this,' or they're under the influence of something — anything....and I've never —well I can't say never-I don't feel like I've participated with someone that was doing it unwillingly...I would...never buy from someone who's forced." Thus, he also communicates a misinterpretation of the information presented during the EST presentation. Instead of grasping the true take-away of the human trafficking discussion — that consumers may not be able to accurately distinguish a human trafficking victim from a prostitute-Craig infers that properly studying body language can definitively differentiate one from the other.

Overall, both Craig and DeShawn demonstrate gaps in their comprehension of basic information presented within the john school. While disparities between their understanding and program information may represent a denial to modify preconceived notions about prostitution laws, STD contraction, human trafficking, or general risk avoidance, both participants displaced their confusion into indecisiveness and anger. For this reason, they exemplify the tenets of unresolved shame.

\subsection{Indecision Regarding Wrongdoing}

A telltale attribute of unresolved shame is the uncertainty offenders feel in determining whether their actions are right or wrong. According to Harris (Ahmed et al. 2001), this indecision 
can spiral into hostility or anger, often directed towards sanctioning and enforcement officials. For DeShawn and Craig, this inconclusiveness resulted in increased hostility towards law enforcement and the government in general.

When DeShawn recounted the events that led up to his arrest, he portrayed two arrest officers: one that appeared anxious to arrest him and send him to jail, and another who encouraged him to admit culpability and receive a citation for court-rather than go directly to jail. Narrating the dialogue between himself and one of the officers that night, he recounts, "This big old black guy come and sit down beside me...He said, 'Dude, I'm going to tell you, he going to take you to jail, I done seen it all night! He done messed with eight people the same way.' Basically, that other officer told me he was going to force me to do it...So that's how it happened." Here, DeShawn depicts himself as the victim of coercive enforcement tactics. While DeShawn believed himself to be innocent, he admitted culpability to avoid going to jail and potentially missing work. His impression of events prompted resentment and anger towards law enforcement, and convinced him that he had been entrapped. In a later portion of the interview, DeShawn describes his overall views of law enforcement, claiming, "Well, you got the good and the bad. You got some on the up and up you got some that's criminals and I don't know what! Like the dude who was pushing me into- that was bullshit! I could have lost my job, my wife, my family, everything!" He then declared, "I was entrapped! That's the honest truth! I'm sitting here in church and I'm telling you the truth! I was entrapped! But...like the officer sitting beside me said, 'Man, if you don't say 'yeah' we gonna take you to jail.' He said, 'I'm sorry 'cuz they're telling me to tell you that. You tell them you did it."” In these excerpts, DeShawn appears convinced of his legal and moral innocence.

However, later comments suggest mixed emotions regarding the shamefulness of his behavior: "It's dumb...I don't want my kids to even know about it, especially my wife, but eventually I sat down and told her...I was sorry, and I told her it would never happen again, and that's the truth! Well, she said she's forgiven me and she trusts me but time will tell...you know? 
I'm disgusted by what the kids will think because I don't want them to be involved in that part." In this segment, DeShawn mentions apologizing to his wife, asking for her forgiveness, and worrying about what his children will think. Such concerns for criticism and exposure, along with promises that 'it will never happen again,' challenge DeShawn's adamant declaration of innocence. His apparent indecisiveness between considerations of his behavior as right or wrong, encapsulates a fundamental component of unresolved shame.

Craig also illustrates contradictory constructions of his behavior. On the one hand, he adheres to the belief that conventional legislation does not apply to Internet-based activities. As such, his participation in commercial sex cannot be construed as illegal. On the other hand, he does acknowledge his own "intent," and therefore how his actions could go against patronizing laws. During our conversation, Craig struggles to define whether he believes that he was entrapped or not, musing, "I guess I'm kind of in the middle, because I don't guess it's classified as entrapment after the lady read off the entrapment law, because you have to be unwilling. I mean, I was willing and so was she, you know, so that got us out of the loophole there." Craig's mixed emotions about entrapment escalated into feelings of anger towards law enforcement agents, as well as towards the government. Even alluding to Mafia-like conspiracies, he claimed, “There's corruption in the mob—-they're still handling everything... But law enforcement... shouldn't do the same wrong they arrest people for doing, because 90 percent of the law enforcement these days, it seems like they do the same thing, they just don't get caught! Or they have the badge to get them out of it."

Craig's belief that enforcement and sanctioning officials are generally corrupt, conspiring, and hypocritical, demonstrates how uncertainty about his own culpability gave rise to hostility. This response is consistent with Harris' (Ahmed et al. 2001) notion that confusion interferes with the capacity to discharge shame, thereby displacing it into anger. This emotional response starkly contrasts that of shame-guilt, in which offenders recognize their own legal and 
moral culpability while expressing minimal resentment towards sanctioning or enforcement officials.

\subsection{Empathy}

A final characteristic of unresolved shame is the concept of empathy. Like other categories of emotional response, participants with unresolved shame expressed varying degrees of empathy for others. While both Craig and DeShawn empathized with sexually abused children, neither one admitted to feelings of sympathy for prostitutes. As was previously mentioned in this study, DeShawn acknowledged "not caring" whether or not others chose to prostitute. Craig, on the other hand, claimed to have experienced negative emotions in the past, but not necessarily pity or consideration for prostitutes. He recalls, "Before I would have this bad feeling afterwards. I mean, it's just like, (sigh) I don't know how to describe it, you just have a bad feeling. It's almost like unsatisfied, or dirty-feeling I guess, or something." In his account, however, the "bad feeling" that accompanied sexual commerce was not one of sympathy, pity, or compassion for prostitutes, potential human trafficking victims, or community members. At no point does Craig express empathy for any of these parties, thus implying a lack of acknowledgement of the potential suffering his behavior may cause others. While consistent with his conceptualizations of sexual commerce as innocuous and justifiable, Craig's overall lack of empathy indicates a lack of recognition of wrongdoing. For John Braithwaite (Ahmed et al. 2001), this unresolved shame increases the possibility for reoffending or entering a deviant subculture.

\section{Shaming and Space}

So far this study has examined the emotional responses of eight john school participants to shaming tactics utilized by program presenters. A more implicit shaming factor that emerged during individual conversations with participants was the space in which the john school program 
was held. Given that the program takes place within the sanctuary of a church, the subtle dynamics of the space carry mixed messages of shaming, forgiveness, visibility, and anonymity for program participants. Such messages worked to both enhance and counteract the restorative, reintegrative shaming objectives of the john school.

According to one faction of participants, St. Ann's Episcopal Church augmented the reintegrative shaming strategy utilized by program presenters. Such participants pointed to the embedded meaning of the space as a place for introspection, reflection, and repentance. Michael, for example, commented, "I think it helps as far as we all need to just sit back and look deep within ourselves and just understand that...look where we are and why we're here, and...I guess just look deep within ourselves and just understand that we should be grateful. And if we truly believe that there is a God, then we need to smile and accept this - this offer of having our record expunged." Daniel seconds this opinion, also noting the subtle implications of the space as one that encourages self-examination, yet acceptance. He also highlights the insulation it offers from public speculation, given its unassuming presence in the community: "There's definitely that whole thought process when you just see where it's at... you automatically start going 'Okay, let me reevaluate some things that are going on in my life,' because unfortunately most people equate church and religion with what's going wrong with your life and how to fix it." Daniel continues, saying, "I definitely think that a church would probably be one of the most nonintrusive ways of handling something along these lines...People drive by and see cars in front of church, they're not really going to think much about it, or if they see you walking out of a church they are not really going to think much about it."

Craig also comments on the benefits of hosting the john school program in a church, yet reveals animosity towards guilty legislators that are not subjected to similar judgments as program participants: "It seems very interesting to be in a church...I believe in God. I actually think it's very suitable, I just wish the legislators and stuff would believe more in God and stuff and what to do, because, you know, they write these laws and then they think, you know, the 
master of the plan, they got to go write laws that are harsh and stuff." In Craig's case, the judgmental connotation of the church building reiterated the unfair treatment he had received within the criminal justice system, thus prompting feelings of unresolved shame to resurface.

On the other hand, some participants believed the church sanctuary to be an inappropriate, even hypocritical space for the NJS program. For Andy, hosting the program in a religious space brought to mind the Church's notorious problems with sexual abuse perpetrated by priests. He, like Matt, also problematized the usage of vulgar language within the church, identifying Kenny Baker's occasional cussing as disrespectful to the space. According to Andy in an individual interview, "I can see why they chose a church, but coming in someone made a crack about how it's a Catholic church, or they thought it was a Catholic church, and they'rehad their issues with sex, so it's like kind of a weird place to do it. I understand it's a community thing so let's host it here, and it doesn't bother me in a way. It still feels weird when he [Kenneth Baker] cusses in it."

Matt also discusses the usage of vulgar and sexual language in general, claiming, "I mean, it's hard to sit here and listen to people cuss and also, even talk about sex, like the gentleman across from me talking about blow jobs. You know, you're here for that...but, you know, it's still a little offensive to be in this setting." For both Matt and Andy, the space represented specific connotations that seemingly negated the objectives of the program. While Matt could not fathom hosting graphic, vulgar, or sexual discussions within a religious space, Andy associated the Church with hypocritical sexual offenses. Although the negative or problematic implications of attending the john school program within a church building may not have interfered with overall feelings of shame-guilt, the special meanings embedded within the space do bear significance in the overall impressions of the NJS.

\section{Exceptions to the Shaming Paradigm}


Out of the ten participants that consented to individual interviews, eight embodied various paradigms of emotional response, even though such categorizations proved problematic at times. However, due to the particular circumstances of their respective cases, two of these participants did not identify with responses of shame-guilt, embarrassment-exposure, or unresolved shame. These outliers give insight about potential idiosyncrasies within the crime control system, thus raising important questions about who gets arrested and how arrestees are diverted.

The first exceptional case was that of Janice, a transgender participant that had been diverted to the john school program after being arrested for solicitation of prostitution. In recounting the events that led to her arrest, she explained that an undercover officer had responded to an ad that she had placed on the Internet, advertising her services as a "paid girlfriend." Janice clarified that she was not a prostitute, but did accept money from men that wanted to spend time with her socially. She then described the conversation that occurred via text message between her and the prospective "customer," claiming that while she never offered herself sexually, "the wrong words were exchanged." Janice's story culminated with "a stampede of undercover cops" banging on her door and subsequently arresting her for solicitation of prostitution. In the aftermath of her arrest, Janice expressed confusion at having been diverted to the NJS program instead of a parallel program for those with solicitation charges, known as the Hannah Project. During our conversation, she concluded that enforcement and sanctioning officials made incorrect assumptions about her gender, thus assigning her to the "men's program." For Janice, this mix-up typified the discrimination she regularly underwent as a transgender individual. In spite of this fact, she provided positive feedback about the program in general, affirming that "it should be an eye-opener or an awakening for the men...so they know what's going on - that they could catch something, that they can get hurt or all that stuff that goes on, like the sex trafficking and everything. I mean, it's a pretty good program...everything's point on. I don't see anything in the program that's misguided or misleading or isn't true. It's all 
true.” Nonetheless, Janice's unusual placement in the john school program reveals potential flaws in appropriate sanctioning and enforcement, and perhaps, systemic gender stereotyping that essentializes patronizing as a male activity and solicitation as female.

A second exception to the shame paradigm is the case of Jeremy, a john school participant that also claimed innocence. In his account of the events leading up to his arrest, Jeremy recounted accepting a ride from an acquaintance so that he could check on his car at the auto shop. While in transit, an undercover cop approached the vehicle and began conversing with Jeremy's friend. Jeremy, on the other hand, claimed to remain silent, despite his personal objections to what was transpiring. In the end, both Jeremy and his friend were arrested for patronizing prostitution, even though only one of their voices was captured on the tape recording law enforcement presented to court. Though Jeremy vows that he had no direct interaction with the "prostitute," he understands how his presence within the vehicle may have been construed as intent to patronize.

Although Jeremy's account may not accurately depict the details of his arrest, a similar situation could transpire, given the relative ease with which intent can be proven. Jeremy's presence in an area of Nashville notorious for prostitution, alongside a friend with clear-cut motives to patronize could easily be construed as an expression of his intent to patronize. While Jeremy fully comprehended this fact, he also denied having participated in sexual commerce in the same capacity as other program participants. Because of his detachment from the crime itself, Jeremy did not experience an emotional response that fit within any of the aforementioned paradigms. For example, though he acknowledged wrongdoing for his actions, this wrongdoing was not linked to the actual crime of patronizing. Instead, Jeremy labeled himself "guilty by association," contending, "I don't really feel like I solicited, but I'm just as guilty because I was there and didn't tell him to stop doing it, and I didn't tell him to pull off... so I was guilty...I pretty much knew she was a cop... and I'm like, 'I know she's not having this conversation!' But I didn't think they was gonna bring ME down 'cuz he was the one." 
In spite of his admission of guilt for not exiting that car as soon as he realized what was occurring, Jeremy did not experience the same type of shame-guilt as participants in the program who had directly patronized prostitution. Though Jeremy did express consensus for conceptualizations of prostitution as morally wrong; high degrees of empathy for prostitutes, human trafficking victims, and vulnerable females in general; a complete lack of animosity towards sanctioning and enforcement officials; and an overall positive attitude towards the john school program that had allegedly inspired him to become an advocate for human trafficking victims, his case does not adequately encapsulate the sentiments underlying shame-guilt. Though Jeremy comprehended how his actions were construed as illegal, he did not communicate feelings of embarrassment, exposure, shame, guilt, regret, remorse, or anger at self. Instead, he approached his placement in the john school program as erroneous, yet constructive in that it enabled him to absorb material that he could utilize to parent his daughters more effectively. In the following excerpt, Jeremy discusses that "takeaways" from the john school program: “I'll never ride with nobody else but myself and my family. You know, if it ain't my family, then I don't want to do it...I give my daughters the world...I also tell my daughters, 'Learn how to depend on yourself and don't have to depend on no man, or don't have to depend on nobody to get anything for you because when you start to depend on other folks you start doing things you don't want to do to get it.",

For Jeremy, the program served an applicable purpose for him as a father, though not as an individual that had directly engaged in sexual commerce. As such, the messages he gleaned from the program, as well as his emotional response to it, strayed slightly from what the program hopes to elicit.

Both Janice's and Jeremy's cases represented interesting examples of potential program misfits. While Janice was completely misdirected by the court system (perhaps due to wrongful assumptions about her gender), Jeremy's supposedly indirect involvement in patronizing prostitution rendered the program's shaming efforts irrelevant. For this reason, neither participant 
experienced feelings of shame-guilt for their respective behaviors, despite an altogether positive outlook on the john school program. 


\section{CONCLUSION}

In light of the controversial space it occupies between non abolitionist and neoabolitionist ideals; draconian penal tactics and restorative justice measures; and historical versus contemporary frameworks to manage "immorality," public health, and safety, the NJS program assumes a challenging undertaking. Its goal to recalibrate moral consciousness through deterrence education and reintegrative shaming, thereby constructing and reproducing societal conceptualizations of prostitution as morally wrong and socially pathological, challenges dominant constructions of masculine sexuality. For many program participants, undergoing punishment for patronizing prostitution called more into question than their sexual tendencies. Rather, it contested their coping methods, relational skills, and restoration of positive selfconcepts. On an even deeper level, it challenged socially informed ideologies of heterosexual male identity. This impact becomes apparent when reviewing participants' self-proclaimed motivations for engaging in sexual commerce through which underlying ideologies surface.

For Matt, Andy, and Daniel, the idea to purchase illicit sexual services emerged from temporary "derangement," in which insurmountable life circumstances and escalated stress levels prevailed over solid decision-making. All three participants recounted difficult life events, such as the loss of an intimate partner, medical issues, and/or loss of employment as incidents that preceded their participation and subsequent arrests. In the wake of such personal tragedies, participants acknowledged feelings of powerlessness, emasculation, and "unconsciousness." In these instances, illicit sex became a coping mechanism. Matt, for example, describes his 
motivations, claiming, "I felt sorry for myself because I was lonely sometimes. My wife was just in the hospital, and I think it was a downer for me in the last two months, her being in the hospital and different things, and I just made a decision, well, maybe, to stop and ask, and if they say 'no', boom!"

Andy also explains the rationale behind his decision to engage in sexual commerce as well as his decision to opt out of legal therapeutic services. "A lot of people don't feel like they're in control of part of their life, which is probably why I did it! I was losing control with everything I had... I just wanted the...relief... Counseling has its own little stigma on it...we think, 'Counseling? That's for wackos!' And then...I was a wacko for thinking I could get counseling from someone I was going to pay...Maybe I just wanted to feel like a man.” Andy mentions his feeling of powerlessness, and his desire to assert control over his circumstances. Rather than seek legal talk therapy avenues, which could construct him as a "wacko," Andy pursues a more "masculine" venue. His remark sheds light on the role that individual perceptions of masculinity played in prompting and conceptualizing participation in commercial sex. Perhaps for some participants, like Andy, the sex industry provides a "manly" forum through which to cope with emotional trauma.

Daniel also reflects on his mentality while purchasing sexual services. Like other participants, he describes himself as oblivious and insensible, making decisions from a state of comatose:"Maybe unconsciously, I mean, I think I was just in that stage where I was just trying to-- getting some normalcy back to my old self, and for whatever stupid reason that I had at that time, that seemed like the way to go and it clearly wasn't, so... I actually think I'm in, you know, a little bit more of a spot now to where I can cope with it a little bit better than what I did."

Matt's, Andy's, and Daniel's reflections indicate how the act of purchasing sexual services, though supposedly out of character for each of them, served as a coping mechanism for tragic life events. While all three participants claimed to have chosen this option out of haste, 
depression, or thoughtlessness, paid sexual gratification appealed to their desires to restore a happier, more powerful, or more masculine self-concept.

Other participants, like Rusty and Craig, mentioned their woes with relationship-building. For these individuals, relationships are scary, complicated, and ultimately futile endeavors given the complex web of social politics one must navigate in order to maintain healthy interactions. Consequently, prostitution provided a clear-cut, "no strings attached" system by which they could reap certain benefits without having to negotiate convoluted social conventions. Rusty, for example, discusses how bad relationship experiences have informed his decision to engage in prostitution. He explains, “Well, I got divorced probably...six or seven years ago, and I haven't really dated since, and it's a situation where every time I think about asking somebody out, I start thinking about all of the confrontations, all the headaches and all the strings, and it just-I run from it; it turns me off. I'm still attracted to women, but...getting involved, it's just a total turnoff without question.”

Craig builds upon this topic, describing how exhausting it is to navigate social convention before reaping the sexual benefits of a relationship: "If I met you at the gas station...I would have to read your body language, if you was attracted to me, or if I was attracted to you, then we would have to exchange contact information...And then you go out and you've got to fight off the sweaty hands and nervousness and everything like that and have dinner...It just takes it out and it's just like you ordering your cable."

For both Rusty and Craig, the sex industry provides a handy outlet for circumventing the confusion and annoyances that come with relationships. Rather than improving their respective abilities to read social cues or negotiate social conventions, both participants preferred the straightforwardness and consistency of prostitution. Hence, prostitution offers a reliable channel through which individuals can theoretically relate to each other in predictable and mutually beneficial ways. 
In spite of the varying rationale that motivates participants to engage in illicit sexual commerce, the NJS program challenges johns to operate differently and to think differently. For program participants, like the ones in this study, this not only calls for a transformation of their sexual habits, but also a modification of their coping methods, relational skills, and techniques for reaffirming a positive self-concept. On a broader spectrum, the NJS also questions dominant tenets of male sexuality perpetuated through socialization and internalized by individual participants. According to Annie Potts dominant Western conceptualizations of masculinity hold that men possess two selves: the external, corporal self, and the internal, cerebral self. Potts refers to this bifurcation as the inside/outside dichotomy, noting how men's "external" selves, symbolized by the penis, exist outside of their conscious control. Because the penis-self acts as its own entity separate from men's internal, cognitive self, men become detached from the sexual actions of their own bodies (2001:145). Though Potts understands that not all men adhere to this dichotomy, she grounds her framework in texts extracted from popular media material, as well as interviews with men and women regarding their notions of heterosexual health, safe sex practices, and male sexuality (ibid:145). In reviewing these popular conceptualizations of masculine sexuality, she concludes,

Men tend to distance themselves from the behaviors of their bodies during sex. In this way, they may also exonerate themselves from responsibility in sexual matters. In a complex synecdochical relationship between man and penis - through the personification of the penis - the attitudes and behaviours of the penis-self are depicted as distinct from, and in opposition to, the conscious rational self-control of the man. This permits individual men to employ the penis-self as a disclaimer, in the flesh, for riskier heterosexual practices and heterosexual coercion (ibid:154).

What Potts observes in her study is how the external penis-self overtakes the internal rational self, thereby making decisions over which the internal self has no control or responsibility. This popular Western conception of male sexuality as bifurcated by an inside/outside dichotomy is mirrored within the NJS. On the one hand, participants in this study 
often characterized their decision-making as "insane," "unconscious," or otherwise guided by overwhelming emotional instability, thus employing a discourse that disconnects the actions of their penis-self with those of their internal "cognitive" self. Participants that experienced feelings of shame-guilt were those that allowed their cognitive self to assume accountability for the actions committed by their penis-self. In so doing, participants united these disparate identities, thus creating a holistic self-concept. On the other hand, participants that adhered to these identity binaries as normative expressions of male sexuality rebelled against constructions of their actions as wrongful. As such, the NJS program not only challenges participants to develop better relational skills, coping techniques, and conceptualizations of masculine sexuality, but also asks them to develop self-concepts that confront dominant tenets of gender socialization ingrained within Western culture. For this reason, the NJS program aids in constructing and reproducing ideologies that uphold patronizing prostitution as morally wrong, unhealthy, and dangerous.

Although the program urges participants to modify the underlying attitudes that govern their sexual behaviors (or at least the sexual behaviors themselves), as well as general ways in which they cope with stress and/or relate to others, it does not instill participants with specific skill sets to tackle these problems. Though many participants in this study spoke highly of Kenneth Baker's presentation, in which he discusses techniques that they can adopt to "live in the present" and avoid entrapment in "psychological time," many left the program without a clear-cut plan as to how to implement these techniques. Additionally, while participants do receive information about Sexaholics Anonymous support groups, not all johns identify as sex addicts, thereby disqualifying them from these supportive services. Hence, participants do receive some resources through the john school program, but are generally left to invent their own protocol for avoiding recidivism. Participants like Andy, Daniel, and Ronald named specific services, such as counseling, a crisis line or Sexaholics Anonymous group as resources they intended to utilize in the aftermath of the john school. Others like Rusty and Michael referred to intangible alternatives 
like willpower or prayer. Participants like Craig, however, hoped that sexual deviancy was a phase that would blow over naturally. When questioned about the strategy he planned to employ to avoid reoffending, he hesitantly responded, "Yeah, I'm really trying to stay self-motivated to get everything with it. I guess it's the one Sexaholics Anonymous speaker... about you can't have sex all the time. Hopefully I'll come out of it; maybe it's just an age thing. But if you look around the audience that was in the class it's really not...I guess it has a lot to do with psychology."

In spite of the john school program's incapacity to provide more comprehensive services to individual offenders given its time and funding constraints, a gap seemingly remains between imploring johns to alter the attitudes and social habits provoking their sexual deviancy, and imparting the skill sets necessary for participants to execute this mandate. While many johns, namely those that experienced shame-guilt, identified specific action steps they would take to avoid reoffending, others appeared vague and indeterminate. While john school presenters do recommend resources and suggest techniques to avoid rash decision-making, more intensely addressing the gap between program expectations and personal implementation may allow for further shame management and reintegration.

Although the NJS can only go so far in reshaping the deep-seated, socially informed ideologies participants embrace before even entering the program, it does accomplish important objectives that render it superior to hard-core penal tactics. By upholding the pillars of reintegrative shaming that John and Valerie Braithwaite (Ahmed et al. 2001) emphasize, which allow participants to discharge shame in a non-dominated and restorative environment, the program can increase empathy for potential victims, reduce hostility towards enforcement and sanctioning authorities, explain rationale behind prostitution laws, and provide forgiveness to offenders through a de-labeling ritual—expungement. As evidenced by the qualitative feedback of participants in this study, the NJS program can elicit feelings of shame-guilt, though only in offenders who share consensus for constructions of prostitution as morally wrong, legitimately 
illegal, dangerous, and/or unhealthy. Moreover, feelings of shame-guilt allowed for healthier shame management—signaled by expressions of empathy for potential victims, consensus regarding the inherent immorality of prostitution, admission of moral wrongdoing, and reduced animosity towards enforcement and sanctioning officials. Additionally, genuine shame-guilt enabled participants to recognize how their actions may have adversely affected others, thus connecting accountability with empathy. On the other hand, participants that experienced embarrassment-exposure and unresolved shame displaced shame into anger, expressing resentment and hostility towards enforcement and sanctioning officials. Such participants also reflected a shaky grasp of information presented in the program, a lack of consensus regarding the legitimacy of anti-prostitution laws, and a denial of moral wrongdoing. Furthermore, embarrassment-exposure and unresolved shame disabled participants from connecting their own participation in sexual commerce to the potential suffering of others. Thus, while some participants did demonstrate sympathy for prostitutes or human trafficking victims, they denied having contributed to their suffering. For these individuals, the john school program may succeed in offsetting previous cost-benefit calculations associated with their decisions to engage in sexual commerce and dissuade participants from reoffending. However, it cannot hope to transform internally ingrained belief systems that ultimately govern individual behavior. Nonetheless, the NJS plays a crucial role in clarifying the rationale behind prostitution laws and their enforcement, increasing understanding for those adversely affected by illicit sexual activity, and providing resources for services related to sexual health or addiction.

Although the NJS program largely exemplifies John and Valerie Braithwaite's and Nathan Harris' model of reintegrative shaming and Kennedy's model of deterrence education, its capacity to affect the underlying attitudes that normalize and condone prostitution remain compromised. This is due, in part, to a greater lack of societal consensus regarding constructions of prostitution as immoral, unhealthy, or legitimately illegal. In fact, electing a legal framework to legitimize, disallow, or limit prostitution remains an extremely controversial issue amongst 
opposing neo and non abolitionist theoretical camps. In order to fully wipe out "demand" and eradicate illicit sexual commerce, patronizing prostitution must be so socially condemned that it becomes "unthinkable." John and Valerie Braithwaite explain this process:

The great power of a conscience that has been constituted by deliberative participation in shaming... is that it tends to put those wrongs right off our deliberative agenda. They become unthinkable to us. Hence when someone annoys us, we refrain from killing them, not because we calculate the costs and benefits of murder, but because murder is not even considered as an option for dealing with a daily problem. (Ahmed et al. 2001:31).

Overall, the NJS program assumes a dialectical stance between constructing and reproducing moral consciousness about prostitution. While it has the power to recalibrate understandings of social normativity and influence behavior through reintegrative shaming, broader societal consensus upholding perceptions of prostitution as wrongful and pathological must be instituted to support it. Thus, if officials truly want to curtail prostitution, they must focus their efforts on creating consensus by changing the cultural attitudes that condone it. Only through widespread societal consensus can patronizing prostitution become "unthinkable. 


\section{REFERENCES}

Ahmed, Eliza, with Nathan Harris, John Braithwaite, and Valerie Brathwaite 2001 Shame Management Through Reintegration. Cambridge: Cambridge University Press.

Barry, Kathleen

1995 The Prostitution of Sexuality. New York: New York University Press.

Bennetts, Leslie

2011 The John Next Door. Newseek Magazine.

http://www.thedailybeast.com/newsweek/2011/07/17/the-growing-demand-forprostitution.html, accessed October 11, 2012.

Bernstein, Elizabeth

2007 Temporarily Yours: Intimacy, Authenticity, and the Commerce of Sex.

Chicago: University of Chicago Press

Blevins, Kristie R. and Thomas J. Holt

2009 Examining the Virtual Subculture of Johns. Journal of Contemporary

Ethnography 38(5):619-648. SAGE Journals.

http://jce.sagepub.com/cgi/reprint/38/5/619

Braithwaite, John

1989 Crime, Shame, and Reintegration. Cambridge: Cambridge University

Press.

Cameron, Sally and Edward Newman

2008 Trafficking in Humans: Social, Cultural and Political Dimensions. Tokyo:

United Nations University Press.

Carline, Anna

2011 Criminal justice, extreme pornography and prostitution: Protecting women or

Promoting morality? Sexualities 14(3):312-333. JSTOR. http://sex.sagepub.com/content/14/3/312, accessed December 12, 2011.

Chuang, Janie

2010 Rescuing Trafficking from Ideological Capture: Prostitution Reform and Anti 
Trafficking Law and Policy. University of Pennsylvania Law Review 158:1655-1728. http://www.law.upenn.edu/journals/lawreview/articles/ Volume158/issue6/Chuang158U.a.L.Rev.1655(2010).pdf, accessed February 3, 2012.

Coalition Against Trafficking in Women. http://www.catwinternational.org/, accessed December 1, 2011.

Cohen, Stanley 1985 Visions of Social Control: Crime, Punishment, and Classification. Cambridge: Polity Press.

Committee of Fifteen

1902 The Social Evil: With Special Reference to Conditions Existing in the City of New York, 1900. New York: The Knickerbocker Press.

Connelly, Mark T.

1980 The Response to Prostitution in the Progressive Era. North Carolina:

University of North Carolina Press.

Dewey, Susan

2011 Neon Wasteland: On Love, Motherhood, and Sex Work in a Rust Belt Town. Berkeley: University of California.

Doezema, Jo

2002 Who Gets to Choose? Coercion, Consent and the UN Trafficking Protocol.

Gender and Development 10(1):20-27.

Donnan, Hastings and Fiona Magowan

2010 Erotic Economies. In The Anthropology of Sex. Pp 71-92. Oxford:

Oxford International Publishers Ltd.

Durkheim, Emile

1982 Rules for the Constitution of Social Facts in The Rules of Sociological Method and Selected Texts on Sociology and its Method. Steven Lukes, ed. W.D. Halls, trans. Pp. 108-118. New York: The Free Press.

Easton, Dossie and Janet W. Hardy 1997 The Ethical Slut: A Practical Guide to Polyamory, Open Relationships, \& Other Adventures. New York: Crown Publishing Group.

Foucault, Michel

1995 Discipline and Punish: The Birth of the Prison. New York: Vintage.

Frank, Katherine. 
2007 Playcouples in Paradise: Touristic Sexuality and Lifestyle Travel. In Love and Globalization: Transformations of Intimacy in the Contemporary World,

Mark B. Padilla, Jennifer S. Hirsch, Miguel Muñoz-Laboy, Robert E. Sember,and Richard G. Parker, eds. Pp 163-85. Nashville, TN: Vanderbilt University Press.

Hicks, David

2010 Ritual and Belief: Readings in the Anthropology of Religion. Lanham, MD: AltaMira.

Isaacs, Lindsay.

2002 Denver uses shame tactics to stop prostitution | [primary-term] content from American City \& County. American City \& County Home Page. http://americancityandcounty.com/news/government_denver_uses_shame, accessed January 3, 2013.

Kennedy, M. Alexis, Carolin Klein, Boris B. Gorzalka, and John C. Yuille. 2004 Attitude Change Following a Diversion Program for Men Who Solicity Sex. Journal of Offender Rehabilitation 40(1):41-60. (accessed October 2, 2010).

Kennedy, David M.

2009 Deterrence and Crime Prevention: Reconsidering the Prospect of Sanction. London: Routledge.

Malarek, Victor

2009 The Johns: Sex for Sale and the Men Who Buy It. New York: Arcade Publishing, Inc.

Middleberg, Maurice I.

2006 The Anti-Prostitution Policy in the US HIV/AIDS Program. Health and Human Rights 9(1):3-15. JSTOR. http://www.jstor.org/stable/4065386, accessed December 12, 2011.

Nassif, Tony. Preventing Abuse Conference. Proceedings of Preventing Abuse

Conference, Orlando. August 16, 2011. Accessed December 12, 2011. http://www.preventingabuse.org/contact.html.

Neumeister, Larry.

2012 Public Shaming Of Prostitution Clients A Growing Trend, Can Harm

Families. Breaking News and Opinion on The Huffington Post. http://www.huffingtonpost.com/2012/10/14/shaming-prostitute-johnspublic_n_1964925.html, accessed January 13, 2012

Pettersson, Tove and Eva Tiby

2003 The Production and Reproduction of Prostitution. Journal of Scandinavian Studies in Criminology and Crime Prevention 3:154-172. 
Potts, Annie

2001 The Man with Two Brains: hegemonic masculine subjectivity and the discursive construction of the unreasonable penis-self. Journal of Gender Studies 10(2):145-156. Academic Search Premier. http://web.ebscohost. Com.echo.louisville.ed/ehost/pdfviewer/pdfviewer?sid=1aa13d9f-c8a 6-4401-b52f-b9913d6e63d\%40sessionmgr111\&vid=6\&hid=122

Rettman, Jeff

1998 Business, Government, and Prostitution in Spokane, Washington: 1889-1910.

The Pacific Northwest Quarterly 8(2):77-83. JSTOR.

http://www.jstor.org/stable/40492387, accessed December 1, 2011.

Roe-Sepowitz, Dominique E. with Kristine E. Hickle, Martha Pérez Loubert, and Tom

Egan 2011 Adult Prostitution Recidivism: Risk Factors and Impact of a Diversion Program. Journal of Offender Rehabilitation 50(5):272-285.

Sawyer, Steven with Michael E. Metz, Jeffrey D. Hinds, and Robert A. Brucker Jr. 2001 Attitudes Towards Prostitution Among Males: A 'Consumer's Report.'

Current Psychology 20(4):363-376. Academic Search Premier. http://web.ebsochost.com.echo.louisville.edu/ehost/pdfviewer/pdfviewer? Vid=3\&sid=7010633f-5a3c-487b-a3a4-f9a93aace4e9\%40sessionmgr 113\&hid=113, accessed April 8, 2013.

Shively, Michael, Ph.D, Sarah Kuck Jalbert, Ryan Kling, William Rhodes, Ph.D, David Squires, Christina Dyous, and Kristin Wheeler. Final Report on the Evaluation of the First Offender Prostitution Program. Report no. 2005-DD-BX-0037. Abf

Associates, 2008. http://www.abtassociates.com/reports/FOPP_Evaluation _FULL_RE, accessed January 13, 2013.

Tennessee Code: Title 39, §§ 13-39-13-512-39-13-515 (2010).

United States of America. U.S Department of State. Office to Monitor and Combat Trafficking in Persons. Trafficking in Persons Report. 2011. http://www.state.gov/documents/organization/164452.pdf, accessed December $1,2012$.

Vice Commission of Chicago

1911 The Social Evil in Chicago: A Study of Existing Conditions. Chicago: Gunthorp-Warren Printing Company.

Wortley, Scot with Benadikt Fischer and Cheryl Webster 2002 Vice lessons: A survey of prostitution offenders enrolled in the Toronto John

School Diversion Program. Canadian Journal of Criminology 44(4):369-402. Academic Search Premier. http://web.ebscohost.com.echo.louisville.edu/ Ehost/detail?sid=64fdb38c-ca4b-4c7d-8bef-194961b0d 


\section{CURRICULUM VITAE}

Robin Valenzuela

2604 Aristocrat Place \#304

Louisville, KY 40299 remalo01@ louisville.edu

Cellular Phone: 502-472-8236

\section{Education}

Master's degree in Anthropology University of Louisville (May 2013)

Master's degree in Spanish University of Louisville (Spring 2012)

Graduate Certificate in Latin American Studies University of Louisville (Spring 2012)

Bachelor of Arts in Spanish University of Louisville (May 2008).

Minor in Latin American Studies University of Louisville (May 2008)

\section{Research Experience}

MA Thesis Research: Department of Anthropology at the University of Louisville, 2012-13 (Research Advisor, Dr. Julie Peteet), "The Nashville John School: Risk Deterrence and the Reintegrative Shaming Approach."

Qualitative study of reintegrative and stigmatizing shaming tactics as crime deterrence strategy in the Nashville john school program, social constructions of sexual normativity and deviance with regards to participation in commercial sex.

\section{Job Experience}

Non-residential Family Advocate, The Center for Women and Families (January 2012-present) Providing individual counseling and intake for victims of domestic violence and sexual assault. providing case management for human trafficking survivors and managing TAPESTRI grant. Also, providing legal advocacy to $U$ visa, $T$ visa, and VAWA candidates.

VAWA Human Trafficking Case Manager, Catholic Charities of Louisville (February 2011December 2011)

Case management for survivors of human trafficking, conducting community trainings on human trafficking

Co-Chair, Louisville Human Trafficking Task Force (2010-2012)

Planning agenda items and facilitating meetings, preparing meeting minutes, overseeing task force subcommittees and bylaws. 
VAWA Immigrant Legal Advocate, The Center for Women and Families (March 2010-February 2011) Court advocacy for immigrant/refugee victims of domestic violence or sexual assault

Spanish Language Interpreter, In Every Language (November 2008-February 2010) Providing Spanish language interpretation for patients and staff members at medical clinics and hospitals

\section{Additional Certifications and Honors}

Phi Kappa Phi National Honors Society, University of Louisville Chapter Magna Cumm Laude Graduate, University of Louisville (2008)

Kentucky Rescue and Restore Liberation Award (Fall 2009)

Dean's List, University of Louisville (2008-2012)

Kentucky Domestic Violence Association Advocacy Certification (2012)

\section{Internships and Fellowships}

Fellowship, Polaris Project in Washington DC (Summer 2009)

Assisting with case management for survivors of human trafficking, attending human trafficking trainings

Internship, Rescue and Restore Victims of Human Trafficking (Fall 2009)

Assisting Project Manager in public awareness events and research efforts concerning human trafficking in Kentucky.

Volunteer, Catholic Charities Migration and Refugee Services (2009)

Assisting with ESL classes for elderly Catholic Charities clients. Also assisting Cuban family with resettlement in Louisville through orientation and job search assistance.

International Outreach Internship, Iroquois Library (Spring 2008)

Coordination of outreach projects through collaboration with International Outreach Director, organization of ESL classes for Spanish speakers and cultural showcase events, translation of library information into Spanish.

Medical Interpretation Internship, Kentucky Racing Health Services Center (2007)

Interpretation for health providers and Hispanic patients, translation of prescription information and medical history forms into Spanish, accompaniment of Hispanic patients to pharmacy and therapy appointments

Volunteer Adventures ESL Internship, Antigua, Guatemala (Summer 2007)

ESL Instruction to 6th grade students in Antigua, Guatemala, lesson planning, training of other ESL instructors

\section{Additional Activities}


Competitive Ballroom Dancer and Instructor

Competent in Portuguese

Private Spanish Tutor 